ADRIANA MIRALLES SCHLEDER

APLICAÇÃO DE REDES BAYESIANAS PARA A ANÁLISE DE CONFIABILIDADE DO SISTEMA DE REGASEIFICAÇÃO DE UMA UNIDADE TIPO FSRU

São Paulo

2012 
ADRIANA MIRALLES SCHLEDER

\section{APLICAÇÃO DE REDES BAYESIANAS PARA A ANÁLISE DE CONFIABILIDADE DO SISTEMA DE REGASEIFICAÇÃO DE UMA UNIDADE TIPO FSRU}

Dissertação apresentada à Escola Politécnica da Universidade de São Paulo para obtenção do título de mestre em ciência.

São Paulo 
ADRIANA MIRALLES SCHLEDER

\title{
APLICAÇÃO DE REDES BAYESIANAS PARA A ANÁLISE DE CONFIABILIDADE DO SISTEMA DE REGASEIFICAÇÃO DE UMA UNIDADE TIPO FSRU
}

\begin{abstract}
Dissertação apresentada à Escola Politécnica da Universidade de São Paulo para obtenção do título de mestre em ciência.
\end{abstract}

Área de concentração:

Engenharia Naval e Oceânica

Orientador:

Prof. Dr. Marcelo Ramos Martins

São Paulo

2012 


\section{Agradecimentos}

Ao Professor Marcelo Ramos Martins pela orientação, paciência e dedicação durante todo o período de desenvolvimento deste trabalho, tendo sido mais do que um orientador e sim um amigo valioso nos momentos de dificuldade.

Aos membros da banca, Professor Gilberto F. M. Souza e Sr. Paulo M. Videiro que forneceram orientações valiosas não só durante o exame de qualificação, mas também ao longo do desenvolvimento deste estudo.

A todos os amigos e professores do Departamento de Engenharia Naval da USP que me apoiaram durante este período, em especial ao grande amigo Ary Carlos de Oliveira que me incentivou desde os primeiros passos desta tarefa.

A CAPES pela bolsa concedida, auxílio que facilitou a execução desta tarefa. 


\section{RESUMO}

A motivação para este trabalho originou-se da atual tendência do Gás Natural Liquefeito (GNL) se tornar uma importante opção para a diversificação da matriz energética brasileira. Atualmente, os terminais de gás natural liquefeito (GNL) são na maioria estruturas "onshore", a construção destes terminais é custosa e muitos investimentos são necessários para atender as legislações ambientais e de segurança. Além disso, um acidente em uma destas instalações poderá produzir um grande impacto em áreas adjacentes. Sob esta perspectiva, surge uma nova proposta: uma unidade flutuante de armazenagem e regaseificação de gás natural liquefeito (FSRU - Floating Storage and Regasification Unit), o qual é uma unidade "offshore" e que pode trabalhar a quilômetros de distância da costa. O objetivo desta pesquisa é desenvolver uma metodologia de análise de Confiabilidade com o uso de Redes Bayesianas (RB) e aplicá-la na análise do sistema de Regaseificação do FSRU. O uso de RB, entre outras vantagens, permite a representação de incertezas no modelo e de dependências condicionais o que não é possível com as técnicas tradicionais, como por exemplo, as árvores de falhas e de eventos. Como resultado do trabalho, além da apresentação da metodologia a ser desenvolvida, serão identificados os pontos críticos do sistema contribuindo para o desenvolvimento de um plano de manutenção que assegure uma boa operabilidade do sistema com níveis razoáveis de dependabilidade.

Palavras-chave: Confiabilidade. Redes Bayesianas. FSRU (Floating Storage Regasification). GNL (Gás Natural Liquefeito). 


\section{ABSTRACT}

The motivation for this research is the propensity of the Liquefied Natural Gas (LNG) becomes an important source of energy. Nowadays, LNG Import Terminals are mostly onshore; the construction of these terminals is costly and many adaptations are necessary to abide by environmental and safety laws. Moreover, an accident in one of these plants might produce considerable impact in neighboring areas. Under this perspective, a new option arises: a vessel known as FSRU (Floating Storage and Regasification Unit), which is an offshore unit, that can work miles away from de coast. The goal is to develop a Bayesian Network Reliability Modeling, which will show a preview of FSRUs Regasification System behavior. Using $\mathrm{BN}$ is possible to represent uncertain knowledge and local conditional dependencies. The results intend to clarify the critical equipment of the system and might improve the development of an effective maintenance plan, which can provide good operability with reasonable dependability levels.

Keywords: Reliability, Bayesian networks. FSRU (Floating Storage Regasification Unit). LNG (Liquefied Natural Gas). 


\section{LISTA DE FIGURAS}

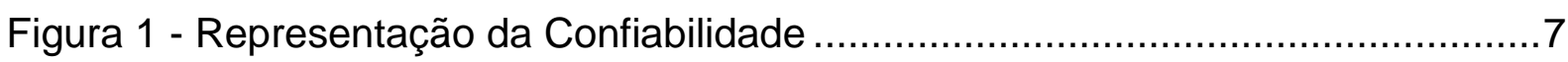

Figura 2 - Esquematização de um diagrama unifilar ..........................................11

Figura 3 - Representação da construção de uma árvore funcional ..........................11

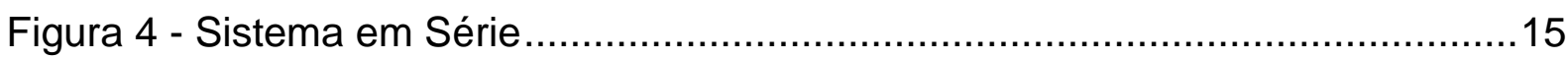

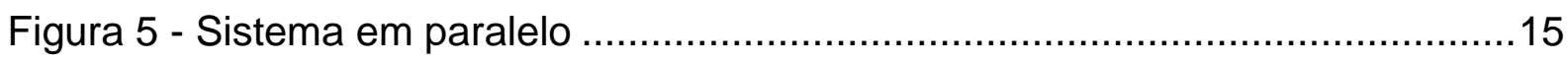

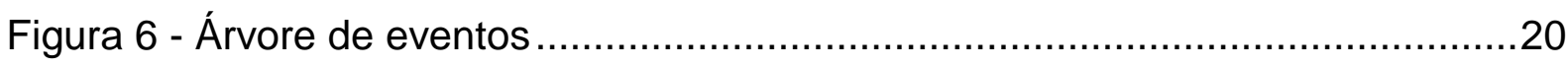

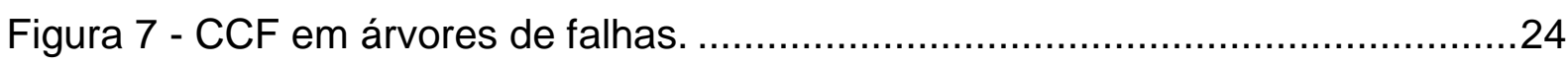

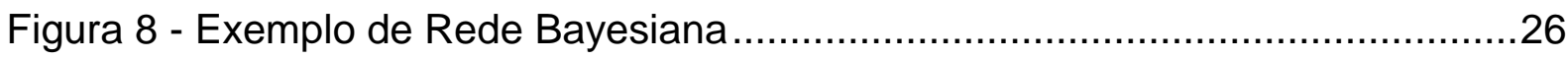

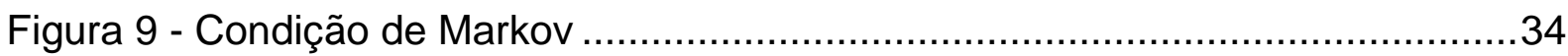

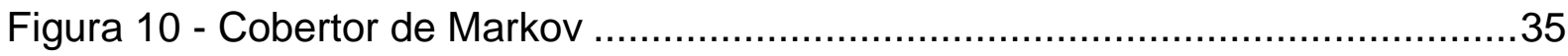

Figura 11 - Estruturas de uma rede: (a) cadeia, (b) garfo e (c) colisão ......................36

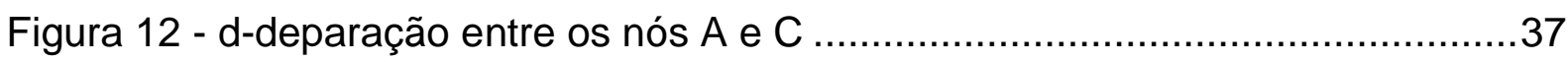

Figura 13 - Representação da árvore de falhas e da rede bayesiana.......................45

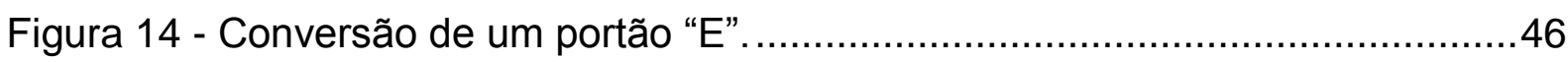

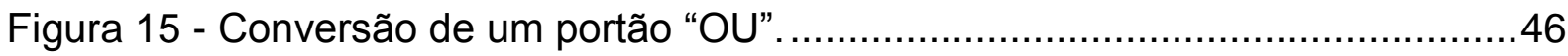

Figura 16 - Conversão de um portão "OU exclusivo". ...........................................4 4

Figura 17 - Equivalência entre um sistema em série e uma RB..............................49

Figura 18 - Equivalência entre um sistema em paralelo e uma RB..........................49

Figura 19 - Inclusão de CCF considerando variáveis discretas...............................50

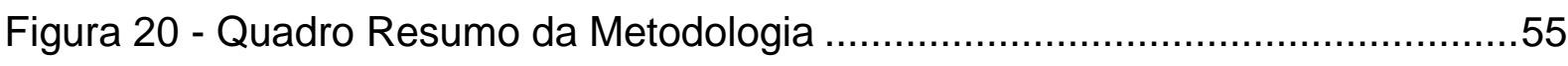

Figura 21 - Sistema de Regaseificação em Cascata.............................................59

Figura 22 - Diagrama unifilar do Sistema de Regaseificação...................................63

Figura 23 - Árvore Funcional do Sistema de Regaseificação....................................66

Figura 24 - 1ํㅡível do diagrama do Sistema de Regaseificação ..............................68

Figura 25 - Sistema de Abastecimento. ..........................................................68

APLICAÇÃO DE REDES BAYESIANAS PARA A ANÁLISE DE CONFIABILIDADE DO SISTEMA DE REGASEIFICAÇÃO DE UMA UNIDADE TIPO FSRU. 
Escola Politécnica da USP

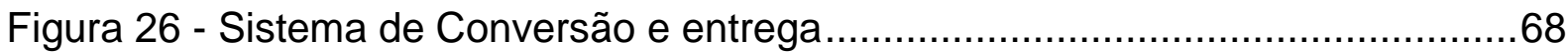

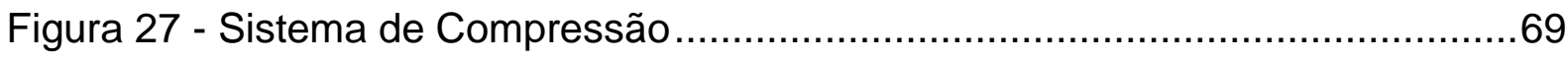

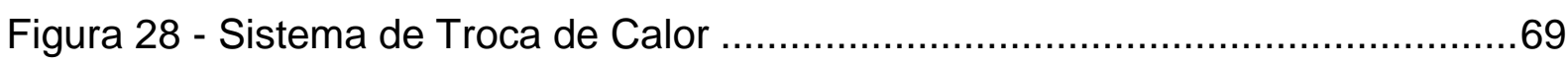

Figura 29 - Sistema de Aquecimento GNL/Propano ............................................69

Figura 30 - Sistema de Aquecimento GNL/Água...............................................70

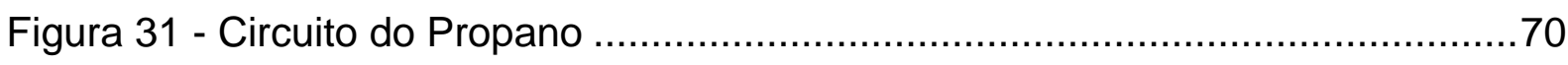

Figura 32 - Sistema de Abastecimento do Propano .................................................71

Figura 33 - Sistema Fechado de Propano ..........................................................

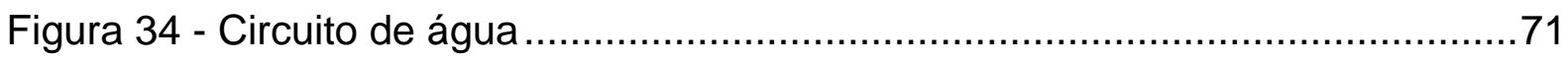

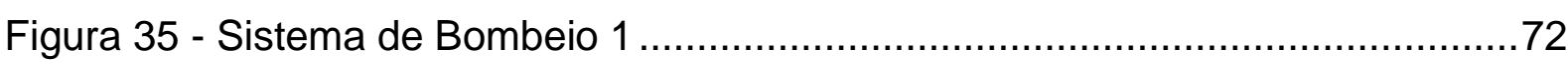

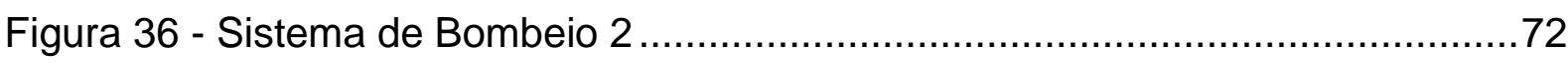

Figura 37 - Diagrama de Blocos Completo do Sistema de Regaseificação ..............73

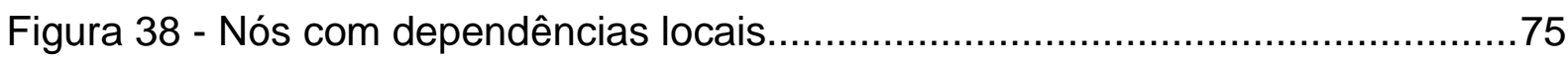

Figura 39 - Rede Bayesiana do Sistema de Regaseificação …………………......76

Figura 40 - Rede Bayesiana do Sistema de Regaseificação com CCF ...................85

Figura 41 - Gráfico de Criticidade: Componentes X Confiabilidade …....................87

Figura 42 - Gráfico de criticidade Subsistemas X Sistema de regaseificação............88

Figura 43 - Rede Bayesiana referente ao cenário 1 ..........................................

Figura 44 - Rede Bayesiana referente ao cenário 2 .........................................94

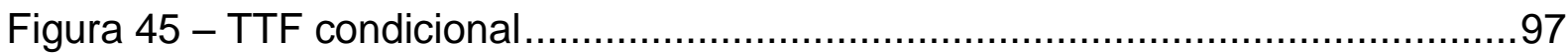

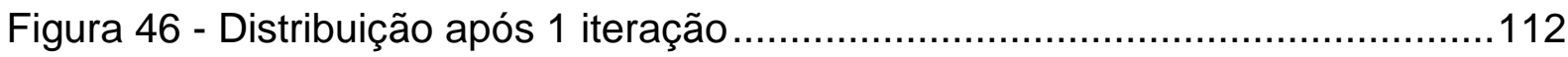

Figura 47 - Distribuição após 2 iterações ......................................................112

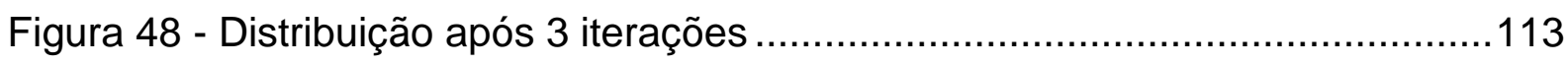

Figura 49 - Distribuição após 4 iterações ........................................................113

Figura 50 - Distribuição após 5 iterações ......................................................114

Figura 51 - Distribuição após 45 iterações ......................................................114 REGASEIFICAÇÃO DE UMA UNIDADE TIPO FSRU. 
Escola Politécnica da USP

\section{LISTA DE TABELAS}

Tabela 1 - Informações para elaboração da FMEA (CARAZAS, 2006)....................13

Tabela 2 - Símbolos dos portões lógicos (KECECIOGLU, 1991)...........................17

Tabela 3 - Símbolos para a representação de eventos (KECECIOGLU, 1991).......18

Tabela 4 - Características dos navios Golar Spirit e Golar Winter ...........................57

Tabela 5 - Propriedades do Gás Natural ...................................................60

Tabela 6 - Propriedades do Propano .........................................................61

Tabela 7 - Nomenclatura usada no diagrama unifilar .....................................64

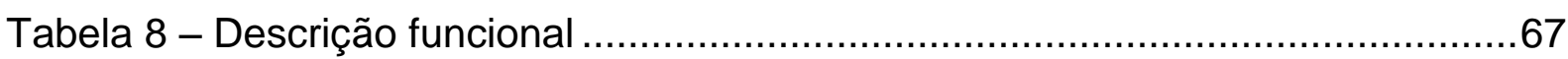

Tabela 9 - Componentes ..................................................................... 78

Tabela 10 - Taxa de falha do trocador de calor GNL/Propano ................................81

Tabela 11 - Taxa de falha do trocador de calor GNL/água ...................................81

Tabela 12 - Taxa de falha do trocador de calor Propano/água .............................81

Tabela 13 - Grupos de CCF ................................................................. 84

Tabela 14 - Probabilidade de falha antes e depois da inclusão de CCF ................84

Tabela 15 - Probabilidades de falha antes e depois da falha de um equipamento

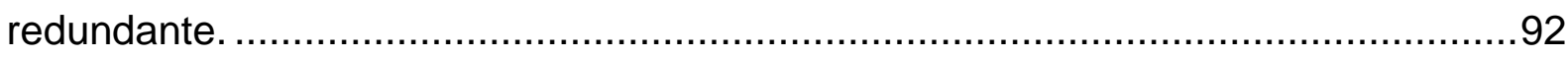

Tabela 16 - Iterações de uma distribuição normal.............................................111

APLICAÇÃO DE REDES BAYESIANAS PARA A ANÁLISE DE CONFIABILIDADE DO SISTEMA DE REGASEIFICAÇÃO DE UMA UNIDADE TIPO FSRU. 


\section{SUMÁRIO}

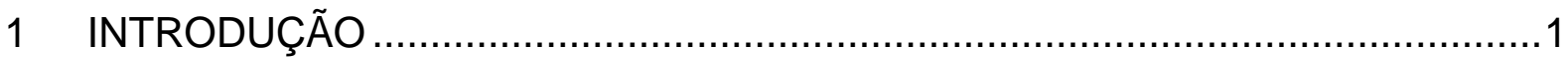

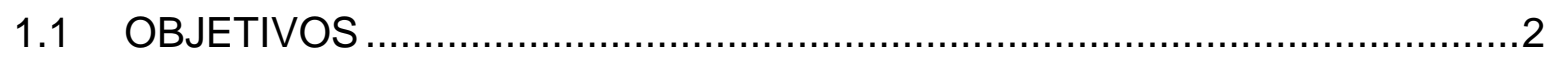

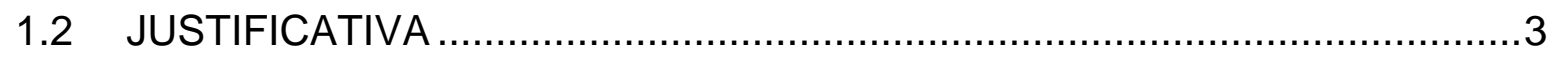

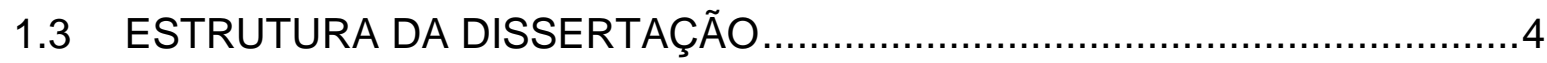

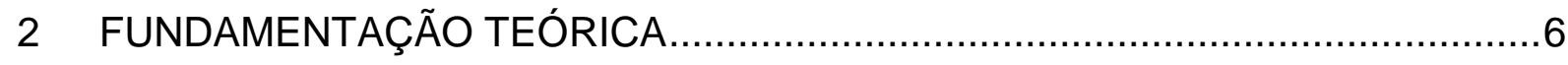

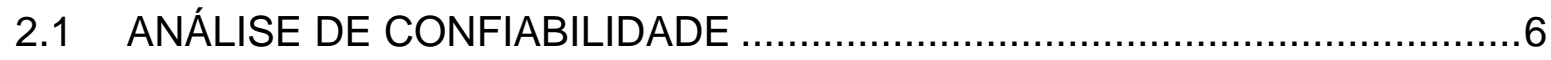

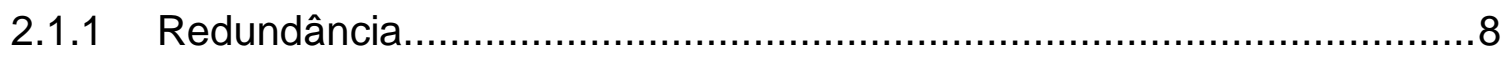

2.1.2 Técnicas de análise e suporte à análise .............................................

2.1.2.1 Árvore funcional e diagrama unifilar ...............................................

2.1.2.2 Análise de Modo de Falhas e Efeitos ...........................................11

2.1.2.3 Diagrama de Blocos ................................................................. 14

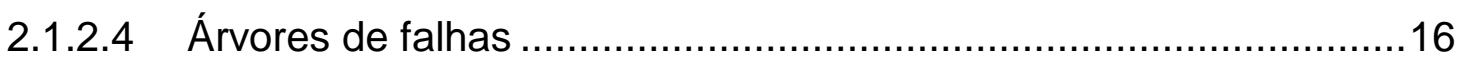

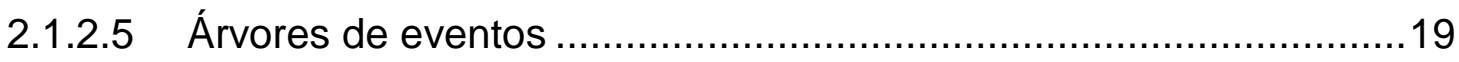

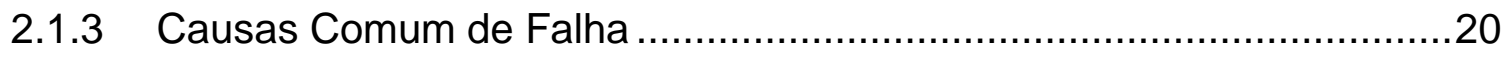

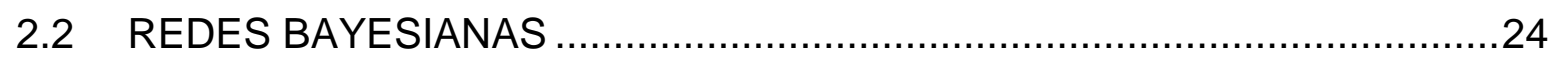

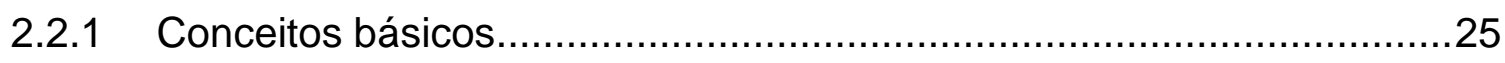

2.2.1.1 Espaços amostrais, conjuntos e eventos …...............................27

2.2.1.2 Incertezas, probabilidade a priori e probabilidade posterior ............27

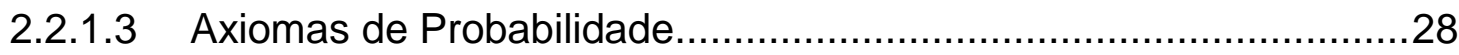

2.2.1.4 Probabilidade Condicional e independência ..................................29

APLICAÇÃO DE REDES BAYESIANAS PARA A ANÁLISE DE CONFIABILIDADE DO SISTEMA DE REGASEIFICAÇÃO DE UMA UNIDADE TIPO FSRU. 
Escola Politécnica da USP

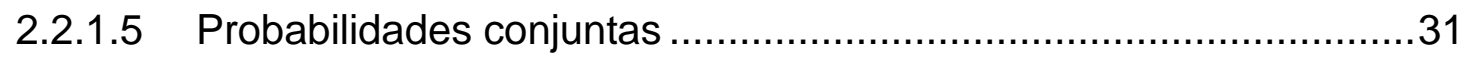

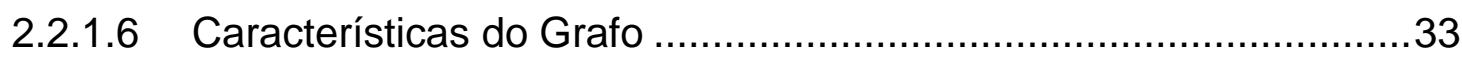

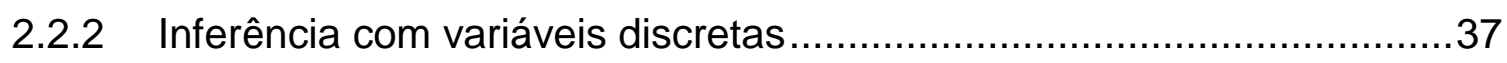

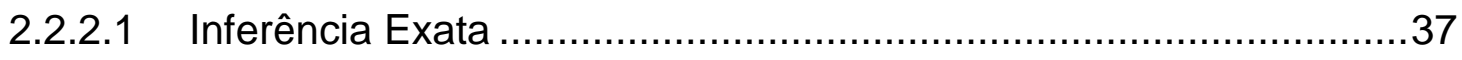

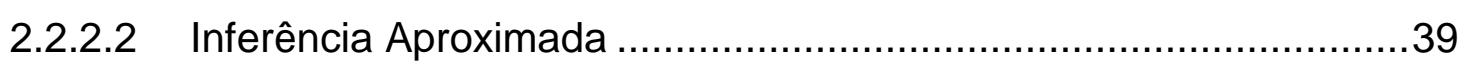

2.2.3 Inferência com variáveis contínuas....................................................40

2.2.4 Redes Bayesianas na análise da Confiabilidade ................................42

2.2.4.1 Conversão de árvores de falhas em Redes Bayesianas..................44

2.2.4.2 Conversão de diagramas de blocos em Redes Bayesianas ............48

2.2.4.3 Causas Comum de Falha em Redes Bayesianas ...........................49

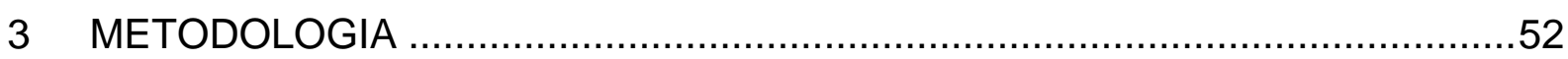

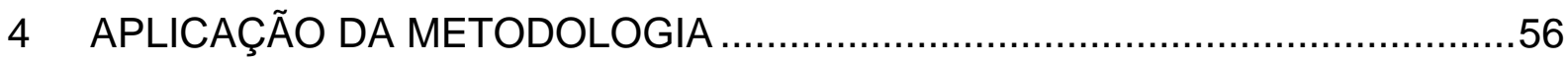

4.1 FAMILIARIZAÇÃO COM O SISTEMA..................................................56

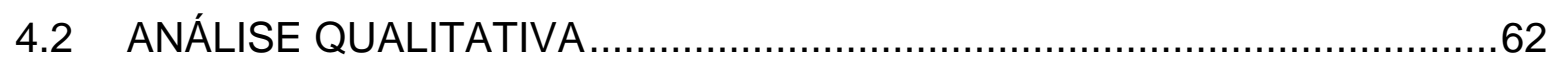

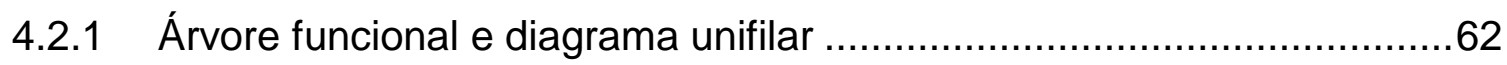

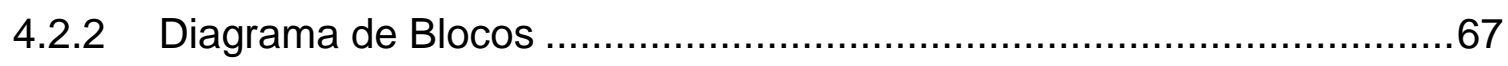

4.2.3 Conversão do Diagrama de Blocos em Rede Bayesiana .......................74

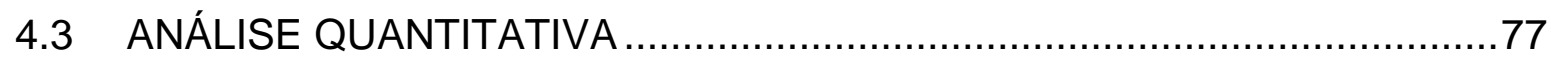

4.3.1 Análise quantitativa por diagrama de blocos …………………..........77

4.3.2 Complementação da Rede Bayesiana: probabilidades a priori e probabilidades condicionais ................................................................. 80

4.3.3 Confiabilidade do Sistema de Regaseificação.......................................82

4.3.3.1 Falhas de Causa Comum na Rede Bayesiana ................................83

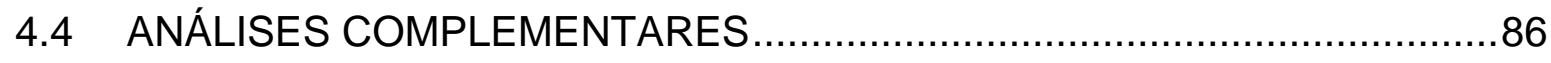

APLICAÇÃO DE REDES BAYESIANAS PARA A ANÁLISE DE CONFIABILIDADE DO SISTEMA DE REGASEIFICAÇÃO DE UMA UNIDADE TIPO FSRU. 
Escola Politécnica da USP

4.4.1 Análise de criticidade. .86

4.4.2 Análise de diferentes cenários .88

4.4.2.1 Cenário 1 - Melhoria na confiabilidade de um componente crítico do sistema 89

4.4.2.2 Cenário 2 - Falha de um componente redundante 92

4.4.2.3 Cenário 3 - Inclusão de redundância...........................................95

4.4.3 Confiabilidade Condicionada .......................................................95

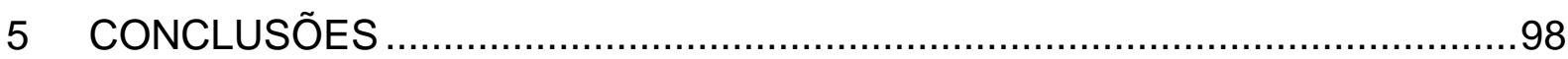

5.1 SUGESTÕES PARA TRABALHOS FUTUROS ................................100

6 REFERÊNCIAS BIBLIOGRÁFICAS ................................................. 101

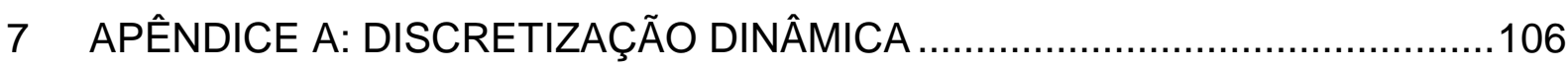


Escola Politécnica da USP

\section{INTRODUÇÃO}

O gás natural liquefeito (GNL) adquire cada vez mais destaque no cenário mundial e no Brasil, principalmente, após a descoberta de novas reservas nas bacias de exploração de petróleo. Além disso, o GNL é uma fonte de energia limpa quando comparada com outros combustíveis e é uma importante opção para a diversificação da matriz energética do país, o que incentiva o desenvolvimento de tecnologias eficazes para exploração e distribuição do GNL.

Nesse cenário o Brasil começa a diversificar sua forma de abastecimento de gás natural (GN), até então, feito apenas pela importação via gasodutos. Nesta nova fase, o país começa importar GNL por meio de navios. O GNL chega ao país em navios tanque que atracam em terminais previamente preparados e o gás liquefeito é transportado através de braços criogênicos até um novo navio, conhecido como FSRU (Floating Storage and Regasification Unit), onde fica armazenado. Quando existe a demanda, nesse mesmo navio 0 GNL é regaseificado e então disponibilizado para a malha de gasodutos que abastecem o interior do país.

No Brasil existem dois terminais com capacidade de realizar esta operação, um em Pecém no estado do Ceará e outro na Baía da Guanabara no estado do Rio de Janeiro. Também são duas as unidades FSRU utilizadas, o navio Golar Spirit e o Golar Winter. Estes navios, antes utilizados apenas para o transporte e armazenamento de GNL foram adaptados para serem capazes de realizar também o processo de regaseificação do gás natural liquefeito; ambos serão apresentados no item 4.1. Também existe a aprovação para a construção de um terceiro terminal na Baía de Todos os Santos no estado da Bahia, que juntamente com os dois terminais já em funcionamento atingiriam a capacidade de regasificar 35 milhões de metros cúbicos por dia, o que supera os 31 milhões importados via gasodutos da Bolívia.

Usualmente o processo de regaseificação é feito em plantas "onshore", localizadas na costa. O uso de estações regaseificadoras em navios é inédito, sendo

APLICAÇÃO DE REDES BAYESIANAS PARA A ANÁLISE DE CONFIABILIDADE DO SISTEMA DE REGASEIFICAÇÃO DE UMA UNIDADE TIPO FSRU. 
Escola Politécnica da USP

as duas unidades usadas no Brasil as primeiras deste tipo no mundo. Justamente por ser um processo novo, em relação ao qual ainda não existe um histórico de falhas adequado para análise e elaboração de um planejamento de manutenção eficaz, este trabalho tem como objetivo o desenvolvimento de uma metodologia de análise de Confiabilidade com o uso de Redes Bayesianas para subsidiar o desenvolvimento de plano de manutenção.

Um bom plano de manutenção é fundamental neste caso, uma vez que acidentes envolvendo gás natural podem ser catastróficos, causando grandes danos econômicos, pessoais e ambientais.

\subsection{OBJETIVOS}

O objetivo desta pesquisa é desenvolver uma metodologia de análise de Confiabilidade com o uso de RB e aplicá-la na análise do sistema de regaseificação do FSRU. E durante o desenvolvimento da metodologia pretende-se explorar as vantagens e desvantagens da aplicação de RB em comparação com as técnicas tradicionalmente empregadas. Entre outros aspectos, será explorada especialmente a conversão de diagrama de blocos e árvores de falhas para RB.

Apesar do foco desta pesquisa ser o desenvolvimento da metodologia, como exposto no parágrafo anterior, também se espera que este estudo permita uma análise da confiabilidade de um sistema de regaseificação de um navio tipo FSRU e gere resultados que contribuam para a elaboração de um plano eficaz de manutenção, para que assim o processo se torne mais previsível e mais bem compreendido, de maneira a facilitar a tomada de decisões, os diagnósticos e os prognósticos. A aplicação da metodologia deverá permitir o mapeamento dos equipamentos e pontos críticos de operação assim como fornecer diretrizes para o 
Escola Politécnica da USP

planejamento da manutenção.

\subsection{JUSTIFICATIVA}

A escolha da técnica de Redes Bayesianas para análise da Confiabilidade foi feita com base em algumas vantagens mostradas em trabalhos anteriores (Hamada et al., 2008; Marques, Neil e Fenton, 2010; Bobbio et al., 2001; Langseth e Portinale, 2005) sobre as técnicas tradicionalmente empregadas. Na aplicação de técnicas tradicionais são usados eventos determinísticos enquanto na abordagem por RB é possível o uso de eventos não determinísticos. Na aplicação de RB pode se efetuar todas as análises feitas por meio das técnicas tradicionais e ainda é permitida a inclusão de características extras ao modelo, como dependências locais, variáveis com múltiplos estados, incertezas e a adição da opinião de especialistas para estimativa de dados quando não se tem acesso a dados históricos suficientes e/ou adequados.

As vantagens oferecidas pelo uso de Redes Bayesianas demonstram o potencial dessa técnica para análise de Confiabilidade, porém existem algumas dificuldades em sua aplicação, entre elas, a obtenção de todas as probabilidades condicionais do modelo e o tratamento quantitativo dos dados quando usadas variáveis contínuas no modelo. Estas dificuldades serão abordadas durante a revisão bibliográfica sobre Redes Bayesianas no item 3.2 e a aplicação da metodologia no Capítulo 5.

Como mencionado na introdução, o processo de regaseificação é feito usualmente em plantas "onshore" e o uso de estações regaseificadoras "offshore" é pioneiro, sendo assim, a aplicação da metodologia neste sistema se justifica pela falta de estudos sobre o mesmo e visa contribuir para a formação de uma base de 
conhecimento sobre este sistema de regaseificação e assim subsidiar a elaboração de um plano de manutenção eficaz que colabore para tornar a operação do sistema mais confiável, segura e previsível.

Existem estudos, que servirão como referência para este trabalho, sobre riscos de vazamento de GNL na água, confiabilidade de navios de transporte de GNL e riscos de aproximação de navios GNL nos terminais de descarga (Wighus, 1994; Raj, 2005; Johnson e Cornwell, 2006; Bubbico, Cave e Mazzarotta, 2009). Porém não se conhece nenhum estudo sobre os riscos envolvidos com as estações de regaseificação de unidades FSRU.

Também existem algumas referências sobre o uso de RB na análise da confiabilidade. Contudo, os estudos já existentes foram desenvolvidos para aplicações na indústria aeronáutica e nuclear (Kipersztok e Dildy, 2002; Darken e Erdmann, 1999; Marquez, Neil e Fenton, 2010), este trabalho executará uma adaptação desses conceitos para a indústria naval, especificamente para as unidades FSRU.

\subsection{ESTRUTURA DA DISSERTAÇÃO}

Esta dissertação está estruturada em seis capítulos, sendo a primeiro, o capítulo 1, uma composição de uma breve introdução sobre o assunto, dos objetivos da pesquisa e desta apresentação da estrutura do texto apresentado.

No capítulo 2 é apresentada uma revisão bibliográfica, onde são revistos os conceitos teóricos relevantes ao desenvolvimento deste trabalho. Primeiramente serão apresentados conceitos da Teoria da Confiabilidade, seguidos pelos fundamentos teóricos de RB e suas aplicações.

APLICAÇÃO DE REDES BAYESIANAS PARA A ANÁLISE DE CONFIABILIDADE DO SISTEMA DE REGASEIFICAÇÃO DE UMA UNIDADE TIPO FSRU. 
Escola Politécnica da USP

No capítulo 3, será apresentada a metodologia proposta por este estudo, de acordo com os conceitos do capítulo 2, de forma a facilitar a compreensão do capítulo seguinte no qual será feita a aplicação da metodologia proposta.

No capítulo 4, segue-se a apresentação do sistema de regaseificação da unidade FSRU juntamente com a composição do cenário em que este está inserido. Nesta fase é apresentada uma análise do problema, onde é aplicada a metodologia proposta no capítulo 3. Durante o desenvolvimento deste trabalho será elaborada uma análise que mapeará os pontos críticos do sistema para que se possa ter uma melhoria no processo de tomada de decisões e da análise da confiabilidade.

No capítulo 5, serão apresentadas as conclusões sobre os resultados obtidos na etapa anterior e as recomendações para acompanhamento do comportamento da confiabilidade do sistema estudado. Recomendações para trabalhos futuros também são apresentadas neste capítulo.

Finalmente, no capítulo 6, serão apresentadas as referências usadas na elaboração deste estudo, que poderão ser consultadas para aprofundamento do conhecimento. 


\section{FUNDAMENTAÇÃO TEÓRICA}

Neste capítulo serão apresentados os conceitos teóricos usados durante o desenvolvimento deste estudo. Inicialmente são apresentados os conceitos fundamentais da análise de Confiabilidade e são discutidas as técnicas tradicionais de análise enfatizando as vantagens e desvantagens de cada uma. Para tornar a análise mais completa, também serão apresentados conceitos referentes a redundância em sistemas e causas comuns de falha. $\mathrm{Em}$ seguida, são apresentados conceitos necessários para o bom entendimento do que são e como funcionam as Redes Bayesianas. Algumas de suas aplicações relevantes a este estudo também serão discutidas assim como as vantagens e desvantagens do uso de RB em comparação com as técnicas tradicionais. Dessa forma espera-se fornecer um embasamento teórico à elaboração da metodologia apresentada no capítulo 4.

\subsection{ANÁLISE DE CONFIABILIDADE}

A análise de confiabilidade é uma técnica de suporte a tomadas de decisão e controle que auxilia gestores na busca da garantia da execução satisfatória das funções do indivíduo, trabalhador ou equipamento, a respeito do sistema, considerando suas limitações, o seu desgaste e os fatores que influenciam seu desempenho (Firmino, 2004).

Confiabilidade é a probabilidade de um sistema funcionar, sob condições prédeterminadas, num determinado intervalo de tempo, dado que estava funcionando no instante inicial. Ou seja, como definido pela "International Organization 
Escola Politécnica da USP

Standardization" (ISO, 2004), confiabilidade é a capacidade de um item desempenhar uma função, sob determinadas condições ambientais e operacionais durante um determinado período de tempo. Outras referências para aprofundamento no tema são: Modarres (1993), Leitch (1995) e Hamada et al. (2008).

Como visto na definição anterior, a confiabilidade de um componente dependerá da função do componente, do meio onde ele vai operar e do tempo em que será analisado. Portanto para se avaliar a confiabilidade é preciso definir claramente o cenário e o período em que se espera que o componente exerça sua função.

A confiabilidade de um sistema depende da confiabilidade de cada um de seus componentes e também da maneira como esses componentes interagem. Podemos representar a confiabilidade ao longo do tempo de acordo com a Figura 1.

Como visto na definição, a confiabilidade é calculada dado que o sistema estava funcionando no instante inicial, portanto o valor inicial da confiabilidade é igual a 1 e decresce ao longo do tempo, enquanto que a probabilidade de falha aumentará ao longo do tempo (Leitch, 1995).

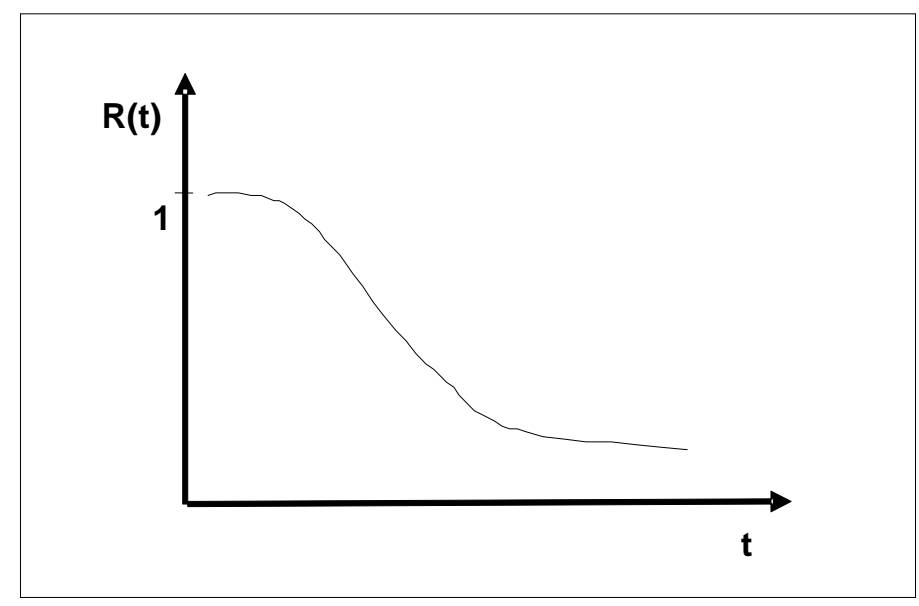

Figura 1 - Representação da Confiabilidade

A metodologia proposta para análise de Confiabilidade do sistema de REGASEIFICAÇÃO DE UMA UNIDADE TIPO FSRU. 
Escola Politécnica da USP

regaseificação acatará a definição confiabilidade apresentada nesta seção.

\subsubsection{Redundância}

Para melhorar a confiabilidade de um sistema, alguns tipos de redundância podem ser inseridos e muitos autores tratam o tema de maneira semelhante (Lewis, 1994; Modarres, 1993; Hamada et al., 2008; Smith, 2001). Neste estudo será seguida a abordagem de Lewis (1994), que está apresentada nos próximos dois parágrafos.

A mais simples é a redundância ativa total, onde se colocam os componentes em paralelo e para que o sistema continue funcionando é necessário que apenas um componente continue funcionando, assim o sistema falhará apenas quando todos os componentes em paralelo falharem. Nesse caso, para análise da confiabilidade, deve-se considerar as causas comuns de falhas (detalhadas posteriormente no item Causas Comum de Falha).

Outros tipos de redundância são: redundância ativa parcial, onde é necessário um número mínimo de componentes funcionando, por exemplo, um sistema 2/3, onde é necessário que pelo menos 2 dos 3 componentes funcionem e redundância "Standby" onde o componente redundante só é ativado após a falha do componente principal. $\mathrm{Na}$ análise de confiabilidade de um sistema que possui redundância "Standby" deve-se considerar uma possível falha na ativação do componente redundante ou uma falha do componente redundante anterior à falha do principal. No primeiro caso a falha pode ser causada, por exemplo, por uma falha no sistema de controle. No segundo caso a falha pode ocorrer, por exemplo, devido à deterioração do componente enquanto estava fora de operação (em Standby).

Essas técnicas de redundância podem aumentar significativamente a REGASEIFICAÇÃO DE UMA UNIDADE TIPO FSRU. 
Escola Politécnica da USP

confiabilidade de um sistema, porém devem ser aplicadas com critério, pois possuem um custo associado. A análise de diferentes cenários, onde sejam estudadas inclusões de diferentes tipos de redundância, colabora com a análise de Confiabilidade do sistema.

\subsubsection{Técnicas de análise e suporte à análise}

Com o objetivo de esclarecer o processo de análise de Confiabilidade serão apresentadas aqui as técnicas de análise e de suporte à análise, tradicionalmente aplicadas, enfatizando as vantagens e desvantagens de cada uma. As primeiras técnicas apresentadas, diagrama unifilar e árvore funcional, são de suporte à análise, pois visam proporcionar uma compreensão inicial do sistema a ser estudado e assim facilitar a definição do sistema e do cenário antes do início da análise de Confiabilidade propriamente dita. Em seguida, apresenta-se a técnica de análise de modo de falhas e efeitos, a qual não é uma ferramenta de análise de confiabilidade, mas de suporte, pois visa prever possíveis sequências de eventos que levam à falha do sistema. Segue-se com a apresentação do método de diagrama de blocos, o qual permite a compreensão das relações entre subsistemas ou componentes, e a técnica de árvore de falhas que permite a representação de causas de eventos indesejados no sistema estudado. Estas duas técnicas são usualmente aplicadas para análise da confiabilidade, pois permitem uma visão do arranjo e do funcionamento do sistema e posterior cálculo do valor da confiabilidade. E finalmente é apresentada uma seção sobre árvore de eventos, que também é uma ferramenta para análise quantitativa.

\subsubsection{1 Árvore funcional e diagrama unifilar}

APLICAÇÃO DE REDES BAYESIANAS PARA A ANÁLISE DE CONFIABILIDADE DO SISTEMA DE REGASEIFICAÇÃO DE UMA UNIDADE TIPO FSRU. 
A árvore funcional e o diagrama unifilar são ferramentas que facilitam a compreensão do sistema, o que é fundamental para uma boa análise da confiabilidade. É preciso conhecer o comportamento e as interações entre os componentes do sistema para que se possa estimar de maneira eficaz as possíveis falhas.

O diagrama unifilar nos permite visualizar os componentes do sistema, suas ligações e sua localização em relação aos demais. A Figura 2, foi elaborada para facilitar a compreensão, mostra a representação de um diagrama unifilar, onde cada componente é alocado de acordo com a sua posição física em relação aos demais e linhas são usadas para representar ligações entre esses componentes, como por exemplo, um sistema ligado por meio de tubulações.

$\mathrm{Na}$ árvore funcional são representadas as relações entre os diferentes níveis do sistema; inicia-se com o evento topo que representa a função a ser analisada do sistema e passa-se a detalhar como o sistema executará essa função. Sendo assim, na direção descendente é feita a representação de como o sistema e seus subsistemas executarão a função principal e na direção ascendente é representada a causa de existência de cada subsistema. A Figura 3 representa a construção de uma árvore funcional. 
Escola Politécnica da USP

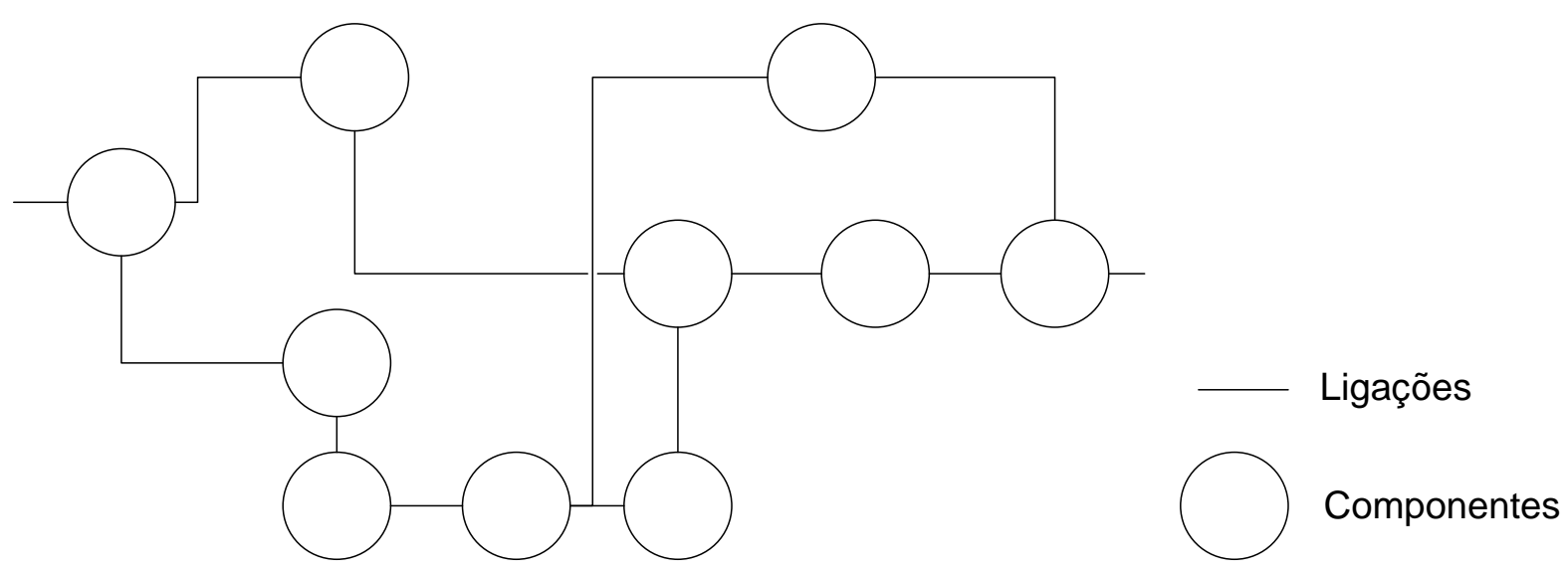

Figura 2 - Esquematização de um diagrama unifilar

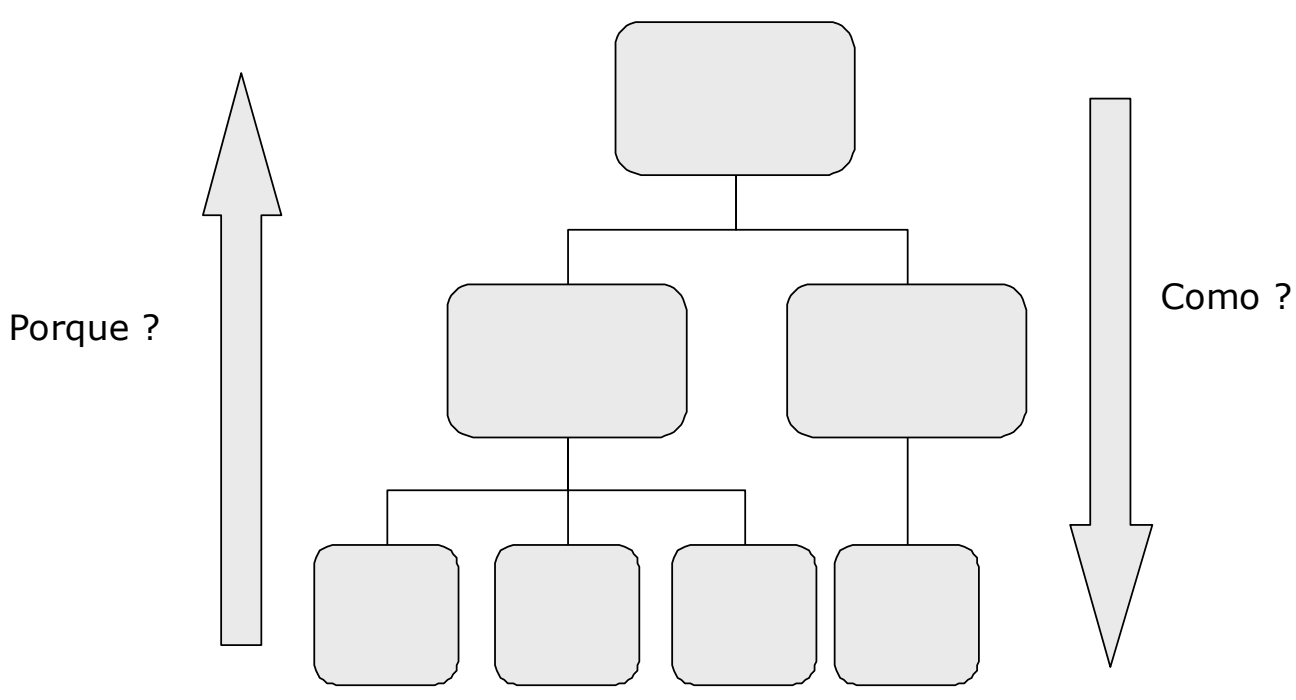

Figura 3 - Representação da construção de uma árvore funcional Adaptado de Natacci, F. B., Martins, M. R., Souza, G. F. M. (2009)

\subsubsection{Análise de Modo de Falhas e Efeitos}

A análise de modos de falha e efeitos (Failure Mode and Effects Analysis -

APLICAÇÃO DE REDES BAYESIANAS PARA A ANÁLISE DE CONFIABILIDADE DO SISTEMA DE REGASEIFICAÇÃO DE UMA UNIDADE TIPO FSRU. 
Escola Politécnica da USP

FMEA) é uma técnica que contribui para análise de confiabilidade, pois visa identificar possíveis sequências de eventos que levem a falha, determinar suas conseqüências e identificar possíveis métodos que minimizem a ocorrência destes eventos (Modarres, 1993). Identificar os modos de falha de equipamentos e seus componentes e principalmente saber quais são os possíveis efeitos provocados dentro do sistema são informações importantes também para uma futura análise de risco.

Segundo Leveson (1995) a FMEA é uma técnica indutiva que é útil quando a estrutura fundamental é temporal e os elementos são eventos, condições ou tarefas. Esta técnica tem um evento de início e traça o caminho do nível mais baixo para o mais alto, ou seja, é uma técnica do tipo "down-top". O resultado é um grupo de estados (onde um estado é um grupo de condições) que representam os efeitos do evento inicial. Esta técnica faz uma análise isoladamente de cada componente, diferentemente da Análise de Árvore de Falhas que faz a análise interatuando o acontecimento de falhas conjuntas que levam até a falha do componente avaliado.

Ainda de acordo com Leveson (1995) o primeiro passo na FMEA é identificar e listar todos os componentes e seus modos de falha, considerando todos os possíveis modos de operação. Para cada modo de falha, os efeitos em todos os outros componentes do sistema são determinados juntamente com o efeito sobre todo o sistema. Os resultados desta análise são documentados em uma tabela no formato apresentado na Tabela 1.

APLICAÇÃO DE REDES BAYESIANAS PARA A ANÁLISE DE CONFIABILIDADE DO SISTEMA DE REGASEIFICAÇÃO DE UMA UNIDADE TIPO FSRU. 
Escola Politécnica da USP

Tabela 1 - Informações para elaboração da FMEA (CARAZAS, 2006).

\begin{tabular}{|c|c|c|c|c|c|c|c|c|c|c|}
\hline \multirow{3}{*}{ 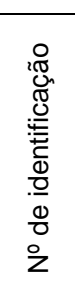 } & \multirow[b]{3}{*}{ 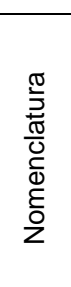 } & \multirow{3}{*}{ 。 } & \multirow{3}{*}{ 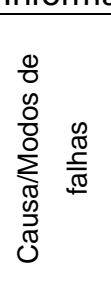 } & \multirow{3}{*}{ 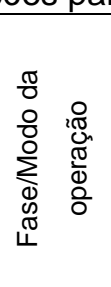 } & \multirow{2}{*}{\multicolumn{3}{|c|}{ Efeitos }} & \multirow{3}{*}{ 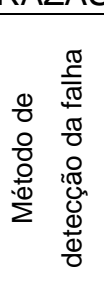 } & \multirow[b]{3}{*}{ 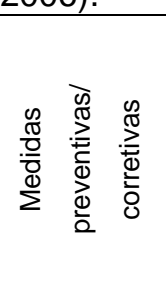 } & \multirow[b]{3}{*}{$\begin{array}{l}\frac{0}{8} \\
\frac{\pi}{0} \\
\frac{0}{0} \\
\stackrel{0}{\infty} \\
\infty\end{array}$} \\
\hline & & & & & & & & & & \\
\hline & & & & & 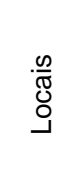 & 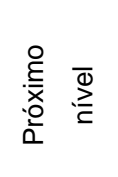 & 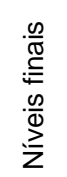 & & & \\
\hline & & & & & & & & & & \\
\hline
\end{tabular}

Segundo Modarres (1993) para preencher a tabela anterior é necessário seguir os seguintes passos:

a. Descrever o sistema para que sua configuração e funcionamento fiquem claros. Esse passo permite preencher as 3 primeiras colunas da Tabela 1: número de identificação, nomenclatura (que é o mesmo que uma identificação funcional) e função do item analisado. A elaboração prévia do diagrama unifilar e do funcional facilita a execução desta tarefa, pois ambos fornecem informações úteis para a descrição do sistema;

b. Listar, na quarta coluna, os modos e as causas de falha de cada item. Os modos serão especificados de acordo com os requisitos préestabelecidos de cada elemento;

c. Examinar e listar as conseqüências de cada modo de falha na coluna "Efeitos", as quais podem ser descritos em três níveis: locais (mostra especificamente o impacto sobre o item considerado), próximo nível (mostra o impacto na saída do item) ou níveis finais (mostra o impacto geral no sistema);

d. Descrever, na sétima e oitava colunas, todas as medidas para detecção, correção e prevenção das falhas. Enfatizar qualquer ação que tenha que ser executada por um operador; 
Escola Politécnica da USP

e. Classificar por nível de severidade cada item, de acordo com o padrão previamente escolhido. O padrão pode ser, por exemplo, uma norma já existente como a MIL-STD-1629A.

A FMEA permite a identificação de áreas potenciais de falhas e fornece documentação detalhada sobre como o a falha do sistema pode ocorrer, é uma ferramenta eficiente para análise qualitativa, porém não gera informações suficientes para uma análise probabilística da confiabilidade.

\subsubsection{Diagrama de Blocos}

Segundo Hamada et al. (2008), um diagrama de blocos (DB) é uma representação do sistema onde cada bloco representa um componente ou um subsistema e tem como função facilitar o entendimento das relações entre estes elementos. Os componentes podem estar arranjados em uma configuração em série, em paralelo ou em uma combinação das duas anteriores. Outros autores apresentam essa técnica com maior ou menor nível de detalhamento (Modarres, 1993; Smith, 2001; Leitch, 1995)

Em sistemas em série, como o mostrado na Figura 4, a falha de um único componente acarreta a falha de todo o sistema, ou seja, assumindo que as falhas de cada componente sejam independentes, temos que a taxa de falha do sistema é igual à soma das taxas de falhas de todos os componentes. Portanto, temos que a confiabilidade de um sistema em séries é dada pela Eq. (1)

$$
R(t)=\Pi_{i=1}^{n} R_{i}(t)
$$


Escola Politécnica da USP

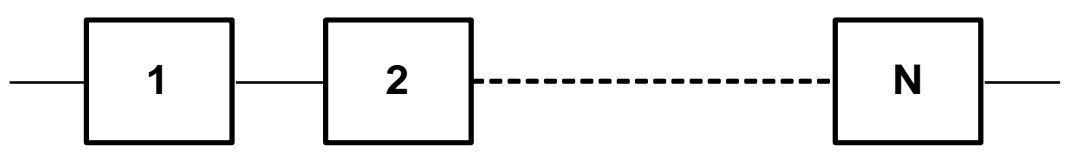

Figura 4 - Sistema em Série

Já em sistemas em paralelo, onde existe a redundância, a falha de um componente não necessariamente acarreta a falha de todo o sistema. A Figura 5 representa um sistema em paralelo, onde o sistema permanecerá funcionando enquanto pelo menos um componente estiver em funcionamento. Para este tipo de configuração temos que a confiabilidade é dada por:

$$
R(t)=1-\Pi_{i=1}^{n}\left[1-R_{i}(t)\right]
$$

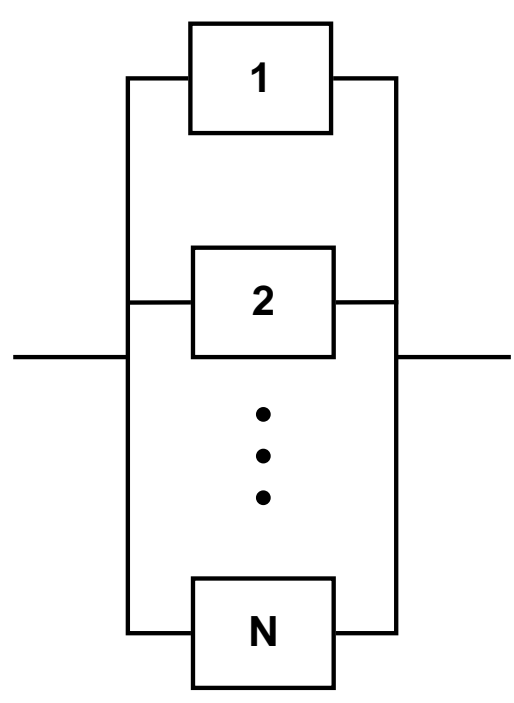

Figura 5 - Sistema em paralelo

APLICAÇÃO DE REDES BAYESIANAS PARA A ANÁLISE DE CONFIABILIDADE DO SISTEMA DE REGASEIFICAÇÃO DE UMA UNIDADE TIPO FSRU. 
Escola Politécnica da USP

O diagrama de blocos tem como ponto forte ser uma ferramenta que proporciona uma representação visual dos componentes e de como eles estão configurados para formar o sistema (Hamada et al., 2008), porém a construção de um diagrama de blocos assume que cada bloco falha de maneira independente, sendo essa uma limitação que pode tornar o modelo pouco realista e por vezes inadequado. Outro ponto fraco, apontado por Modarres (1993), é a dificuldade do uso de diagrama de blocos para o cálculo da Confiabilidade de sistemas que tenham interações físicas e operacionais complexas, como por exemplo, o caso em que a interação humana deva ser modelada.

\subsubsection{4 Árvores de falhas}

Segundo Lee et al. (1985), a análise de árvore de falhas (do inglês Fault Tree Analysis - FTA) é amplamente usada no campo aeroespacial, eletrônico, e nuclear. Esta técnica foi originalmente desenvolvida em 1961 por $\mathrm{H}$. A. Watson em Bell Telephone Laboratories para avaliar o sistema de controle de lançamento de um míssil, para evitar um lançamento não autorizado (acidental).

A FTA é uma técnica para a análise da confiabilidade e segurança que visa determinar as causas de um evento indesejado chamado de "evento topo" (Kececioglu, 1991). Esta técnica está baseada em uma análise dedutiva, onde o evento topo é postulado e os possíveis meios para que este evento ocorra são sistematicamente deduzidos. Sendo assim, é necessário que exista um conhecimento profundo sobre o funcionamento do sistema, o que justifica a aplicação das técnicas apresentadas anteriormente, como a FMEA. A árvore é uma representação gráfica de várias combinações de falhas que levam a ocorrência do evento topo e é usada para demonstrar a lógica do modelo (Modarres, 1993).

APLICAÇÃO DE REDES BAYESIANAS PARA A ANÁLISE DE CONFIABILIDADE DO SISTEMA DE REGASEIFICAÇÃO DE UMA UNIDADE TIPO FSRU. 
Escola Politécnica da USP

A seguir, na Tabela 2, são apresentados os símbolos e significados dos portões lógicos mais utilizados durante a construção da árvore de falha. O portão "E" é usado para representar que a ocorrência do evento de saída somente acontecerá quando todos os eventos de entrada forem verificados simultaneamente. Por sua vez, o portão "OU" é usado para representar que pelo menos um dos eventos de entrada deve ocorrer para que o evento de saída ocorra. Todos os eventos são binários, usualmente representados por "falha/não-falha", "verdadeiro/falso" ou "0/1".

Tabela 2 - Símbolos dos portões lógicos (KECECIOGLU, 1991).

\begin{tabular}{|c|c|l|}
\hline Nome do portão & $\begin{array}{c}\text { Símbolo do } \\
\text { portão }\end{array}$ & \multicolumn{1}{|c|}{ Descrição } \\
\hline Portão E & $\begin{array}{l}\text { O evento de saída ocorre se todos os } \\
\text { eventos de entrada ocorrem }\end{array}$ \\
\hline Portão OU & $\begin{array}{l}\text { O evento de saída ocorre se pelo } \\
\text { menos um dos eventos de entrada }\end{array}$ \\
\hline $\begin{array}{c}\text { Portão OU } \\
\text { exclusivo }\end{array}$ & $\begin{array}{l}\text { O evento de saída ocorre um número } \\
\text { ímpar dos eventos de entrada ocorre. }\end{array}$ \\
\hline
\end{tabular}

A seguir na Tabela 3 são mostrados os símbolos dos eventos mais utilizados na construção de árvores de falhas. 
Escola Politécnica da USP

Tabela 3 - Símbolos para a representação de eventos (KECECIOGLU, 1991).

\begin{tabular}{|c|c|l|}
\hline Nome do evento & $\begin{array}{c}\text { Símbolo do } \\
\text { evento }\end{array}$ & \multicolumn{1}{|c|}{ Descrição } \\
\hline Evento Básico & & $\begin{array}{l}\text { É o evento iniciador, uma falha que não } \\
\text { será mais detalhada. }\end{array}$ \\
\hline Evento resultante & $\checkmark$ & $\begin{array}{l}\text { Evento que resulta da combinação de } \\
\text { eventos um nível abaixo. }\end{array}$ \\
\hline $\begin{array}{c}\text { Evento não } \\
\text { desenvolvido }\end{array}$ & $\begin{array}{l}\text { Evento que não foi desenvolvido por } \\
\text { falta de interesse ou informação. }\end{array}$ \\
\hline $\begin{array}{c}\text { Evento de } \\
\text { transferência para } \\
\text { dentro e para fora }\end{array}$ & $\begin{array}{l}\text { Evento que serve para indicar a } \\
\text { repetição de uma parte da árvore. }\end{array}$ \\
\hline
\end{tabular}

Segundo Modarres (1993), a análise por árvore de falhas envolve dois aspectos: o qualitativo e o quantitativo. $\mathrm{Na}$ análise qualitativa o propósito é reduzir a árvore para levá-la a sua forma equivalente, mostrando as combinações especificas (intersecções) de eventos básicos que são suficientes para causar o evento topo, os chamados cortes-mínimos (do inglês "cut-sets"). E na análise quantitativa o objetivo é determinar a probabilidade de ocorrência do evento topo.

O método mais usual para o cálculo da confiabilidade através de uma árvore de falhas é o método dos cortes mínimos. Um cut-set é uma combinação de eventos básicos que causa o evento topo. E a probabilidade de ocorrência de cada cut-set é determinada multiplicando a probabilidade de todos os eventos base que compõem o cut-set (Smith, 2001), considerando portanto, que os eventos base são independentes; esta técnica não pode ser aplicada sem o uso desta hipótese. Assim, uma vez definidos os cut-sets da árvore, as probabilidades dos eventos básicos podem ser usadas para encontrar a probabilidade de ocorrência do evento topo. A probabilidade do evento topo será a soma das probabilidades de todos os REGASEIFICAÇÃO DE UMA UNIDADE TIPO FSRU. 
Escola Politécnica da USP

cut-sets se estes forem estatisticamente independentes (para o caso de eventos dependentes existem as árvores de falhas dinâmicas, comentadas nos próximos parágrafos). Existem muitas referências sobre a técnica de análise por árvores de falhas, entre elas Modarres (1993), Smith (2001) e Leitch (1995), o método dos cortes mínimos é descrito com detalhes por Smith (2001).

A técnica de árvore de falhas propicia, de maneira mais clara do que o diagrama de blocos, uma visão sobre a estrutura do sistema e sobre como ele pode falhar, permitindo a inclusão de uma gama maior de informação.

Contudo, como apresentado por Bobbio et al. (2001) e Marquez, Neil e Fenton (2010), a técnica de análise por árvore de falhas possui algumas limitações pois não permite a representação de relações de dependência presentes em alguns sistemas e pelos eventos serem necessariamente binários e estatisticamente independentes.

Para mitigar algumas destas limitações foram criadas as chamadas árvores de falhas dinâmicas, as quais consideram, além das combinações de falhas, a sua ordem de ocorrência. Porém, como apontado por Marquez, Neil e Fenton (2010), a evolução dessas árvores possui dois importantes dificultadores: a quantidade de estados cresce exponencialmente de acordo com a complexidade do sistema tornando o tratamento computacional muito complexo e não é possível modelar alguns tipos de redundância.

\subsubsection{5 Árvores de eventos}

Conforme pode ser visto em Lewis (1994), a árvore de eventos é uma ferramenta para análise quantitativa. Inicia-se por um evento que representa a causa de um incidente e segue acompanhando a progressão do incidente de acordo com a 
Escola Politécnica da USP

falha ou o sucesso dos demais componentes. A representação gráfica da árvore de eventos representa as falhas e sucessos dos componentes do sistema de forma seqüencial, terminando no estado final do sistema de sucesso ou falha, conforme ilustrado na Figura 6.

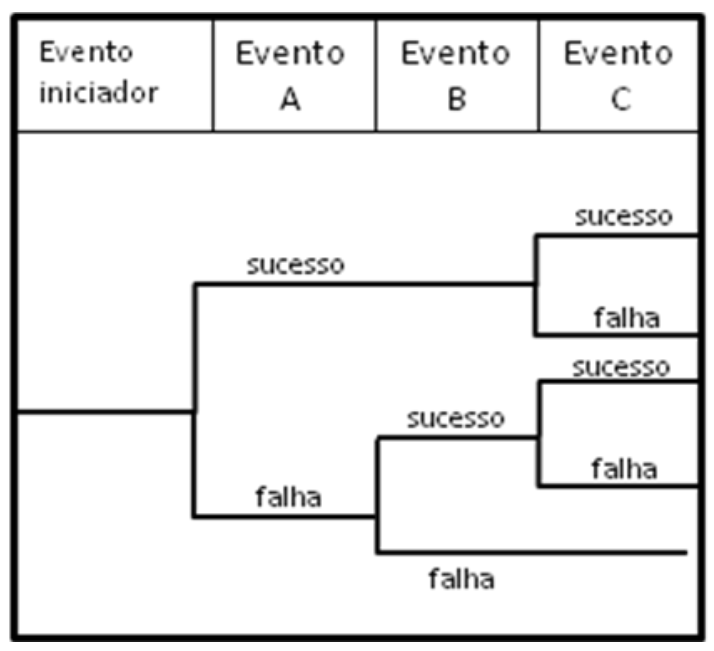

Figura 6 - Árvore de eventos

Fonte: Adaptada de Modarres (1993)

As árvores de eventos são construídas tradicionalmente por eventos binários (por ex.: falha/não-falha). Está técnica tem como ponto forte a capacidade de representar a sequência em que os eventos ocorrem, porém tem como limitação o fato de assumir durante a análise quantitativa a hipótese de que os eventos são independentes (Ayyub, 2003).

\subsubsection{Causas Comum de Falha}

As chamadas causas comuns de falhas (Common Cause Failure - CCF) afetam de maneira significativa a confiabilidade do sistema uma vez que causam a REGASEIFICAÇÃO DE UMA UNIDADE TIPO FSRU. 
falha de mais de um componente resultando, muitas vezes, na ineficácia da proteção por redundância. CCF são falhas que possuem a mesma causa, mesmo que não apresentem o mesmo modo de falha.

Smith (2001) trata das CCF especificamente em sistemas redundantes, assumindo que as falhas não são independentes. Essa abordagem considera que as falhas são dependentes e que ocorrem simultaneamente ou em um intervalo pequeno. São causadas geralmente por especificações de projeto incompletas, imperfeições do projeto (por ex. uma única fonte de energia), baixa qualidade de componentes do mesmo lote, erros de manutenção e condições ambientais.

Para a modelagem de CCF em sistemas redundantes, com vários itens do mesmo componente, Smith (2001) propõe alguns modelos:

a) Modelo Beta: Assume que uma proporção fixa $(\beta)$ das falhas independentes é atribuída às CCF; então para um componente com taxa de falha $\lambda$, a taxa de falha da causa comum é dada por: $\lambda_{1}=\beta \lambda$ e a taxa de falha total do componente é dada por: $\lambda_{c}=\lambda(1+\beta)$;

b) Modelo Beta Parcial: assim como o modelo Beta, assume que a taxa de falha atribuída às CCF é uma proporção da taxa de falha independente, porém considera diferentes graus de influência de acordo com as características de projeto e fabricação dos componentes. Os componentes são agrupados de acordo com itens como: similaridade, separações físicas no arranjo do sistema, análises prévias de possíveis falhas (FMEA, por exemplo) e procedimentos de controle e manutenção;

c) Modelo "Sistema Cut-Off": é o mais simples dos modelos; considera apenas uma taxa de falha que abrange tanto as falhas independentes quanto as dependentes;

d) Modelo Limite: usa dois limites de taxas de falhas, o limite $A$ que assume todas as falhas como comuns e o limite $B$ que assume todas as 
Escola Politécnica da USP

falhas como independentes, o que leva à taxa de falha do sistema $\lambda=\left(\lambda_{B}^{n} \times \lambda_{A}\right)^{\frac{1}{n+1^{2}},}$ onde $\mathrm{n}$ representa 0 grau de diversidade entre os componentes redundantes;

e) Modelo de letras gregas múltiplas: considera que o Beta do modelo Beta varia de acordo com o número de falhas coincidentes, ou seja, para equipamentos que tenham um maior número falhas coincidentes o Beta será maior;

f) Modelo Beta Plus: é um modelo derivado do modelo Beta Parcial, que relaciona uma série de características para a formação dos grupos de componentes, relacionando diferentes pesos para cada característica e considerando o fator de cobertura (fator baseado na estimativa de falhas detectadas por testes).

O Guia de métodos para determinação e processamento de probabilidades do comitê de prevenção de desastres, mais conhecido como "Red Book" (Schüller, 2005) complementa a abordagem de Smith (2001) não tratando apenas as Causas Comuns de Sistemas Redundantes, mas sim tratando eventos de falha dependentes, ou seja, dois ou mais eventos de falhas causalmente relacionados.

Essa abordagem relaciona 8 diferentes tipos de dependências:

1. Equipamentos compartilhados: um componente ou subsistema é compartilhado por mais de um sistema e a falha deste causa a falha dos demais;

2. Dependências funcionais: onde a não operação de um sistema afeta a operação de outro;

3. Iniciadores de causa comum: quando a falha de um sistema de suporte afeta a confiabilidade do sistema suportado;

4. Interação humana dependente: quando a operação humana pode 
causar a falha de mais de um equipamento;

5. Falhas por interação física: quando uma falha causa uma mudança no ambiente e tal mudança gera outras falhas;

6. Causas de falhas comuns: quando dois ou mais componentes idênticos ou similares falham no mesmo instante devido a uma falha comum não coberta explicitamente pelas dependências descritas anteriormente;

7. Causa comum por falha humana: quando ocorre falha humana dado um cenário específico;

8. Evento externo: falha causada por um evento externo capaz de ultrapassar os limites do sistema e causar dano a mais de um equipamento.

Nessa abordagem os 5 primeiros tipos de dependências descritas acima são eventos que podem ser explícitos no modelo, as demais, cujos mecanismos de falha não podem ser explícitos no modelo são chamados de eventos de causa comum.

Para a modelagem de eventos de causa comum são propostos quatro passos: definição dos eventos de causas comuns, seleção do modelo de probabilidade a ser usado, classificação dos dados existentes e estimação de parâmetros.

No primeiro passo são definidos os eventos de causa comum e refeita a modelagem do sistema considerando agora esses eventos, usualmente representados na árvore de falhas pela adição de um portão "ou". No segundo passo, deve se selecionar o modelo de probabilidade a ser usado, para que se possa quantificar a informação incluída do modelo pelo passo anterior. Nesta fase, Schüller (2005) propõe outros métodos além dos propostos por Smith (2001): modelo Paramétrico Básico, modelo Fator Alpha, modelo de Taxa Binomial e assim como Smith, propõe o modelo Beta. A classificação dos dados e a estimação de parâmetros deverão ser feitas com base nos dados históricos existentes e na opinião de especialistas. REGASEIFICAÇÃO DE UMA UNIDADE TIPO FSRU. 
Escola Politécnica da USP

A modelagem de CCF em diagrama de blocos e árvores de falhas apresenta algumas restrições devido ao caráter determinístico dessas técnicas, para a inclusão das CCF é necessária a inclusão de constructos adicionais, como no caso visto da árvore de falhas onde é necessário adicionar um portão extra "Ou" à estrutura. A Figura 7 ilustra a inclusão de uma CCF em uma árvore de falhas, neste caso, para o evento $\mathrm{E}$ ocorrer os componentes $\mathrm{A}$ e $\mathrm{B}$ devem falhar e são inclusos à estruturas elementos que representam as CCF destes componentes.

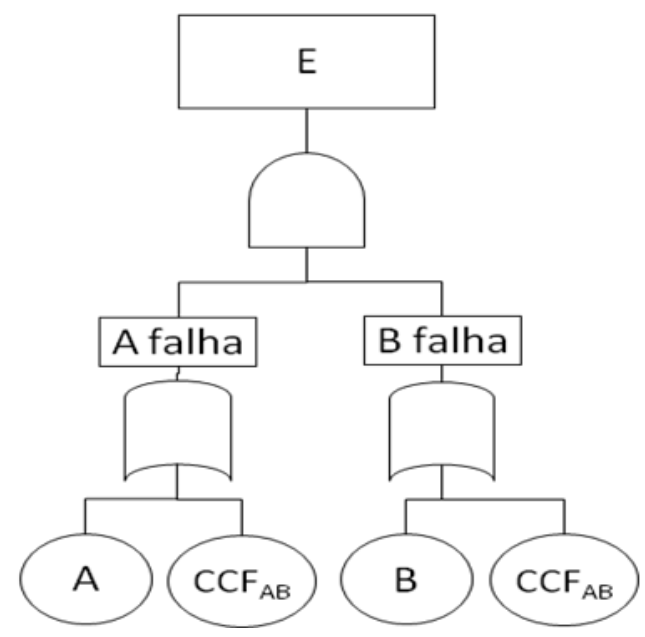

Figura 7 - CCF em árvores de falhas. Adaptada de Hamada et. al (2008).

\subsection{REDES BAYESIANAS}

As Redes Bayesianas são estruturas gráficas usadas para representar as relações probabilísticas entre um grande número de variáveis e desenvolver inferências com essas variáveis. São conhecidas por diferentes nomes, entre eles redes de opinião, redes causais e diagramas de influência (Neapolitan, 2004).

Redes Bayesianas são originárias do campo da Inteligência Artificial, onde 
Escola Politécnica da USP

são usadas como uma ferramenta poderosa para tratar análises nas quais incertezas estão presentes (Langseth e Portinale, 2005). O uso de Redes Bayesianas é abrangente e pode ter inúmeras aplicações e são notadamente úteis em situações onde existem dependências locais entre as variáveis. Modelagens que usam essa técnica ganham flexibilidade, pois permitem a inclusão de evidências durante a análise (Jones et al. 2009).

Para fundamentar o desenvolvimento da metodologia proposta por esta pesquisa, nesta seção serão apresentados tópicos relevantes para uma melhor compressão das Redes Bayesianas e suas aplicações. Primeiramente serão apresentados conceitos relevantes para o desenvolvimento de uma Rede Bayesiana. Em seguida será discutido o uso de Redes Bayesianas na Análise da Confiabilidade e serão apresentadas vantagens e desvantagens do uso desta técnica em comparação com as técnicas tradicionais de análise de Confiabilidade.

\subsubsection{Conceitos básicos}

Uma Rede Bayesiana é um grafo direcionado acíclico o qual é definido por um componente qualitativo e um quantitativo. O componente qualitativo é representado na topologia do grafo e o componente quantitativo é formado pelas probabilidades condicionais associadas ao modelo (Neapolitan, 2004).

A parte qualitativa é dada pelo grafo $G=(V, E)$, onde $V$ são os nós que representam variáveis discretas ou contínuas, e E é um conjunto de pares ordenados de $\mathrm{V}$, chamados de arcos, que representam dependência entre os nós. Vale notar que os nós podem representar variáveis com múltiplos estados. Os arcos e os nós fornecem uma representação de independência ou dependência condicional, o que significa que cada arco construído de uma variável X para uma 
variável $Y$ representa uma dependência direta de $Y$ em relação a $X$, ou seja, uma relação de causa e efeito (Bobbio et al., 2001). Quando um arco é construído de uma variável $X$ para uma variável $Y$, a variável $X$ é chamada de nó pai de $Y$ e a variável $Y$ é chamado de nó filho de X. Para ilustrar apresenta-se a Figura 8, extraída de Sigurdsson et al. (2001), que é um exemplo de Rede Bayesiana, onde o nó $A$ é dito pai dos nós $C$ e $D, B$ é pai de $D, D$ é pai do nó $E$ e os nós $A$ e $B$ não tem pais e portanto são chamados de nós raizes. $A$ interpretação dessas ligações é que os nós pais têm influência direta nos nós filhos.

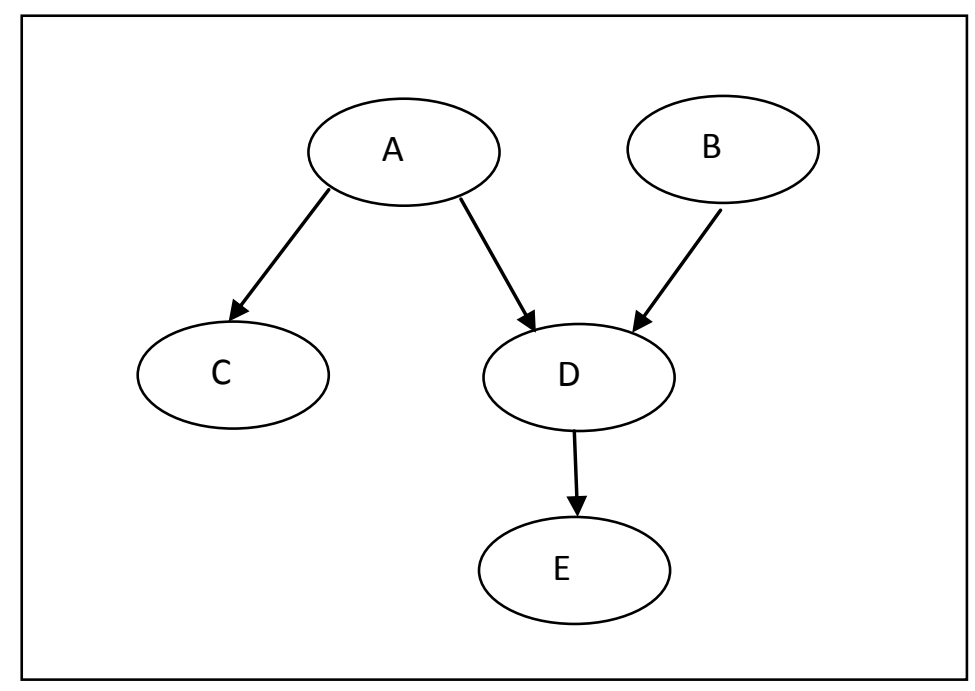

Figura 8 - Exemplo de Rede Bayesiana

Um conjunto de probabilidades condicionais é especificado para cada nó, que não seja um nó raiz, de forma a definir a influência dos nós pais sobre eles e valores de probabilidade à priori (probabilidade estimada inicialmente para nó) são especificados para os nós raiz. Estas probabilidades que são associadas às variáveis compõem o componente quantitativo da Rede Bayesiana e, em se tratando de variáveis discretas, são alocadas em formato de tabela, as chamadas Tabelas de REGASEIFICAÇÃO DE UMA UNIDADE TIPO FSRU. 
Escola Politécnica da USP

Probabilidades Condicionais (TPC) e em se tratando de variáveis contínuas são representadas por funções de densidade de probabilidade condicionada. Sendo assim, as Redes Bayesianas captam as relações causais entre as variáveis e usam as probabilidades condicionais para representar o grau de crença nessas relações (Sigurdsson et al., 2001).

Nos próximos tópicos serão abordados os conceitos de probabilidades condicionais, espaços amostrais, conjuntos, eventos, incertezas, independência condicional, características de um grafo e inferência, estes são conceitos relevantes para o desenvolvimento e análise de uma Rede Bayesiana

\subsubsection{Espaços amostrais, conjuntos e eventos}

Espaços amostrais, conjuntos e eventos são conceitos fundamentais para análise probabilística e sua definição é essencial para a obtenção de resultados realistas.

Ayyub (2003) reporta que um conjunto é definido como uma coleção de elementos ou componentes, usualmente representados por letras maiúsculas (ex.: A, B, C, Y) e seus elementos por letras minúsculas (ex.: a, $x, y$ ). Os conjuntos podem ser finitos ou infinitos e seus elementos podem ser discretos ou contínuos. $\mathrm{Na}$ engenharia, o conjunto de todas as saídas possíveis de um sistema constitui o espaço amostral e um sub-conjunto de uma espaço amostral é chamado de evento.

Essas definições serão usadas nas seções sobre Redes Bayesianas.

\subsubsection{Incertezas, probabilidade a priori e probabilidade posterior \\ O conhecimento total sobre um cenário é quase sempre incompleto; raramente toda a verdade sobre o ambiente é conhecida, sendo assim, na maioria}

APLICAÇÃO DE REDES BAYESIANAS PARA A ANÁLISE DE CONFIABILIDADE DO SISTEMA DE REGASEIFICAÇÃO DE UMA UNIDADE TIPO FSRU. 
Escola Politécnica da USP

dos casos as análises são feitas sob incerteza, onde o conhecimento é representado por um grau de crença sobre os fatos. A teoria da probabilidade atribui um valor numérico de crença, entre 0 e 1, para resumir a incerteza. $A$ crença em determinado fato, dependerá das percepções recebidas, essas percepções são as evidências nas quais as suposições sobre probabilidades serão baseadas (Russel e Norvig, 2004).

O exemplo apresentado por Russel e Norvig (2004) ilustra bem esses conceitos: caso uma pessoa tenha dor de dente, é possível que essa dor seja causada por uma cárie, porém não são todas as cáries que causam dor de dente e não é sempre que uma dor de dente é causada por uma cárie, existem outros fatores que podem causar dor de dente, como por exemplo, gengivite, abscessos e outros. Porém de acordo com as informações existentes sobre o assunto, pode-se dizer que dada a evidência de uma pessoa estar com dor de dente acredita-se que exista uma chance de $80 \%$ de que a pessoa tenha cárie.

Dessa maneira todas as asserções sobre probabilidades devem mencionar as evidências associadas, para o caso em que nenhuma evidência foi observada as probabilidades serão chamadas de probabilidades a priori ou incondicionais; após a observação de qualquer evidência as probabilidades serão chamadas de posterioris ou condicionais (Russel e Norvig, 2004).

\subsubsection{Axiomas de Probabilidade}

Para facilitar a compreensão dos conceitos discutidos nos próximos itens é necessária a apresentação dos axiomas da probabilidade, também conhecidos como axiomas de Kolmogorov, os quais apresentam os princípios básicos para elaboração da teoria da probabilidade.

Segundo Russel e Norvig (2004), estes axiomas são:

APLICAÇÃO DE REDES BAYESIANAS PARA A ANÁLISE DE CONFIABILIDADE DO SISTEMA DE REGASEIFICAÇÃO DE UMA UNIDADE TIPO FSRU. 
Axioma 1 - Todas as probabilidades estão entre $[0,1]$.

$$
0 \leq P(a) \leq 1
$$

Axioma 2 - Proposições verdadeiras tem probabilidade $1 \mathrm{e}$ proposições falsas 0 .

$$
\begin{gathered}
P(\text { verdadeiro })=1 \\
P(\text { falso })=0
\end{gathered}
$$

Axioma 3 - A probabilidade de uma disjunção é dada por:

$$
P(a \cup b)=P(a)+P(b)-P(a \cap b)
$$

Estes axiomas serão importantes para a compreensão dos itens 3.2.1.5, 3.2.2 e 3.2.3 sobre probabilidades conjuntas e inferência.

\subsubsection{Probabilidade Condicional e independência}

Segundo Ayyub (2003), é comum o interesse em probabilidades de ocorrência de eventos que são condicionados à ocorrência de outros eventos o que gera a necessidade de definição do conceito de probabilidade condicional (posterior). Sendo a probabilidade do evento $a$ dado que o evento $b$ ocorreu denotada por $P(a \mid b)$, e $P(a, b)=P(A \cap B)$, a probabilidade condicional de $a$ dado $b$ REGASEIFICAÇÃO DE UMA UNIDADE TIPO FSRU. 
Escola Politécnica da USP

é dada por:

$$
P(a \mid b)=\frac{P(a, b)}{P(b)} \text { se } P(b) \neq 0
$$

Essa equação também pode ser escrita como:

$$
P(a, b)=P(a \mid b) P(b)
$$

A Eq. (8), é denominada Regra do Produto e representa o fato de que para $a$ e $b$ serem verdadeiros, é necessário que $b$ seja verdade e também que $a$ seja verdade dado $b$, o que pode ser escrito no sentido oposto também:

$$
P(a, b)=P(b \mid a) P(a)
$$

Se A e B são eventos independentes, e as probabilidades a priori de $a$ e b são $P(a)$ e $P(b)$, pela Eq.(7), pode-se definir que:

$$
\begin{gathered}
P(a \mid b)=P(a) \\
P(b \mid a)=P(b) \\
P(a, b)=P(a) P(b)
\end{gathered}
$$

Das equações (7) e (9) pode-se extrair a relação do Teorema de Bayes, Eq. REGASEIFICAÇÃO DE UMA UNIDADE TIPO FSRU. 
Escola Politécnica da USP

(13), que será empregado nos tópicos sobre o processo de inferência.

$$
P(a \mid b)=\frac{P(a) P(b \mid a)}{P(b)}
$$

A análise quantitativa das Redes Bayesianas é feita com base no pressuposto de independência condicional e no Teorema de Bayes, portanto dadas três variáveis $X, Y$ e $Z, X$ é condicionalmente independente de $\mathrm{Y}$ dado $\mathrm{Z}$ se $P(X, Y \mid Z)=P(X \mid Z) P(Y \mid Z)$. A relação probabilística de cada nó $X$ e seus respectivos pais $p a(X)$ é definida pela distribuição de probabilidades condicionais.

\subsubsection{Probabilidades conjuntas}

Para o caso de variáveis discretas, a distribuição de probabilidade conjunta, será uma representação das probabilidades de todas as combinações de valores de um conjunto de variáveis aleatórias e é usualmente representada em uma tabela chamada de Tabela de Probabilidades Condicionais (TPC). Para o caso de variáveis contínuas é impossível a representação da distribuição de probabilidade conjunta através de uma tabela, pois as combinações possíveis são infinitas. Neste caso são usadas funções de densidade de probabilidade.

Como demonstrado em detalhes por Maturana (2010) e Russel e Norvig (2004), a distribuição de probabilidade conjunta de uma variável, é obtida a partir do conceito de independência condicional. Considerando $P\left(x_{1}, x_{2}, \ldots, x_{n}\right)$ equivalente à $P\left(X_{1}=x_{1}, X_{2}=x_{2}, \ldots, X_{n}=x_{n}\right)$, onde $X_{i}$ é a denominação de uma variável e $x_{i}$ é uma denominação de seus estados, pela Regra do Produto, apresentada na Eq. (9), a 
Escola Politécnica da USP

probabilidade conjunta será dada por:

$$
P\left(x_{1}, x_{2}, \ldots, x_{n}\right)=P\left(x_{n} \mid x_{n-1}, \ldots, x_{1}\right) P\left(x_{n-1}, \ldots, x_{1}\right)
$$

E através da replicação da Regra do Produto, se obtém as Eq. (15) e (16). Essa replicação é chamada de Regra da Cadeia.

$$
\begin{gathered}
P\left(x_{1}, x_{2}, \ldots, x_{n}\right)=P\left(x_{n} \mid x_{n-1, \ldots,}, x_{1}\right) P\left(x_{n-1} \mid x_{n-2}, \ldots, x_{1}\right) \ldots P\left(x_{2} \mid x_{1}\right) P\left(x_{1}\right) \\
P\left(x_{1}, x_{2}, \ldots, x_{n}\right)=\prod_{i=1}^{n} P\left(x_{i} \mid x_{i-1}, \ldots, x_{1}\right)
\end{gathered}
$$

Para o caso de uma Rede Bayesiana, as equações acima permitem a representação de independência de um nó em relação aos seus ascendentes, exceto os pais. Considerando como verdade a Eq. (17) para os nós pais e usando a relação expressa na Eq. (14), chega-se a Eq. (18) para Redes Bayesianas.

$$
\begin{gathered}
\text { pais }\left(X_{\mathrm{i}}\right) \subseteq\left\{X_{\mathrm{i}-1, \ldots,}, X_{1}\right\} \\
P\left(x_{i} \mid x_{i-1, \ldots,} x_{1}\right)=P\left(x_{i} \mid \operatorname{pais}\left(x_{i}\right)\right)
\end{gathered}
$$

E considerando as Eq. (16) e (17), a probabilidade conjunta de uma Rede Bayesiana será dada por: REGASEIFICAÇÃO DE UMA UNIDADE TIPO FSRU. 
Escola Politécnica da USP

$$
P\left(x_{1}, x_{2}, \ldots, x_{n}\right)=\prod_{i=1}^{n} P\left(x_{i} \mid \text { pais }\left(x_{i}\right)\right)
$$

Esta equação permitirá a obtenção de qualquer probabilidade conjunta de uma Rede Bayesiana a partir dos valores encontrados nas tabelas de probabilidades condicionais.

\subsubsection{Características do Grafo}

Como mencionado anteriormente, o grafo de uma Rede Bayesiana é composto por nós e arcos que representam as variáveis estudadas e suas relações, essas relações tratam da independência entre as variáveis ou de dependências locais. A partir da estrutura deste grafo pode-se identificar todas as suposições de independências condicionais entre as variáveis de uma Rede Bayesiana. Esta identificação é feita através do conceito de d-separação (será apresentado na próxima seção), o qual permite uma representação compacta da distribuição conjunta de probabilidade (Boudali e Dugan, 2006). A capacidade de fazer uma representação compacta da distribuição conjunta de probabilidades, evitando assim o problema de explosão amostral encontrado em outras técnicas, torna as Redes Bayesianas uma técnica apropriada para aplicação em modelos que possuem um grande número de variáveis envolvidas. O problema de explosão amostral é detalhado por Neapolitan (2004).

As relações de independência representadas no grafo podem ser identificadas de maneiras diferentes, através de três conceitos: condição de Markov, cobertor de Markov e d-separação.

A condição de Markov estabelece que um nó seja condicionalmente

APLICAÇÃO DE REDES BAYESIANAS PARA A ANÁLISE DE CONFIABILIDADE DO SISTEMA DE REGASEIFICAÇÃO DE UMA UNIDADE TIPO FSRU. 
Escola Politécnica da USP

independente do conjunto de nós de seus não-descendentes dado o conjunto de seus nós pais. Para ilustrar podemos usar a Figura 9, extraída de Neapolitan (2004), onde $\mathrm{F}$ é condicionalmente independente de $\mathrm{C} \mathrm{e} \mathrm{H}$ (conjunto de nós não descendentes, exceto pais) dado $B$ e $L$ (o conjunto de nós pais). Esta condição nos permite estabelecer a relação independência condicional de uma variável em relação aos seus não descendentes dada as evidências nas variáveis representadas pelos nós pais.

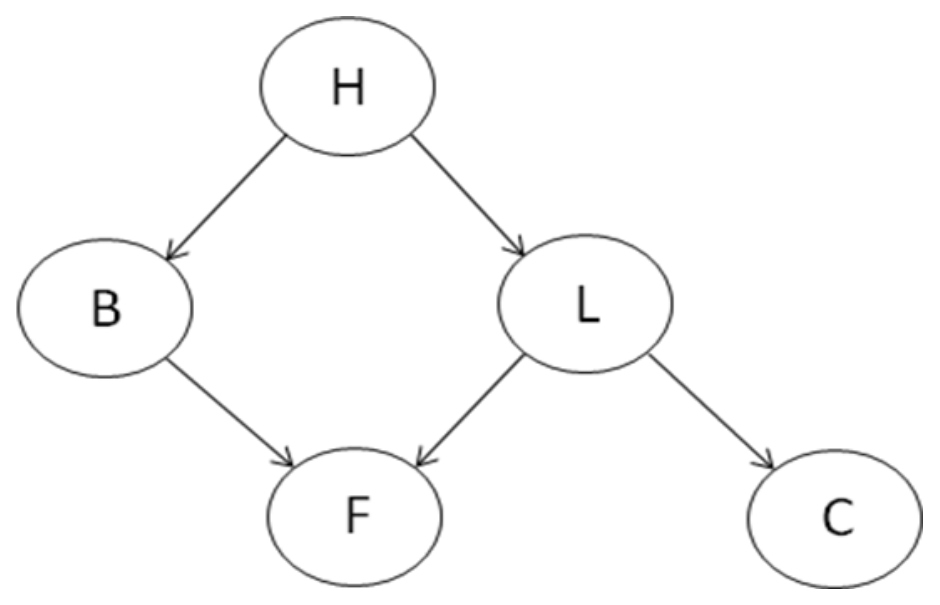

Figura 9 - Condição de Markov

O conceito de Cobertor de Markov é um pouco mais amplo do que o anterior, pois permite a visualização da independência condicional de um nó em relação a todos os nós da rede, exceto seus pais, filhos e nós pais de seus filhos. Dessa forma é possível verificar se há ou não independência entre duas variáveis específicas de interesse. O Cobertor de Markov de uma variável $X$ é o conjunto de nós formados pelos nós pais, filhos e pais dos filhos dessa variável. Para ilustrar esta definição temos a Figura 10 também retirada de Neapolitan (2004); o Cobertor de Markov da variável $X$ é formado pelas variáveis $T$ (pai), $Z$ (filho) e $Y$ (pai do filho de $X$ ), sendo REGASEIFICAÇÃO DE UMA UNIDADE TIPO FSRU. 
Escola Politécnica da USP

assim $X$ é condicionalmente independente de $S$ e $W$ dados $T, Z$ e $Y$.

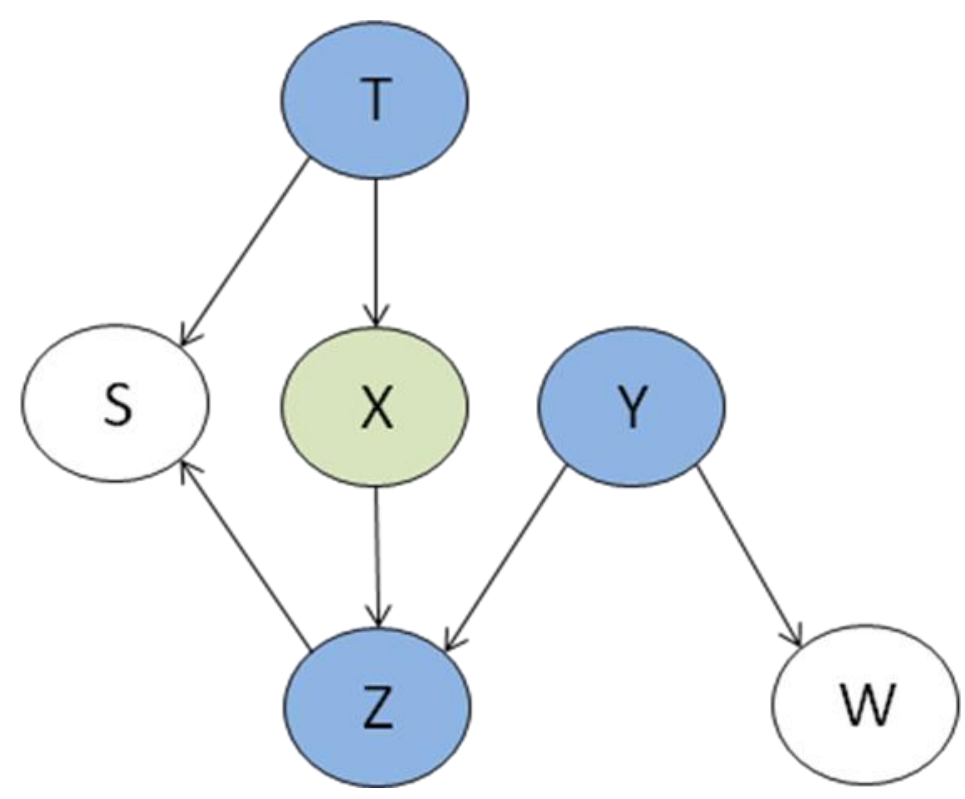

Figura 10 - Cobertor de Markov

Outra maneira de constatar se há ou não independência condicional entre duas variáveis específicas de interesse é através da verificação da existência ou não de uma d-separação. Existem três estruturas básicas que podem existir em uma rede: a cadeia (onde as variáveis são conectadas em série), o garfo (onde uma variável é conectada a outras duas) e a colisão (onde duas variáveis são conectadas a uma terceira). A Figura 11 ilustra as três estruturas (Langseth e Portinale, 2005). 


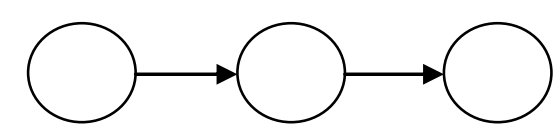

(a)

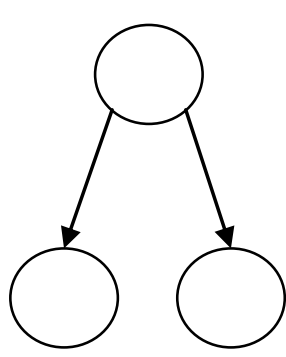

(b)

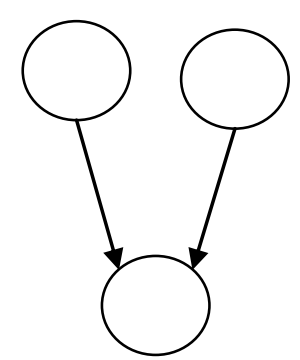

(c)

Figura 11 - Estruturas de uma rede: (a) cadeia, (b) garfo e (c) colisão Fonte: adaptada de Langseth e Portinale (2005)

Duas variáveis são consideradas $d$-separadas e portanto condicionalmente independentes se forem separas por um garfo ou uma cadeia e for dada uma evidência da variável central ou se forem separadas por uma colisão e não existir uma evidência. A Figura 12, extraída e adaptada de Maturana (2010), ilustra estas três situações: na primeira rede as variáveis $A$ e $C$ são separadas por uma cadeia $e$ existe a evidência $E$ da variável $B$; na segunda rede as variáveis $A$ e $C$ são separadas por um garfo e também existe a evidência $E$ referente à variável $B$; finalmente, na terceira rede, as variáveis $A$ e $C$ são separadas por uma colisão e não existe evidência relacionada à variável intermediária $D$.

Para aprofundamento do conhecimento Langseth e Portinale (2005) e Neapolitan (2004) são referências que detalham o conceito de d-separação. 
Escola Politécnica da USP

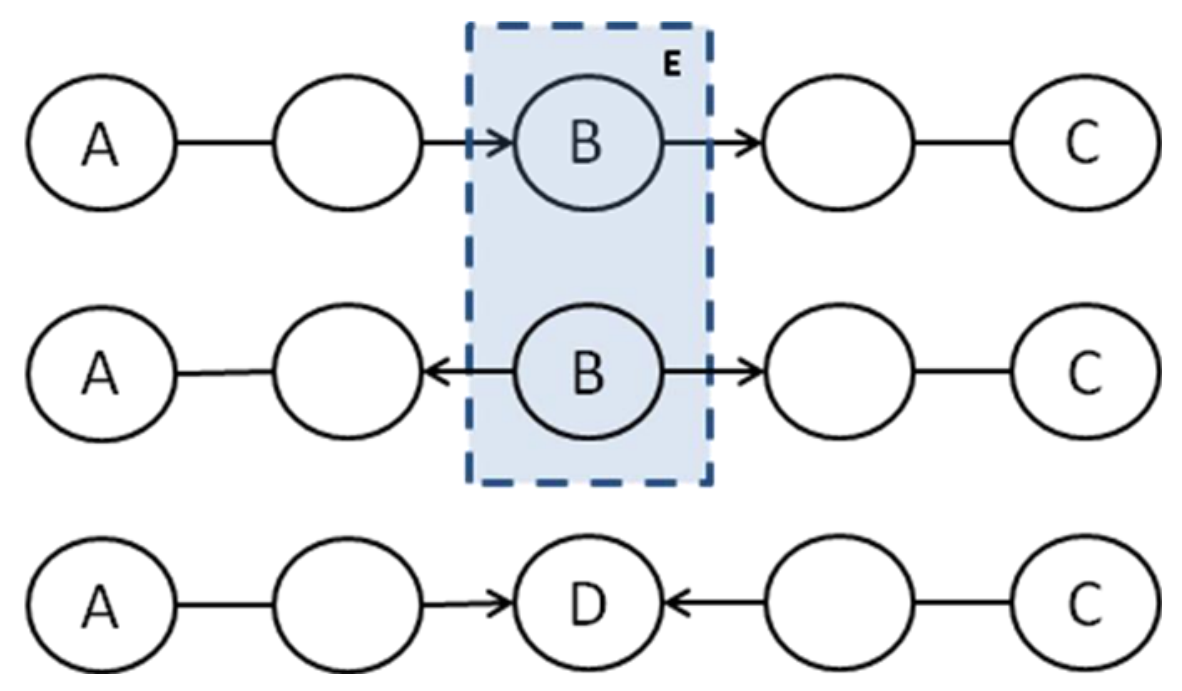

Figura 12 - d-deparação entre os nós A e C Fonte: Adaptado de Maturana (2010)

\subsubsection{Inferência com variáveis discretas}

A tarefa de uma Rede Bayesiana é calcular a distribuição de probabilidade para um conjunto de variáveis de interesse, dado um evento (ou seja, variáveis de evidência). Para tal tarefa existem dois tipos de inferência: inferência exata e inferência aproximada.

\subsubsection{Inferência Exata}

A partir do segundo axioma de Kolmogorov, Eq. (4) e (5), temos que:

APLICAÇÃO DE REDES BAYESIANAS PARA A ANÁLISE DE CONFIABILIDADE DO SISTEMA DE REGASEIFICAÇÃO DE UMA UNIDADE TIPO FSRU. 
Escola Politécnica da USP

$$
P(\bar{a})=1-P(a)
$$

onde $P(\bar{a})$ é a probabilidade de a ser falso.

Essa equação pode ser estendida para o caso discreto geral, sendo $D$ uma variável discreta que tem domínio $\left[d_{1}, \ldots, d_{n}\right]$, então pode-se dizer que qualquer distribuição de probabilidade sobre uma única variável deve somar 1 , por tanto pode-se dizer que:

$$
\sum_{\mathrm{i}=1}^{n} P\left(D=d_{\mathrm{i}}\right)=1
$$

Também é válido dizer que qualquer distribuição de probabilidade conjunta sobre qualquer conjunto de variáveis deve somar 1 . Sendo assim, a partir do terceiro axioma de Kolmogorov, pode-se obter que a probabilidade $\mathrm{P}(a)$ é igual a soma de seus eventos:

$$
P(a)=\sum_{i=1}^{n} P\left(e_{i}\right)
$$

A probabilidade condicional de uma variável de interesse é dada pelo somatório de termos da distribuição total conjunta, a prova desta relação pode ser encontrada em Russel e Norvig (2004). Ou seja, para uma variável de interesse $X$, dada uma evidência $e$ e sendo $\mathrm{Y}$ as variáveis restantes não observadas, teremos a Eq. (23).

$$
P\left(\left.X\right|_{e}\right)=\alpha \sum_{y} P\left(X, e_{s} y\right)
$$


Escola Politécnica da USP

onde $\alpha$ é dado por:

$$
\alpha=\frac{1}{P(e)}
$$

Sendo assim, em uma Rede Bayesiana a probabilidade condicional conjunta de uma variável é calculada somando-se os produtos de probabilidades condicionais da rede. Esta abordagem poder ser aplicada a qualquer rede, porém conforme a complexidade da rede aumenta mais dispendioso é esse cálculo. Essa dificuldade gerou o desenvolvimento de algumas técnicas para simplificação do cálculo, entre elas as principais são enumeração e eliminação de variáveis, ambas discutidas por Russel e Norvig (2004). Entretanto, mesmo com a utilização dessas técnicas, em casos de redes muito complexas a inferência exata pode se tornar intratável e nesses casos são usados métodos de inferência aproximada.

\subsubsection{Inferência Aproximada}

A inferência aproximada é usada quando o tratamento da rede por meio de inferência exata torna-se intratável; usualmente são usadas técnicas de aproximação estocástica como ponderação de probabilidade e cadeia de Markov para se obter uma estimativa das probabilidades conjuntas. São muitos os algoritmos que podem ser usados para estes casos, Russel e Norvig (2004) e Neapolitan (2004) apresentam os principais.

Os métodos de inferência aproximada podem ser combinados com outras técnicas para inferência de variáveis contínuas, portanto, como durante a elaboração deste estudo foram usadas variáveis contínuas, nas próximas seções será apresentado o desenvolvimento da inferência para variáveis contínuas. 


\subsubsection{Inferência com variáveis contínuas}

Na seção anterior foi apresentada a inferência para Redes Bayesianas que possuem apenas variáveis discretas, porém de acordo com a aplicação, pode se tornar necessária a inclusão de variáveis contínuas ao modelo o tornando um modelo híbrido.

Existem diferentes métodos para tratar a inferência em casos de redes híbridas, Langseth et al. (2009) traçam um histórico sobre o desenvolvimento dos métodos usados para inferência de redes híbridas, Russel e Norvig (2004) e Boudali e Dugan (2006) apresentam um método para o desenvolvimento de Redes Bayesianas Dinâmicas (redes temporais) e Marquez, Neil e Fenton (2010) desenvolvem um método com o emprego de discretização dinâmica. Este último será apresentado nesta seção, pois é o método empregado pelo programa comercial usado neste estudo, o Agena Risk (Agena Risk Desktop, 2011) disponibilizado pelo LabRisco-USP.

Segundo Marquez, Neil e Fenton (2010), a proposta é produzir uma fina discretização nas regiões que mais contribuem para a estrutura da função de densidade dos nós (que representa a distribuição da variável contínua) e ao mesmo tempo ajustar as regiões de alta densidade dadas as evidências. Isso é possível integrando uma discretização iterativa dentro de um algoritmo robusto que trata Redes Bayesianas. No Apêndice A esta abordagem é apresentada com mais detalhes, porém como a análise detalhada do método de inferência não é foco deste trabalho, a seguir, serão apresentados apenas os principais passos:

1. Considere um nó contínuo $\zeta$ na Rede Bayesiana; a faixa de alcance (o domínio) de $\zeta$ como $\Omega_{\zeta}$; a função densidade de probabilidade de $\zeta$ 
como $f_{\zeta}$; e a distribuição condicional de $\zeta$ como uma função de seus nós pais: $\zeta=g(p a(\zeta))$, onde $p a(\zeta)$ são os nós pais de $\zeta$;

2. Suponha um sistema formado por dois componentes $A$ e $B$, a distribuição condicional do sistema será dada por uma função de seus componentes, $\zeta_{S}=g\left(\zeta_{A}, \zeta_{B}\right)$.

3. Suponha que o sistema tenha variáveis contínuas $\zeta_{A}$ e $\zeta_{B}$ e que as variáveis $\zeta_{A}$ e $\zeta_{B}$ tenham discretizações $\psi_{A}$ e $\psi_{B}$ sobre seus respectivos domínios $\Omega_{A}$ e $\Omega_{B}$. Para cada par de intervalos nos conjuntos $\Psi_{A}$ e $\psi_{B}$, tal que $\left(\mathrm{a}_{1}, \mathrm{a}_{2}\right)$ em $\psi_{A}$ e $\left(\mathrm{b}_{1}, \mathrm{~b}_{2}\right)$ em $\boldsymbol{\psi}_{B}$, o algoritmo usado pelo programa calcula o valor mínimo I e o valor máximo u para cada conjunto de valores $g\left(a_{1}, b_{1}\right), g\left(a_{1}, b_{2}\right), g\left(a_{2}, b_{1}\right)$ e $g\left(a_{2}, b_{2}\right)$;

4. Sendo $Z$ o conjunto de todos os pares dos intervalos dos conjuntos das discretizações, tem-se um conjunto de intervalos $\left(\mathrm{l}_{\mathrm{i}}, \mathrm{u}_{\mathrm{i}}\right)$ para cada $\mathrm{i} \in \mathrm{Z}$ e isto gera uma massa de densidade de probabilidade uniforme, $U\left(\mathrm{l}_{\mathrm{i}}\right.$, $\left.u_{i}\right)$, sobre a faixa de $\zeta_{s}$, sendo $\zeta_{s}=g\left(\zeta_{A}, \zeta_{B}\right)$.

5. Assumindo que $\psi_{S}$ consiste de intervalos $\omega_{1} \ldots \omega_{n}$, uma aproximação da tabela de probabilidade condicional para a função de densidade condicional do nó $\zeta_{s}, \hat{f}(\zeta \mid p a(\zeta))$, é definida por uma distribuição uniforme ponderada:

$$
p_{1_{i}, u_{\mathrm{i}}}\left(\zeta s \in \omega_{\mathrm{k}}\right) \mathrm{U}\left(\zeta_{;} \mathrm{l}_{\mathrm{i}}, \mathrm{u}_{\mathrm{i}}\right)
$$

Onde: $p_{\mathrm{l}_{\bar{i}} \mathrm{u}_{\mathrm{i}}}\left(\zeta, s \in \omega_{\mathrm{k}}\right)$ representa a fração massa uniforme $\mathrm{U}\left(\zeta_{i} \mathrm{l}_{\mathrm{i}}, \mathrm{u}_{\mathrm{i}}\right)$ correspondente ao intervalo $\omega_{\mathrm{k}}$, ou seja:

$$
p_{\mathrm{l}_{\mathrm{i}} \mathrm{u}_{\mathrm{i}}}\left(\zeta \mathrm{s} \in \omega_{\mathrm{k}}\right)= \begin{cases}\int_{\omega_{\mathrm{k}}} \mathrm{U}\left(\zeta_{;} \mathrm{l}_{\mathrm{i}}, \mathrm{u}_{\mathrm{i}}\right) \mathrm{d} \zeta & \text { se } \omega_{\mathrm{k}} \cap\left(\mathrm{l}_{\mathrm{i}}, \mathrm{u}_{\mathrm{i}}\right) \neq 0 \\ 0 & \text { caso contrário }\end{cases}
$$

6. Através da atualização iterativa destes intervalos executada pelo 
método de discretização dinâmica, ou seja, recalculando-se as aproximações das tabelas de probabilidades condicionais sobre os domínios discretizados, propagando a Rede Bayesiana para calcular a função da probabilidade posterior de cada nó e então separando/unindo os intervalos de acordo com o critério de entropia Kullback-Leibler (proposto por Koslov e Koller, 1997) relativa até o método convergir, é possível desenvolver a inferência da Rede Bayesiana.

Para aprofundamento do tema inferência com variáveis contínuas pode-se consultar Marquez, Neil e Fenton (2010), Neil, Tailor e Marquez (2007) e Neil et al. (2008).

\subsubsection{Redes Bayesianas na análise da Confiabilidade}

$\mathrm{Na}$ análise de confiabilidade é comum o uso de árvores de falhas e de diagrama de blocos, onde as relações são determinísticas, ou seja, falha ou não falha. Com o uso das Redes Bayesianas (RB) na análise de confiabilidade se ganha flexibilidade, sendo possível acrescentar eventos não determinísticos, como por exemplo, o desgaste na análise de falha, ou incertezas quanto às conseqüências de determinado evento.

Um dos primeiros estudos sobre o uso de Redes Bayesianas para análise Confiabilidade data de 1988. Desde então, a aceitação da idéia do uso de Redes Bayesianas para análise de confiabilidade tem crescido devido a sua facilidade em representar sistemas e sua eficiência para obter informações sobre as relações entre os componentes. Mais recentemente ganhou força com o desenvolvimento de softwares voltados para seu uso (Doguc e Marquez, 2009). 
Escola Politécnica da USP

Atualmente o uso de Redes Bayesianas para análise de confiabilidade tem se mostrado uma ferramenta eficaz, como mostram os estudos de Hamada et al. (2008), Bobbio et al. (2001), Jones et al.(2009) e Huang et al. (2007). Pois qualquer análise feita com o uso das técnicas tradicionais descritas anteriormente pode ser feita por Redes Bayesianas e, além disso, pode se agregar ao modelo relações de dependência, incertezas, variáveis com múltiplos estados e conhecimento de especialistas para criar estimativas quando não existirem dados estatísticos suficientes e/ou adequados.

Bobbio et al. (2001) demonstram em seu artigo que o uso de Redes Bayesianas no lugar de Árvores de Falhas pode trazer incrementos significativos tanto no nível de análise quanto no nível de modelagem. Na modelagem, algumas hipóteses bastante restritivas (tais como eventos binários e relações determinísticas) implícitas na modelagem por FT podem ser removidas e dependências locais podem ser adicionadas. Adicionalmente, a capacidade de análise pode ser amplificada uma vez que o formalismo das Redes Bayesianas permite a inclusão de evidências durante a análise.

Langseth e Portinale (2005) demonstram que, diferentemente das Árvores de Falhas e dos Diagramas de Blocos, a modelagem de variáveis com múltiplos estados e de causas comuns não é complexa em uma Rede Bayesiana; modelagens estas apresentadas e discutidas nos itens 3.2.4.2 e 3.2.4.3 respectivamente. Também afirmam que com o uso de Redes Bayesianas é possível a representação de incertezas no modelo, tarefa que não é possível com o uso de Árvores de Falhas e Diagramas de Blocos. Marques, Neil e Fenton (2011) também apresentam algumas vantagens do uso Redes Bayesianas sobre técnicas tradicionais, especialmente Árvores de Falhas. Árvores de Falhas estáticas não são capazes de representar as relações de dependência e para atender a necessidade de resolver essa limitação foram criadas as Árvores de Falhas Dinâmicas, que REGASEIFICAÇÃO DE UMA UNIDADE TIPO FSRU. 
consideram além das combinações de eventos a seqüencia em que eles ocorrem. Porém as Árvores de Falhas Dinâmicas possuem duas grandes limitações: o espaço amostral usado por elas cresce exponencialmente, muitas vezes tornando-se intratável e elas são incapazes de representar alguns tipos de redundância. Algumas técnicas que usam integração numérica e simulação de Monte Carlo têm sido testadas para superar essas deficiências. Contudo, o uso de Redes Bayesianas tem se mostrado uma ferramenta poderosa para análise de sistemas complexos, pois alguns de seus pontos fortes são justamente sua capacidade de representar dependências e sua eficiência em modelar redundâncias.

O uso das Redes Bayesianas na análise da Confiabilidade permite: a inclusão no modelo de variáveis com múltiplos estados; a análise de eventos não determinísticos (conforme apresentado na seção 3.2.1); a representação de dependências funcionais e/ou temporais (conforme item 3.2.1.6); modelagens de variados modos de redundância (itens 3.2.4.2); consideração de Causas Comuns de Falha tanto em modelos que possuem variáveis discretas quanto em modelos que possuem variáveis contínuas (conforme item 3.2.4.3); análises de incertezas do modelo e análises de diferentes cenários (conforme item 5.4.2).

Para aprofundamento do conhecimento sobre o uso de Redes Bayesianas na análise da Confiabilidade, nos próximos itens serão apresentados métodos para conversão de diagrama de blocos e árvores de falhas (técnicas tradicionais de análise de Confiabilidade) em Redes Bayesianas e em seguida uma apresentação do tratamento de Causas Comum de Falha durante a modelagem por Redes Bayesianas.

\subsubsection{Conversão de árvores de falhas em Redes Bayesianas}

APLICAÇÃO DE REDES BAYESIANAS PARA A ANÁLISE DE CONFIABILIDADE DO SISTEMA DE REGASEIFICAÇÃO DE UMA UNIDADE TIPO FSRU. 
Escola Politécnica da USP

Converter uma árvore de falhas em uma Rede Bayesiana não é um processo complexo; uma descrição detalhada desse processo pode ser encontrada em Bobbio et al. (2001) e Hamada et al. (2008).

O primeiro passo para converter uma FT em uma Rede Bayesiana é criar um nó para cada evento e para cada elemento básico da FT. Mesmo que algum elemento seja representado mais de uma vez na FT, na RB ele deve ser apresentado apenas uma única vez. O segundo passo é conectar os nós de acordo com os portões presentes na FT. A Figura 13 ilustra esses passos considerando uma árvore de falhas contendo o evento topo $(E)$ conectado a três eventos básico através de um portão do tipo $E$. Neste caso, é criado um nó para o evento $E$ conforme na FT e três nós que representam os elementos básicos $A, B$ e $C$ e, em seguida, são criados os arcos que conectam esses nós assim como o portão lógico conecta os elementos de um FT.
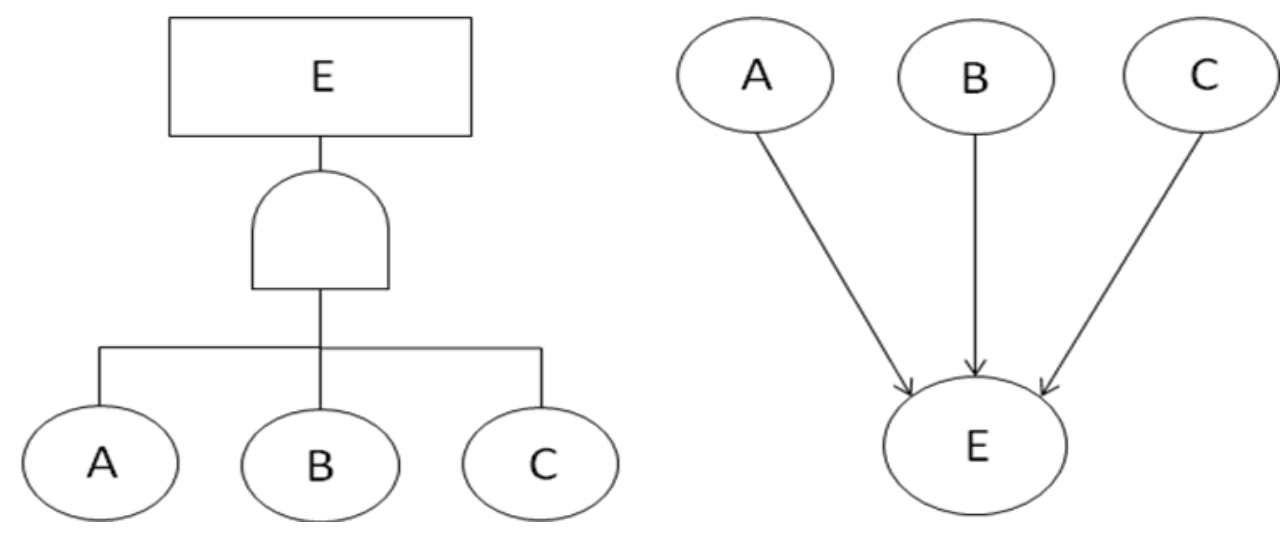

Figura 13 - Representação da árvore de falhas e da rede bayesiana.

O terceiro passo é a construção da tabela de probabilidades condicionais de REGASEIFICAÇÃO DE UMA UNIDADE TIPO FSRU. 
Escola Politécnica da USP

cada nó, seguindo a lógica dos portões da FT. Nas figuras 14, 15 e 16 tem-se uma representação dos portões "E", "OU" e "OU exclusivo" com suas respectivas Tabelas de Probabilidades Condicionais. Os portões representam relações determinísticas entre os nós, então suas entradas são 0 s e 1 s, onde 1 representa a falha e 0 representa o bom funcionamento.

Outros tipos de portões que por ventura estejam representados na FT devem ser convertidos para combinações de portões "E" e "OU" para depois serem representado na $\mathrm{RB}$.
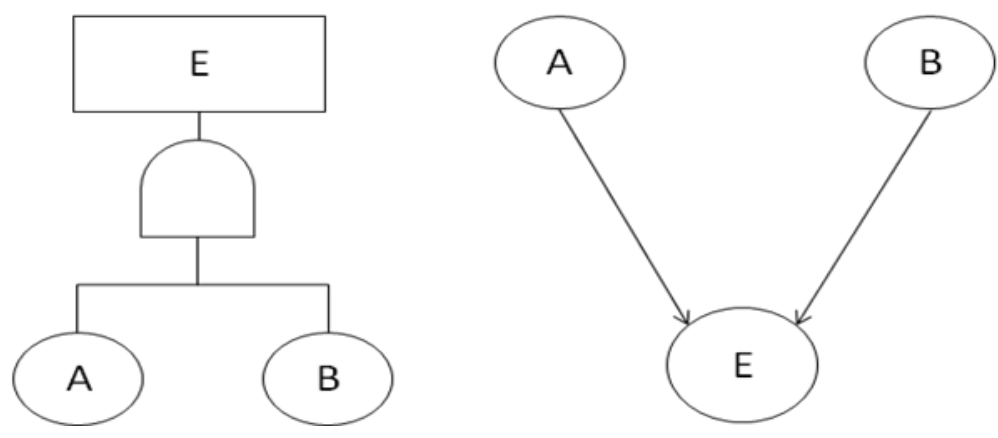

$$
\begin{aligned}
& P(E=1 \mid A=0, B=0)=0 \\
& P(E=1 \mid A=0, B=1)=0 \\
& P(E=1 \mid A=1, B=0)=0 \\
& P(E=1 \mid A=1, B=1)=1
\end{aligned}
$$

Figura 14 - Conversão de um portão "E".
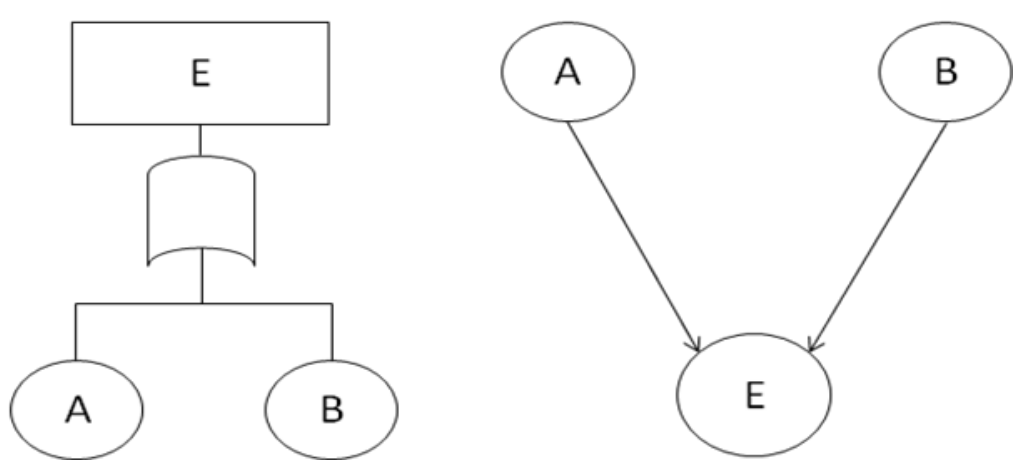

$$
\begin{aligned}
& P(E=1 \mid A=0, B=0)=0 \\
& P(E=1 \mid A=0, B=1)=1 \\
& P(E=1 \mid A=1, B=0)=1 \\
& P(E=1 \mid A=1, B=1)=1
\end{aligned}
$$

Figura 15 - Conversão de um portão "OU".

APLICAÇÃO DE REDES BAYESIANAS PARA A ANÁLISE DE CONFIABILIDADE DO SISTEMA DE REGASEIFICAÇÃO DE UMA UNIDADE TIPO FSRU. 

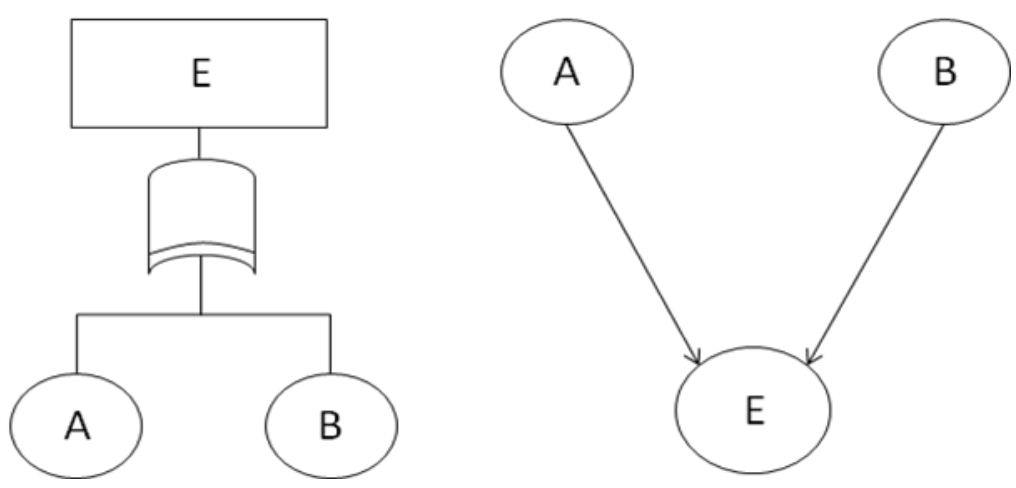

$$
\begin{aligned}
& \mathrm{P}(\mathrm{E}=1 \mid \mathrm{A}=0, \mathrm{~B}=0)=0 \\
& \mathrm{P}(\mathrm{E}=1 \mid \mathrm{A}=0, \mathrm{~B}=1)=1 \\
& \mathrm{P}(\mathrm{E}=1 \mid \mathrm{A}=1, \mathrm{~B}=0)=1 \\
& \mathrm{P}(\mathrm{E}=1 \mid \mathrm{A}=1, \mathrm{~B}=1)=0
\end{aligned}
$$

Figura 16 - Conversão de um portão "OU exclusivo".

Para finalizar o desenvolvimento da $\mathrm{RB}$, os nós raízes devem ser completados com as probabilidades a priori (probabilidade anterior a qualquer evidência) dos elementos básicos correspondentes da FT, que podem ser estimadas a partir de dados estatísticos ou a partir da opinião de especialistas. $\mathrm{O}$ artigo de Schleder, Martins e Souza (2011) apresenta os passos de uma conversão de árvores de falhas em RB com variáveis discretas.

Até este ponto todo o processo de conversão de FT em Rede Bayesiana considerou as variáveis como discretas e as relações entre elas como determinísticas. Porém, como apresentado por Marquez, Neil e Fenton (2010), as variáveis podem ser contínuas e os portões lógicos podem ser não determinísticos. Para tanto, as probabilidades a priori dos nós raiz devem ser substituídas por funções de densidade de probabilidade e as relações dos portões lógicos são representadas de acordo com a Eq. 25 para um portão "E" e de acordo com a Eq. 26 para um portão "Ou". Para que ocorra falha no portão "E" é necessário que todos os componentes conectados a ele falhem, dessa forma, considerando $\zeta_{i}$ o tempo até a falha (do inglês time to failure - TTF) do componente $i$ e que $\zeta_{E}$ representa o tempo até a falha para o portão "E", então a probabilidade de falha deste portão no REGASEIFICAÇÃO DE UMA UNIDADE TIPO FSRU. 
intervalo $[0, t]$ é dada pela Eq. 25.

$$
P\left(\zeta_{E} \leq t\right)=P\left(\zeta_{1} \leq t_{s}\right.
$$

Para que ocorra falha no portão "Ou" é necessário que pelo menos um dos componentes conectados a ele falhe, dessa forma, considerando que $\zeta_{o u}$ representa o TTF para o portão "Ou", então a probabilidade de falha deste portão no intervalo $[0, t]$ é dada pela Eq. 26

$$
P\left(\zeta_{\text {OU }} \leq t\right)=1-P\left(\zeta_{1}>t, \ldots, \zeta_{M}>t\right)=P\left(\min \left\{\zeta_{1}\right\} \leq t\right)
$$

\subsubsection{Conversão de diagramas de blocos em Redes Bayesianas}

Conforme comentado na seção 3.1.2.3, em um diagrama de blocos cada bloco representa um componente e as funções estruturais permitem que se calcule a confiabilidade do sistema considerando que cada componente é uma variável binária com os estados: funcionando ou não funcionando.

Em uma RB, como mostrado por Hamada et al. (2008), o sucesso ou a falha dos componentes determina a probabilidade de sucesso dos eventos. Como mencionado anteriormente, os sistemas podem ser formados por estruturas em série, em paralelo e combinações dessas. Essas estruturas podem ser facilmente representadas por redes bayesianas. O método usado é muito similar ao da conversão de FT em RB. A Figura 17 e a Figura 18 ilustram a conversão de um sistema em série e de um em paralelo e suas respectivas TPC, para a conversão é criado um nó para cada elemento e um nó que irá representar todo o sistema. O que definirá se a rede representa um sistema em paralelo ou em série será a TPC, que 
Escola Politécnica da USP

mostrará as relações entre o estado final do sistema de acordo com os estados dos elementos.

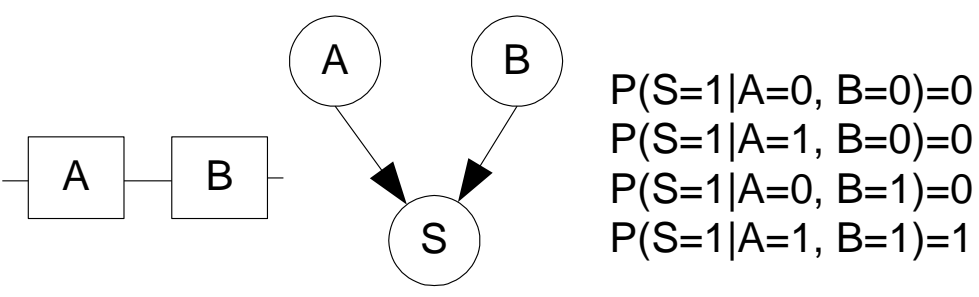

Figura 17 - Equivalência entre um sistema em série e uma RB.

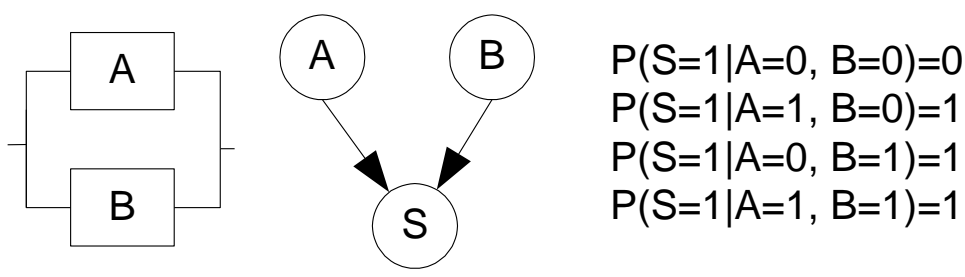

Figura 18 - Equivalência entre um sistema em paralelo e uma RB.

Assim como na seção anterior o método pode ser empregado para o caso de variáveis contínuas e relações não determinísticas. As Eq. 25 e 26 também são válidas para a conversão de Diagrama de Blocos em Redes Bayesianas.

Todas as relações entre variáveis apresentadas em Diagrama de Blocos ou Árvores de Falhas podem ser facilmente representadas em uma Rede Bayesiana.

\subsubsection{Causas Comum de Falha em Redes Bayesianas}


Escola Politécnica da USP

A representação de Causas comum de falha em uma Rede Bayesiana não é um processo complexo. Nos casos em que a Rede Bayesiana é construída com variáveis discretas as probabilidades de CCF são representadas diretamente na TPC, dispensando-se a inserção de constructos extras, como é usualmente feito durante a inclusão de uma CCF em uma árvore de falhas por exemplo. Para melhor ilustrar este procedimento é apresentado a Figura 19, extraída de Bobbio et al. (2001), na qual está representada a inclusão da probabilidade de falha do sistema devido à CCF ( $\left.L_{C C F}\right)$ em um portão "E". Considerando eventos básicos $A$ e $B$ e o evento final $C$ em uma estrutura com um portão "E", tem-se que: se ocorrer falha em $A$ e $B(A$ e $B=1)$ então ocorre a falha em $C(C=1)$. Porém, caso não ocorra a falha em ambos os eventos básicos a probabilidade de que ocorra a falha em $C$ será aquela associada à CCF ( $\left.\mathrm{L}_{\mathrm{CCF}}\right)$.

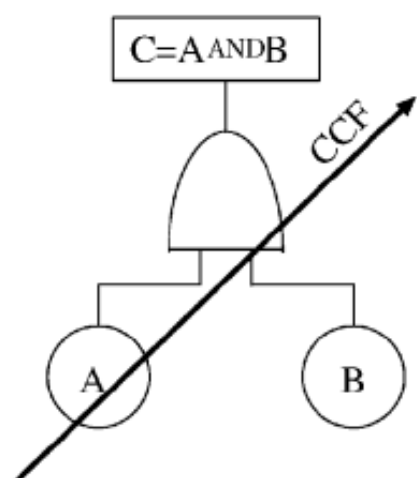

Figura 19 - Inclusão de CCF considerando variáveis discretas Fonte: adaptado de Bobbio et al.(2001)

Por esse método, apresentado por Bobbio et al. (2001), verifica-se que, para a consideração das CCF em redes com variáveis discretas, é necessária apenas a inclusão da probabilidade do sistema falhar devido a uma CCF à tabela de probabilidade condicional.

Para casos de redes de variáveis contínuas, não é possível a inclusão de um REGASEIFICAÇÃO DE UMA UNIDADE TIPO FSRU. 
Escola Politécnica da USP

valor discreto da $\mathrm{L}_{\mathrm{CCF}}$ diretamente na TPC, uma vez que as TPC são substituídas neste caso por uma densidade de probabilidade e estas são geradas a partir da associação de distribuições de probabilidades de falhas. Porém, a análise considerando-se CCF pode ser executada de maneira semelhante ao processo de inclusão de CCF em árvores de falhas, ou seja, pela inclusão de uma estrutura equivalente a um portão "OU”, um nó contínuo que represente a distribuição da $L_{C C F}$ e a construção de uma TPC que apresente as relações de um portão "OU", conforme item 3.2.4.1.

As Redes Bayesianas discretas propiciam uma representação de CCF mais simples do que a usualmente feita em FT, uma vez que permite a inclusão da $L_{C C F}$ diretamente nas TPC, dispensando assim a inserção de constructos adicionais ao modelo. E as Redes Bayesianas contínuas permitem a representação de CCF de maneira similar à tradicionalmente executada em $\mathrm{FT}$, porém permitindo a modelagem com variáveis contínuas através da adição de um nó contínuo que represente a distribuição da $L_{C C F}$. 


\section{METODOLOGIA}

Sendo o objetivo deste estudo, desenvolver uma metodologia de análise de Confiabilidade com o uso de Redes Bayesianas e aplicá-la na análise do sistema de regaseificação do FSRU, nesta seção será apresentada uma visão geral da metodologia proposta, de forma a facilitar a compreensão do item 4.

A metodologia foi construída através de uma composição dos métodos já existentes para análise de confiabilidade (apresentados no capítulo 2). Propostas de diferentes autores e diferentes técnicas foram unidas para a formação de uma metodologia, o que resultou na elaboração de uma metodologia de quatro etapas: familiarização, análise qualitativa, análise quantitativa e análises complementares.

\section{Etapa 1: Familiarização}

Nesta etapa deve ocorrer a familiarização com o sistema, dados sobre o sistema, seu funcionamento e o cenário em que está inserido devem ser coletados nesta fase. Sugere-se como atividades a revisão dos dados existentes (documentação e opinião de especialistas) e se possível uma visita ao local onde o sistema está ou será instalado.

\section{Etapa 2: Análise qualitativa}

A análise qualitativa deve fornecer uma visão clara do sistema e das relações entre os elementos do sistema. Primeiramente procura-se estabelecer uma representação física e funcional do sistema, para facilitar a 
compreensão do mesmo; nesta fase propõe-se o uso das técnicas de árvore funcional (para representação das funções) e diagrama unifilar (para representação do arranjo físico dos elementos do sistema) conforme item 3.1.2.1. Em seguida recomenda-se o desenvolvimento de uma representação mais detalhada das relações entre os elementos; essa representação pode ser feita por meio da construção de um diagrama de blocos ou de uma árvore de falhas, de acordo com os itens 3.1.2.3 e 3.1.2.4. Finalmente, é feita a conversão do diagrama de blocos (ou FT) para Redes Bayesianas, construindo-se uma rede híbrida, onde existam nós de variáveis contínuas que representem a probabilidade de falha dos equipamentos e subsistemas e nós de variáveis discretas que representem a confiabilidade dos equipamentos, subsistemas e do sistema em geral para um determinado tempo de missão. No desenvolvimento desta rede também deve-se incluir as informações adicionais que a conversão em RB permite, conforme item 3.2.

\section{Etapa 3: Análise quantitativa}

A análise quantitativa inicia-se com a inclusão na Rede Bayesiana de todas as probabilidades a priori dos nós raízes. Essas probabilidades podem ser fornecidas por dados estatísticos e/ou estimativas feitas por especialistas. Em seguida preenchem-se as TPC, nas quais são especificadas as relações entre os nós discretos ou para o caso de variáveis contínuas define-se as funções densidade de probabilidade. Finalmente obtém-se a probabilidade conjunta da rede para a variável de interesse, no caso o nó que representa a confiabilidade (de acordo com o item 3.2).

Para complementar a análise, nesta etapa, é proposta a inclusão informações sobre Falhas de Causa Comum, essa inclusão deverá ser feita conforme item 3.2.4.3. 
Escola Politécnica da USP

\section{Etapa 4: Análises Complementares}

Esta fase visa complementar a análise de Confiabilidade através da exploração de benefícios que a aplicação de Redes Bayesianas oferece. São propostas três variantes de análise: análise de criticidade, análise de diferentes cenários e análise da confiabilidade condicionada.

A análise de criticidade visa fornecer dados sobre a influência dos equipamentos e subsistemas no comportamento geral do sistema, identificando quais são os pontos críticos do sistema. Pode ser executada através de uma análise das probabilidades posteriores de cada elemento, sendo a probabilidade posterior a probabilidade de falha do equipamento dado que a falha do sistema ou subsistema ocorreu.

A análise de diferentes cenários visa encontrar um modo de melhorar a confiabilidade do sistema uma vez que são conhecidos os pontos críticos. Pode-se ainda propor medidas como a inclusão de redundâncias e modelálas na Rede Bayesiana para que a verificação dos efeitos da medida na confiabilidade do sistema.

Finalmente, a análise de confiabilidade condicionada, fornece uma representação do comportamento da confiabilidade do sistema dadas evidências como tempo de operação e execuções ou não de tarefas de manutenção.

Durante a elaboração desta metodologia, nas duas primeiras fases, de familiarização e de análise qualitativa foram usadas técnicas tradicionais apresentadas por Modarres (1993), Smith (2001), Leitch (1995), Kececioglu (1991) e Lewis (1994). Nas duas seguintes fases foram adotas técnicas baseadas em uma abordagem bayesiana apresentadas por Bobbio et al. (2001), Sigurdsson et al. (2001), Langseth e Portinale (2005), Jones et al. (2009), Boudali e Dugan (2006), Marquez, Neil e Fenton (2010) e Marquez, Neil e Fenton (2011). Na análise 
Escola Politécnica da USP

quantitativa usou-se especificamente a proposta de Marquez, Neil e Fenton (2010) para a análise da confiabilidade.

Para facilitar a compreensão, a Figura 20 apresenta um quadro resumo das etapas da metodologia descrita, o quadro divide-se em duas partes: a primeira onde estão listadas as tarefas a serem executadas em cada etapa e a segunda onde estão listados os meios sugeridos para a execução destas tarefas.

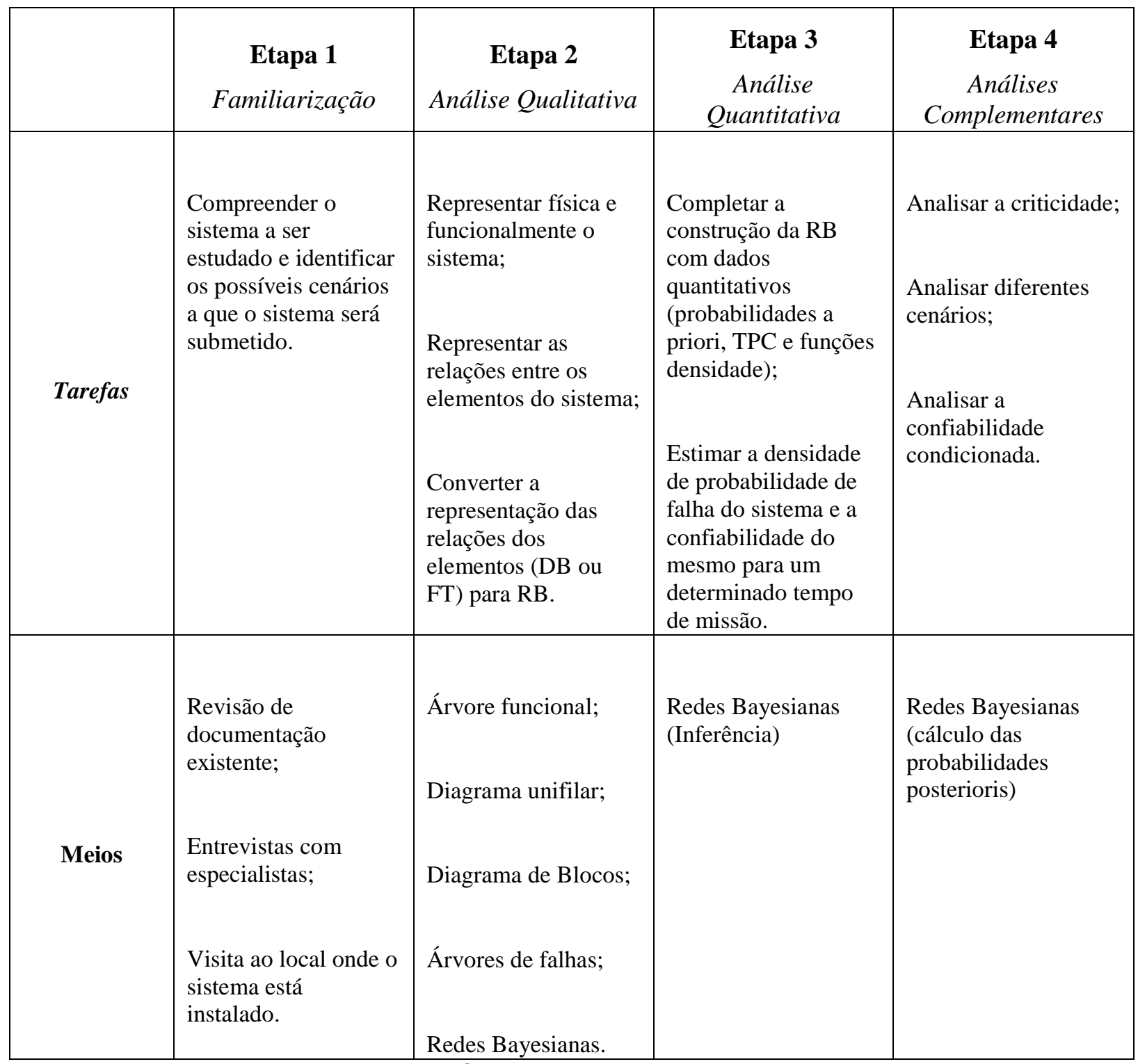

Figura 20 - Quadro Resumo da Metodologia 
Escola Politécnica da USP

\section{APLICAÇÃO DA METODOLOGIA}

Neste capítulo será apresentada a aplicação da metodologia, proposta no capítulo 4, em um Sistema de Regaseificação de um FSRU. Primeiramente serão apresentadas as informações coletadas sobre o sistema e o cenário em que está inserido. Em seguida, será feita uma análise qualitativa do sistema em três fases, conforme metodologia proposta: representação física e funcional do sistema, representação das relações entre os elementos do sistema e conversão da representação das relações para Rede Bayesiana. Posteriormente, será feita uma análise quantitativa, onde será estimada a densidade de probabilidade de falha do sistema e a confiabilidade do mesmo para um determinado tempo de missão. $E$ finalmente serão apresentadas as três análises complementares sugeridas na etapa 4 da metodologia: análise de criticidade, análise de diferentes cenários e confiabilidade condicional dadas evidências de tempo de operação e manutenção.

Conforme mencionado anteriormente, para confecção e tratamento da Rede Bayesiana foi usado o programa AgenaRisk (Agena Risk Desktop, 2011) disponibilizado pelo LabRisco-USP.

\subsection{FAMILIARIZAÇÃO COM O SISTEMA}

O passo inicial para aplicação da metodologia proposta para a análise de confiabilidade foi efetuar uma pesquisa sobre o Sistema de Regaseificação do FSRU, suas funcionalidades e o cenário onde está instalado. Estas informações serão apresentadas nesta seção.

Como já apresentado, o Brasil diversificou nos últimos anos sua forma de abastecimento de GN, até então feito apenas pela importação via gasodutos. O país começou importar GNL por meio de navios; o GNL chega ao país em navios tanque

APLICAÇÃO DE REDES BAYESIANAS PARA A ANÁLISE DE CONFIABILIDADE DO SISTEMA DE REGASEIFICAÇÃO DE UMA UNIDADE TIPO FSRU. 
Escola Politécnica da USP

que atracam em terminais previamente preparados e o gás liquefeito é transportado através de braços criogênicos até um FSRU, onde fica armazenado até que exista a demanda. Quando existe a demanda o GNL é regaseificado e então disponibilizado para a malha de gasodutos que abastecem o interior do país.

No Brasil existem dois terminais com capacidade de realizar esta operação, um em Pecém no estado do Ceará e outro na Baía da Guanabara no estado do Rio de Janeiro. Também são duas as unidades FSRU utilizadas, o navio Golar Spirit e o Golar Winter (Blackwell, 2009). Estes navios, antes utilizados apenas para 0 transporte e armazenamento de GNL foram adaptados para serem capazes de realizar também o processo de regaseificação do gás natural liquefeito.

As conversões dos dois navios foram feitas no estaleiro Keppel Fels Singapura pela companhia Golar LNG e o primeiro a ser entregue foi o Golar Spirit em junho de 2008; o Golar Winter foi entregue em maio de 2009. Os navios apresentam algumas diferenças relevantes, como capacidade de armazenamento, tipos de tanques de armazenagem, capacidade de regaseificação do GNL e inclusive o sistema de regaseificação usado (Keppel, 2009). A Tabela 4, montada com informações extraídas de Blackwell (2009) e Keppel (2009), apresenta um quadro resumo das principais características dos dois navios.

Tabela 4 - Características dos navios Golar Spirit e Golar Winter

\begin{tabular}{lcc}
\hline \multicolumn{1}{c}{ Característica } & Golar Spirit & Golar Winter \\
\hline $\begin{array}{l}\text { Capacidade de armazenamento } \\
\text { de GNL }\end{array}$ & $129000 \mathrm{~m}^{3}$ & $138000 \mathrm{~m}^{3}$ \\
Capacidade de regaseificação & 7 milhões de $\mathrm{m}^{3} / \mathrm{dia}$ & 14 milhões de $\mathrm{m}^{3} / \mathrm{dia}^{-}$ \\
Tanques de armazenagem & Esféricos & Membrana \\
Sistema de regaseificação & $\begin{array}{c}\text { Direto, por troca de calor com } \\
\text { água em circuito fechado. }\end{array}$ & $\begin{array}{c}\text { Em cascata, por troca de calor } \\
\text { em dois estágios: água e } \\
\text { propano. }\end{array}$ \\
& & propano \\
\hline
\end{tabular}

APLICAÇÃO DE REDES BAYESIANAS PARA A ANÁLISE DE CONFIABILIDADE DO SISTEMA DE REGASEIFICAÇÃO DE UMA UNIDADE TIPO FSRU. 
Escola Politécnica da USP

A operação de regaseificação adiciona novas características, potencialmente perigosas, à operação do navio gaseiro, pois além do GNL agora também existe gás natural comprimido no processo. $\mathrm{E}$ acidentes na estação de regaseificação podem ter efeitos sobre o restante do navio e atingir, por exemplo, os tanques de armazenamento de gás natural liquefeito.

Para aplicação da metodologia proposta neste estudo foi escolhido um sistema de regaseificação similar ao usado no navio Golar Winter, ou seja, um Sistema de Regaseificação em Cascata, que está representado na Figura 21, adaptada de Hamworthy (2010). Neste sistema o GNL circula através das tubulações ilustradas em azul. O gás liquefeito que está armazenado a uma temperatura de aproximadamente $-163^{\circ} \mathrm{C}$ é aquecido em duas etapas (as propriedades do GNL serão descritas mais adiante, para melhor compreensão do processo). Na primeira etapa o gás natural liquefeito é aquecido por propano, em um trocador de calor compacto $\left(\mathrm{HE}_{1}\right)$. Sua temperatura se eleva de $-163^{\circ} \mathrm{C}$ até aproximadamente $-10^{\circ} \mathrm{C}$. Na segunda etapa o GNL é aquecido, por água do mar, em outro trocador de calor do tipo tubo\&casco $\left(\mathrm{HE}_{2}\right)$. O propano usado na primeira etapa circula em circuito fechado, através das tubulações apresentadas em vermelho na Figura 21; ao deixar o trocador de calor com GNL $\left(\mathrm{HE}_{1}\right)$ sua temperatura é de $-5^{\circ} \mathrm{C}$ e seu estado é líquido. Então o propano é bombeado até um trocador de calor de titânio $\left(\mathrm{HE}_{3}\right)$ e aquecido, por água do mar, até uma temperatura de $0^{\circ} \mathrm{C}$ e vaporiza. E novamente segue para 0 trocador de calor $\mathrm{HE}_{1}$. $\mathrm{A}$ água que passa tanto pelo trocador de calor $\mathrm{HE}_{2}$ quanto pelo trocador de calor $\mathrm{HE}_{3}$, circula pelas tubulações desenhadas em verde na Figura 21 e é obtida através de um sistema redundante de abastecimento. 
Escola Politécnica da USP

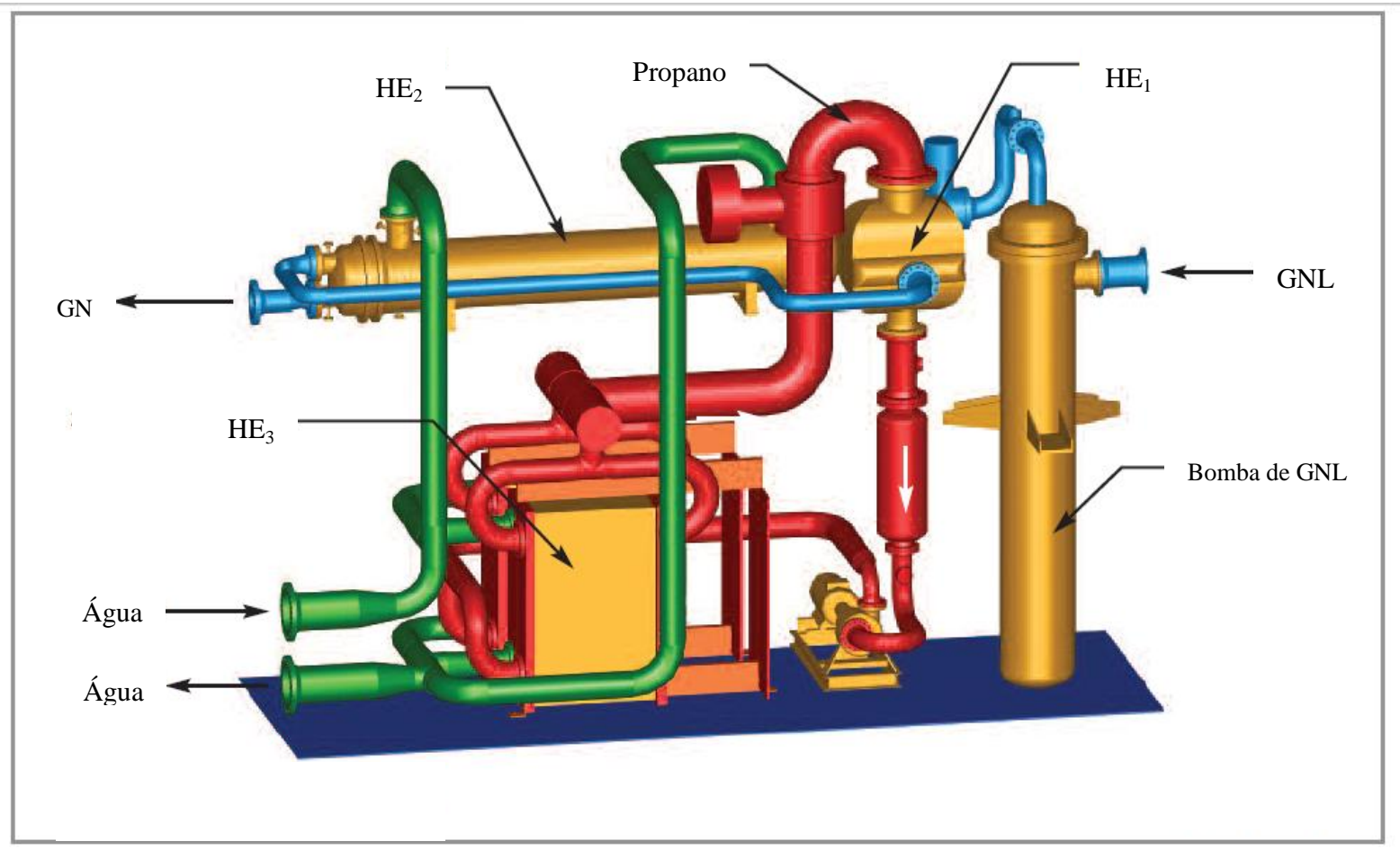

Figura 21 - Sistema de Regaseificação em Cascata

Fonte: Adaptada de Hamworthy (2010)

Esse sistema trabalha com as seguintes substâncias: GNL, gás natural comprimido e propano.

\section{Gás natural}

O gás natural é uma mistura de hidrocarbonetos, sendo o metano o de maior proporção, no nosso caso cerca de $98 \%$, e o restante formado principalmente por propano, etano, butano e hexano. As propriedades estão apresentadas na Tabela 5, cujas informações foram extraídas de White Martins (2004) e Foss (2003). 
Tabela 5 - Propriedades do Gás Natural

\begin{tabular}{|c|c|c|c|}
\hline Propriedade & $\begin{array}{c}\text { Condição de } \\
\text { referência }\end{array}$ & Unidade & Gás natural \\
\hline Densidade do vapor & $20^{\circ} \mathrm{C}$ & - & $0,60-0,81$ \\
\hline Ponto de congelamento & - & $\stackrel{\circ}{\mathrm{C}}$ & $-182,6$ \\
\hline Ponto de fulgor & - & $\stackrel{\circ}{\mathrm{C}}$ & $-187,8$ \\
\hline Temperatura de auto-ignição & $1 \mathrm{~atm}$ & $\stackrel{\circ}{\mathrm{C}}$ & 482 \\
\hline Limite inferior de flamabilidade* & - & $\%$ vol. & 6,5 \\
\hline Limite superior de flamabilidade* & - & $\%$ vol. & 17 \\
\hline
\end{tabular}

De acordo com essas propriedades é possível obter algumas conclusões:

- Habitualmente o gás natural tem densidade menor do que 0 ar, portanto se dispersa facilmente e sendo assim não costuma oferecer risco de asfixia em lugares abertos ou ventilados. Porém, quando em temperaturas baixas, com é o caso em um FSRU, pode apresentar-se como uma densidade maior do que a do ar e consequentemente causar asfixia, por falta de oxigênio (Foss, 2003);

- O gás natural apresenta perigo de fogo quando exposto à chama, porém sua faixa de flamabilidade é estreita, o que reduz a área sujeita à ignição (Vanem et al., 2007)

- Tem um elevado ponto de auto-ignição $\left(482^{\circ} \mathrm{C}\right)$ quando comparado a combustíveis como gasolina $\left(25^{\circ} \mathrm{C}\right)$ e diesel (315으) (Foss, 2003);

- Considerando que o gás natural é composto majoritariamente por metano, é aceitável considerá-lo como não tóxico (Foss, 2003 e Vanem et al., 2007); 
Escola Politécnica da USP

GNL

O GNL, como o próprio nome indica, é o gás natural na forma liquefeita, que para condensar, sob pressão atmosférica, precisa ser resfriado a temperatura de aproximadamente $-163^{\circ}$ C. Portanto é um líquido criogênico a baixíssimas temperaturas com alto poder de congelamento.

Foss (2003), Natacci, Ikeda e Martins (2010), Vanem et al. (2007) e Bubbico, Cave e Mazzarotta (2009) são boas referências para o estudo sobre perigos e consequências de um vazamento de gás natural; Schleder, Martins e Souza (2011) elaboram uma análise preliminar de perigos do Sistema de Regaseificação de um FSRU.

Propano

O propano foi escolhido para esse sistema devido as suas características termodinâmicas e seu baixo ponto de congelamento. As propriedades estão apresentadas na Tabela 6, cujas informações foram extraídas de White Martins (2004) e Foss (2003).

Tabela 6 - Propriedades do Propano

\begin{tabular}{cccc}
\hline Propriedade & $\begin{array}{c}\text { Condição de } \\
\text { referência }\end{array}$ & Unidade & Propano \\
\hline Densidade do vapor & $20^{\circ} \mathrm{C}$ & - & 0,52 \\
Ponto de congelamento & - & $\stackrel{\circ}{ }$ C & $-187,68$ \\
Ponto de fulgor & & ${ }^{\circ} \mathrm{C}$ & -104 \\
Temperatura de auto-ignição & $1 \mathrm{~atm}$ & $\stackrel{\circ}{\mathrm{C}}$ & 450 \\
Limite inferior de flamabilidade & - & $\%$ vol. & 2,1 \\
Limite superior de flamabilidade & - & $\%$ vol. & 9,5 \\
\hline
\end{tabular}

Analisando estas características podemos também obter algumas conclusões REGASEIFICAÇÃO DE UMA UNIDADE TIPO FSRU. 
Escola Politécnica da USP

a respeito do propano:

- Possui um baixíssimo ponto de congelamento, o que é indicado para a troca de calor com o GNL, uma vez que outra substância com um ponto de congelamento mais alto poderia congelar durante a troca de calor e interromper o fluxo no sistema (Hamworthy, 2010);

- O propano possui um alto ponto de auto-ignição e uma pequena faixa de flamabilidade, características que diminuem a probabilidade de uma explosão (Hamworthy, 2010).

\subsection{ANÁLISE QUALITATIVA}

Nesta seção serão apresentados os passos executados para 0 desenvolvimento da etapa 2 da metodologia proposta no Capítulo 3. Primeiramente será feita uma representação física e funcional do sistema, através da construção de uma árvore funcional e um diagrama unifilar. Em seguida será apresentada uma representação das relações entre os elementos do sistema de regaseificação, através do desenvolvimento de um diagrama de blocos. E finalmente será feita a conversão deste diagrama de blocos para uma Rede Bayesiana.

\subsection{1 Árvore funcional e diagrama unifilar}

Durante esta pesquisa não foi possível a obtenção de descrições detalhadas sobre o sistema usado no navio Golar Winter, todas as informações usadas são aquelas disponíveis para o público e apresentadas no item 4.1. Sendo assim foi necessário desenvolver, baseando-se nas informações disponíveis, um modelo 
Escola Politécnica da USP

semelhante ao que se acredita ser o sistema de regaseificação usado no navio Golar Winter. O primeiro passo para iniciar a análise foi a construção de um diagrama unifilar capaz de representar um sistema de regaseificação como o descrito no item anterior. Este diagrama está ilustrado na Figura 22; do lado esquerdo pode-se observar o tanque de armazenamento de GNL $\left(T_{1}\right)$ e a partir deste ponto para a direita segue-se a rota do GNL, através dos 2 trocadores de calor $\left(\mathrm{HE}_{1}\right.$ e $\left.\mathrm{HE}_{2}\right)$. Acima destes trocadores de calor estão posicionados os sistemas onde circulam o propano e água. Para facilitar a compreensão, a Tabela 7 fornece a nomenclatura utilizada no diagrama unifilar. Este diagrama foi apresentado previamente em seminário durante o curso da disciplina PMR5201 da Escola Politécnica da Universidade de São Paulo (Schleder e Silva, 2010).

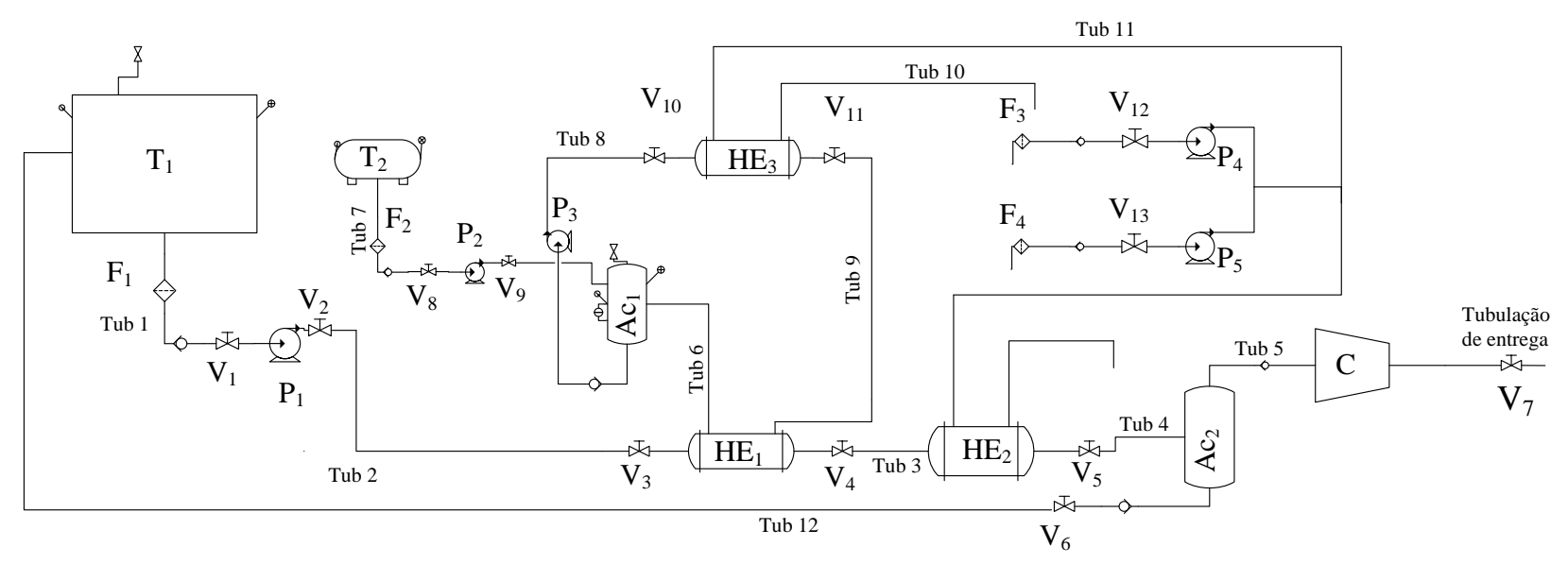

Figura 22 - Diagrama unifilar do Sistema de Regaseificação REGASEIFICAÇÃO DE UMA UNIDADE TIPO FSRU. 
Tabela 7 - Nomenclatura usada no diagrama unifilar

\begin{tabular}{cc}
\hline Item & Descrição \\
\hline T1 & Tanque GNL \\
\hline T2 & Tanque de propano \\
\hline $\begin{array}{c}\text { V1, V2, V3, V6, V8, V9, V10, } \\
\text { V11, V12, V13 }\end{array}$ & Válvulas gaveta para líquido \\
\hline V4, V5, V7 & Válvulas gaveta para gás \\
\hline P1 & Bomba de abastecimento de GNL \\
\hline P2, P3 & Bombas de propano \\
\hline P4, P5 & Bombas de água \\
\hline
\end{tabular}

Tubulações 1, 2, 3, 4, 5, 6, 7, 8, 9, $10,11,12$.

Tubulações com diâmetro menor do que 10"

Tubulação de entrega Tubulação com o diâmetro menor do que 12"

Ac1

Ac2

HE1

HE2

HE3

C

F1

F2

F3, F4
Acumulador de propano

Acumulador de GNL

Trocador de calor GNL/Propano

Trocador de calor água/GNL

Trocador de calor água/propano

Compressor

Filtro do tanque de GNL

Filtro do tanque de propano

Filtros de entrada de água

O segundo passo desta fase foi a construção de uma árvore funcional (Figura 23) e da descrição funcional de cada componente do sistema(Tabela 8). Essa construção tem como objetivo proporcionar uma visão clara sobre as relações funcionais presentes no sistema. No topo da árvore funcional está representada a função principal do Sistema de Regaseificação: "entregar gás natural”; os níveis 
abaixo representam como o sistema executará essa função. É possível que o leitor questione a falta de representação de sistemas de segurança e de controle nesta árvore, porém como durante o período de pesquisa não foram encontradas informações sobre estes sistemas, optou-se por não considerá-los durante a análise. Outra observação importante é que apesar de não constar em nenhuma das literaturas consultadas, foi suposto que exista um sistema de isolamento térmico que garanta a temperatura do gás natural controlada durante 0 processo de regaseificação e entrega do gás às tubulações. Foi considerado um sistema de isolamento térmico $\left(l_{1}, l_{2}\right.$ e $\left.I_{3}\right)$ para cada um dos seguintes blocos representados na árvore funcional da Figura 23: "Sistema de Abastecimento de GN", "Sistema de Aquecimento GNL/Propano" e "Sistema de Aquecimento GNL/Água".

A representação por árvore funcional facilita a compreensão do sistema e é usada como apoio para a construção do diagrama de blocos (item 5.2.2). 


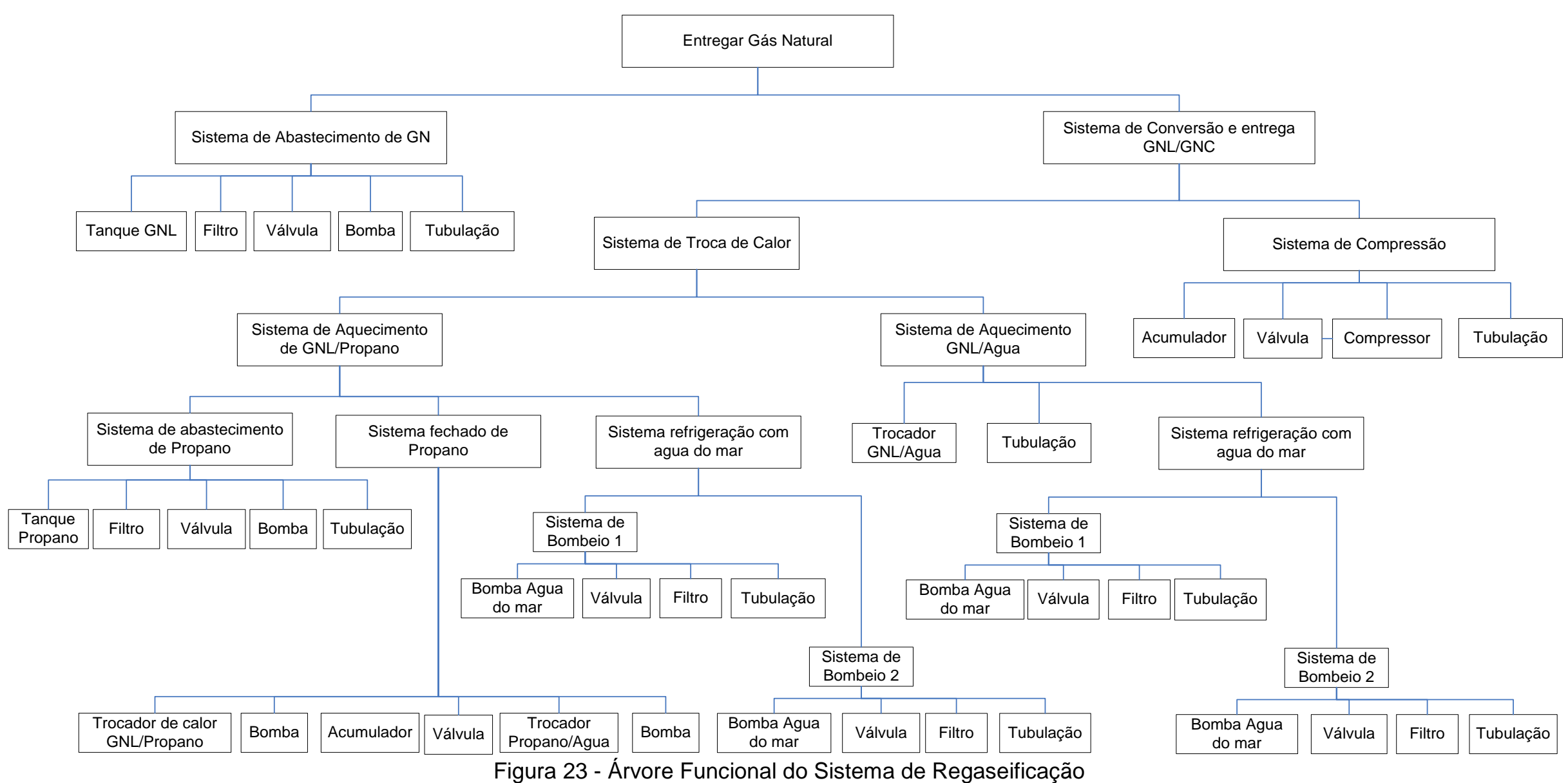

APLICAÇÃO DE REDES BAYESIANAS PARA A ANÁLISE DE CONFIABILIDADE DO SISTEMA DE REGASEIFICAÇÃO DE UMA UNIDADE TIPO FSRU. 
Tabela 8 - Descrição funcional

\begin{tabular}{cc}
\hline Item & Descrição \\
\hline T1 & Armazenar GNL \\
\hline T2 & Armazenar propano \\
\hline $\begin{array}{c}\text { V1, V2, V3, V6, V8, V9, V10, } \\
\text { V11, V12, V13 } \\
\text { V4, V5, V7 }\end{array}$ & Controlar o fluxo de líquido \\
\hline P1 & Controlar o fluxo de gás \\
\hline P2, P3 & Bombear o GNL do tanque para o sistema \\
\hline P4, P5 & Bombear o propano para o trocador de calor \\
\hline
\end{tabular}

Tubulações 1, 2, 3, 4, 5, 6, 7, 8, 9, Transportar o GNL e o propano através do sistema de $10,11,12$. regaseificação

Tubulação de entrega

Ac1

Ac2

HE1

HE2

HE3 C

F1

F2

F3, F4
Transportar o GN do sistema de regaseificação até o gasoduto

\begin{tabular}{cc} 
Ac1 & Armazenar o propano que está sendo usado na troca de calor \\
Ac2 & Armazenar o GNL que não gaseificou \\
\hline HE1 & Aquecer o GNL pela troca de calor com o propano \\
\hline HE2 & Aquecer o GNL pela troca de calor com a água \\
\hline HE3 & Aquecer o propano pela troca de calor com a água \\
\hline C & Comprimir o gás natural \\
\hline F1 & Filtrar impurezas durante o abastecimento do tanque de GNL \\
\hline
\end{tabular}

Filtrar impurezas durante o abastecimento do tanque de propano

Filtrar impurezas durante a entrada de água no sistema

\subsubsection{Diagrama de Blocos}

O diagrama de blocos ou a FT são representações mais detalhadas das relações entre os elementos do sistema. Neste estudo optou-se pela construção de um diagrama de blocos, pois sua representação visual neste texto seria mais fácil. 
No primeiro nível do diagrama de blocos está representado o primeiro nível da árvore funcional, em seguida, cada bloco é subdividido para detalhar os blocos do próximo nível e assim sucessivamente até que se alcance o nível onde cada bloco representa um elemento básico do sistema. A Figura 24 representa o primeiro nível:

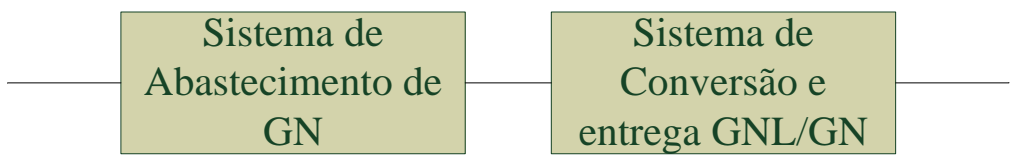

Figura 24 - 1o nível do diagrama do Sistema de Regaseificação

Cada um dos blocos da figura anterior é detalhado de forma a representar o segundo nível da árvore funcional. Na Figura 25 temos o detalhamento (até o nível em que cada bloco representa um elemento) do primeiro bloco "Sistema de abastecimento de GN" e na Figura 26 temos o detalhamento do segundo bloco "Sistema de Conversão e entrega de GNL/GN.

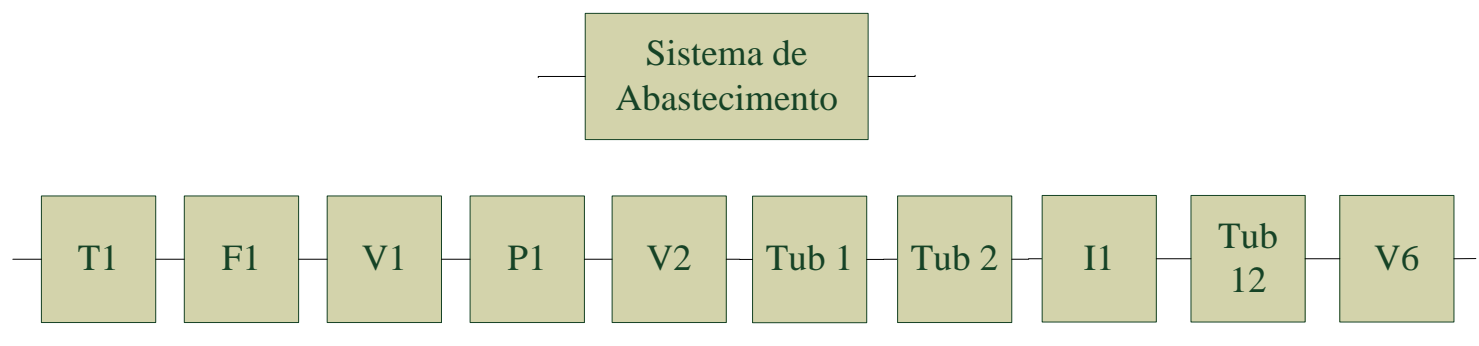

Figura 25 - Sistema de Abastecimento.

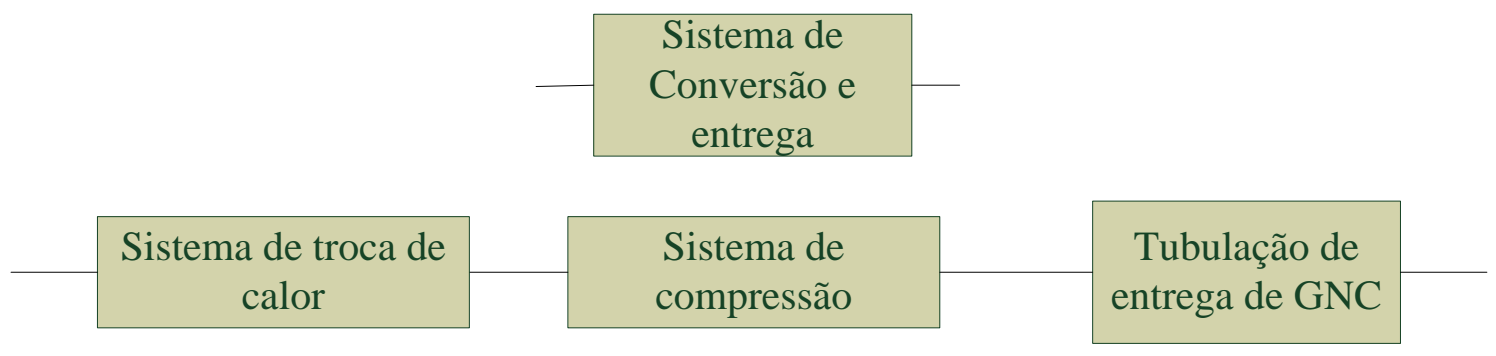

Figura 26 - Sistema de Conversão e entrega 
A Figura 27 ilustra o detalhamento do bloco "Sistema de compressão", onde são representados todos os elementos que compõem esse bloco.

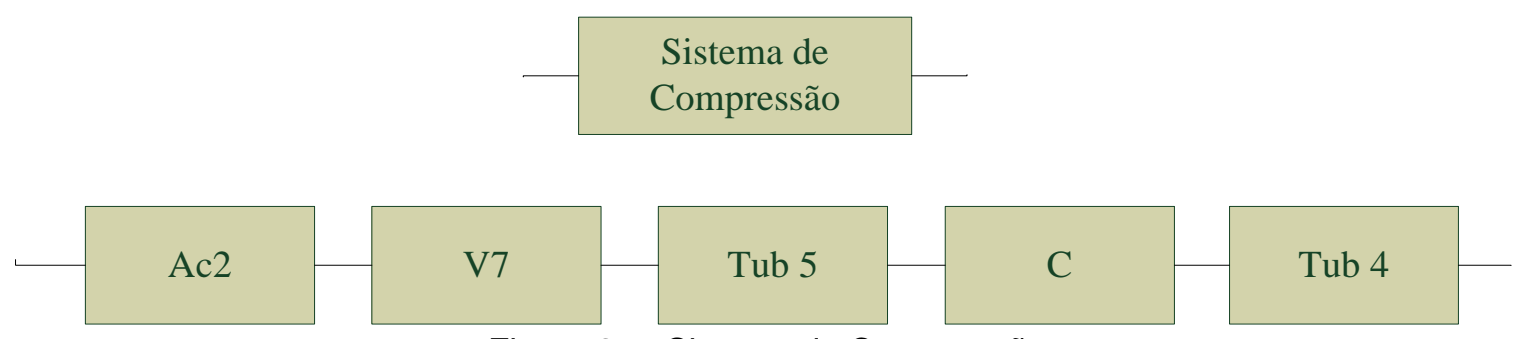

Figura 27 - Sistema de Compressão

O bloco "Sistema de Troca de Calor" é decomposto em várias fases até atingir o nível onde cada bloco representa um elemento do sistema. Primeiramente é decomposto em dois subsistemas: Sistema de Aquecimento GNL/Propano e Sistema de Aquecimento GNL/Água (Figura 28).
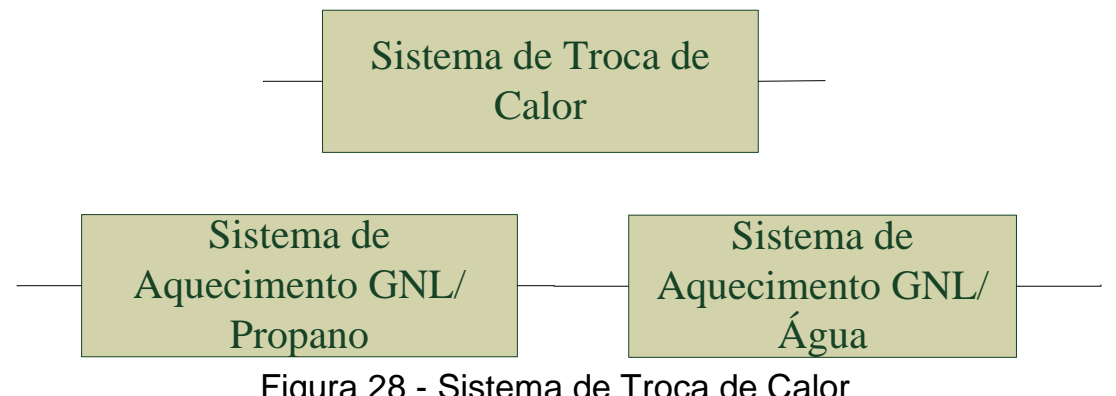

Figura 28 - Sistema de Troca de Calor

O "Sistema de Aquecimento GNL/Propano" é decomposto em outros 3 blocos, conforme Figura 29. E o "Sistema de Aquecimento GNL/Água é decomposto em 4 blocos, conforme Figura 30.
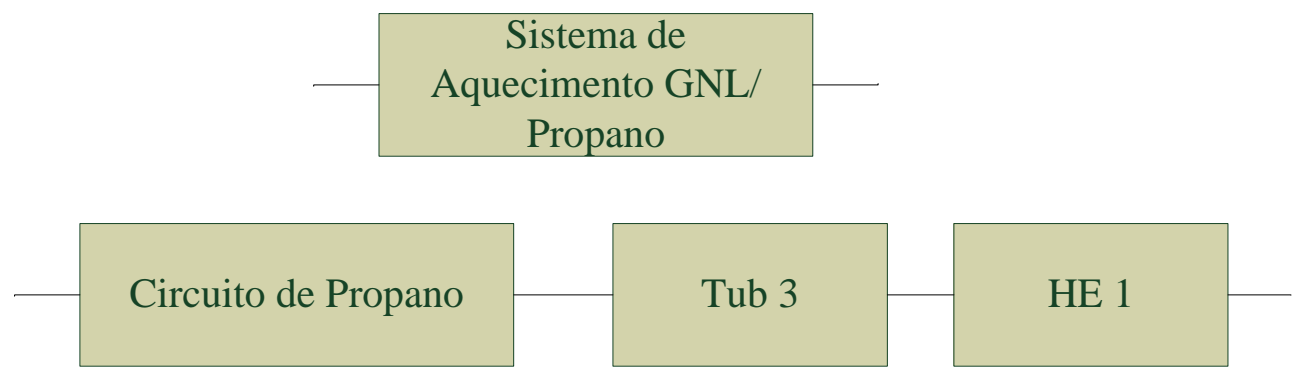

Figura 29 - Sistema de Aquecimento GNL/Propano 


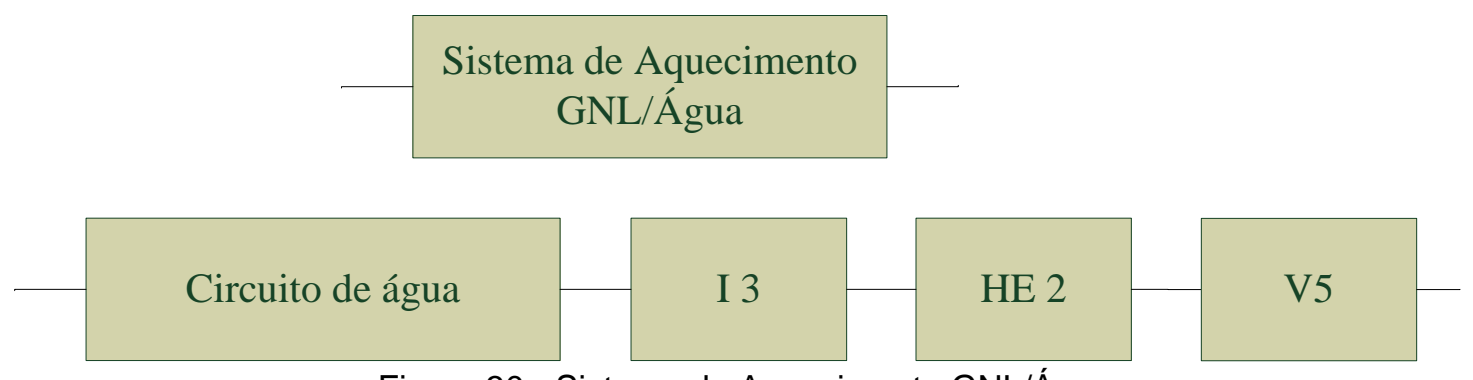

Figura 30 - Sistema de Aquecimento GNL/Água

Nesta fase alguns dos blocos já representam elementos do sistema, prossegue-se efetuando a decomposição apenas daqueles que ainda não alcançaram o nível mais baixo da árvore funcional. Sendo assim, os blocos "Circuito de Propano" e "Circuito de água" são decompostos conforme ilustrado na Figura 31 e na Figura 34 respectivamente.

\section{Circuito do Propano}

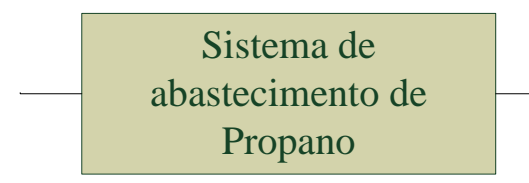

Sistema fechado de

Propano

Circuito de Água

Figura 31 - Circuito do Propano

O subsistema "Sistema de abastecimento de Propano" do "Circuito de Propano" é composto pelos elementos da Figura 32. Assim como o subsistema "Sistema fechado de Propano" é composto pelos elementos da Figura 33. 


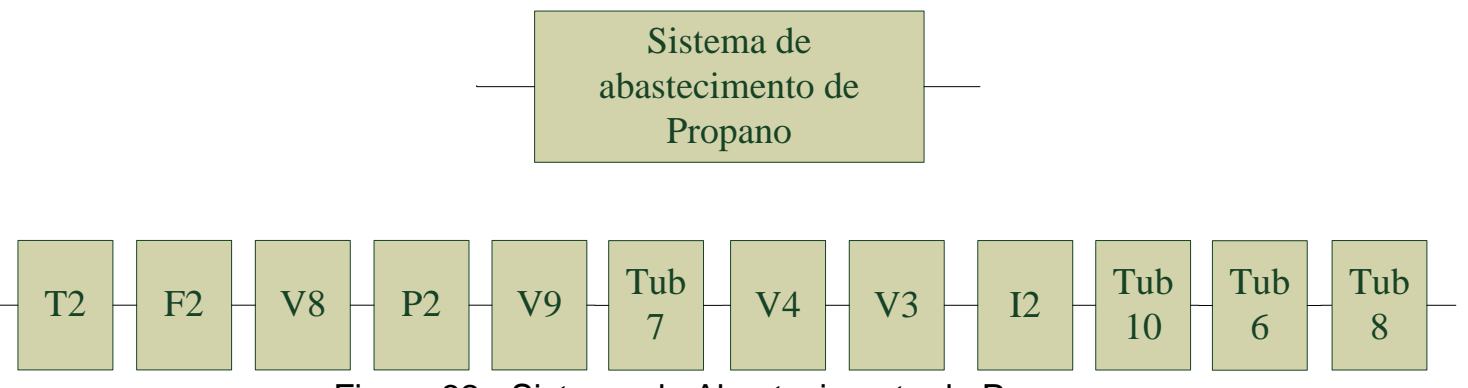

Figura 32 - Sistema de Abastecimento do Propano

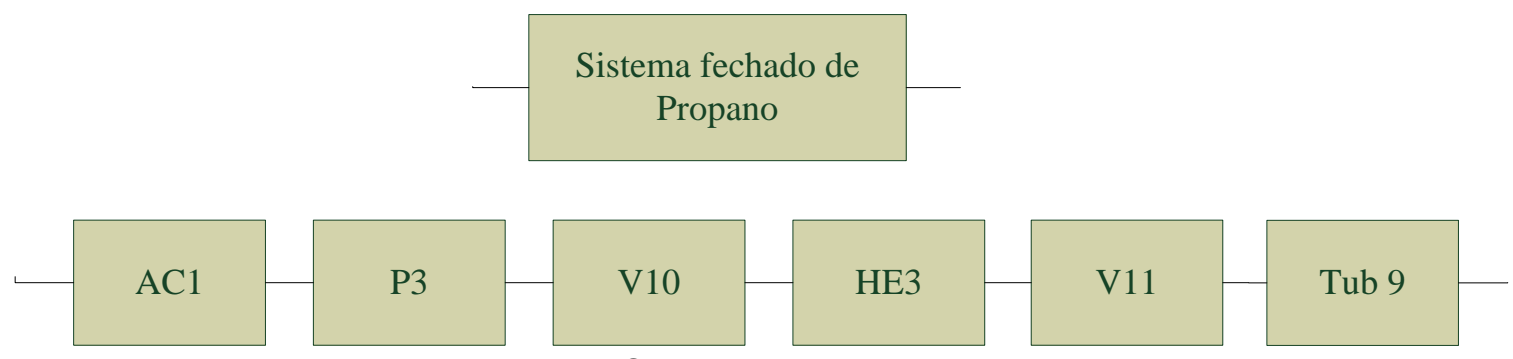

Figura 33 - Sistema Fechado de Propano

Em seguida é feita a representação do "Circuito de Água", lembrando que conforme visto no item 5.1, existe um sistema redundante para o bombeamento da água. Sendo assim, a representação é feita por dois sistemas de bombeio em paralelo ligados em série à tubulação que leva a água até os trocadores de calor (Figura 34).

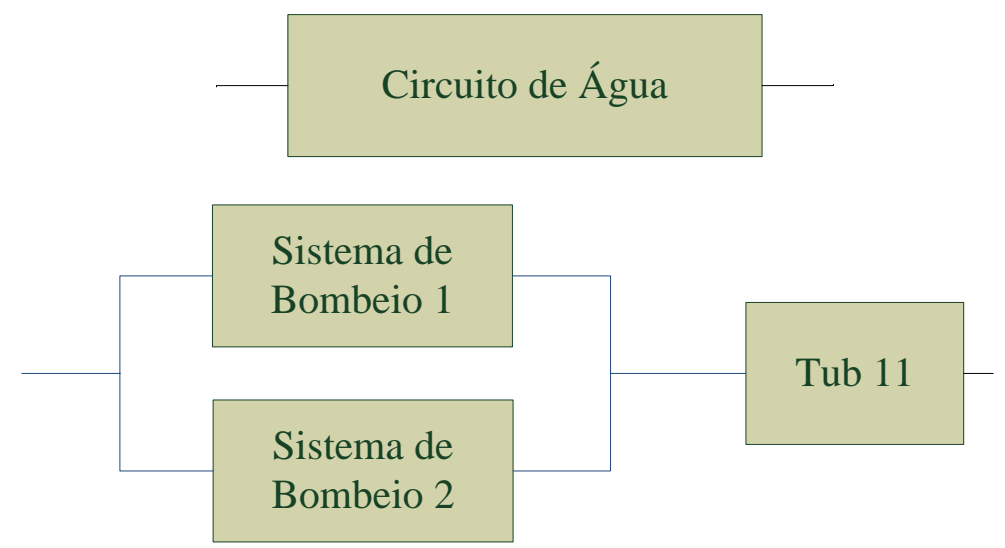

Figura 34 - Circuito de água

Finalmente são construídos os diagramas de blocos de cada "Sistema de Bombeio", onde são representados os elementos de cada um (Figura 35 e Figura 
36).

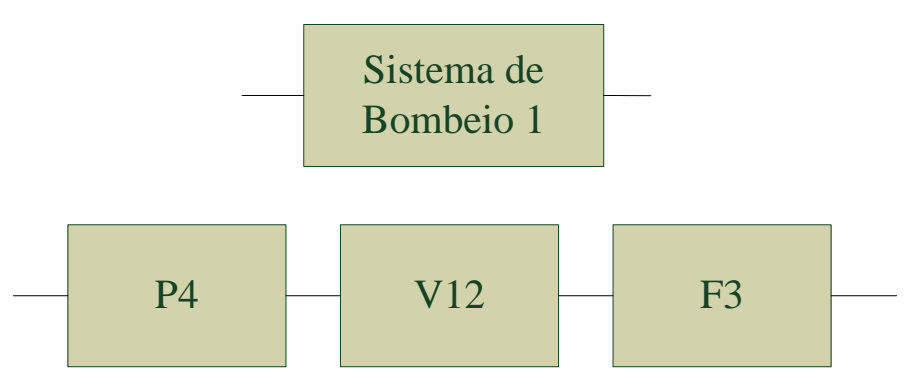

Figura 35 - Sistema de Bombeio 1

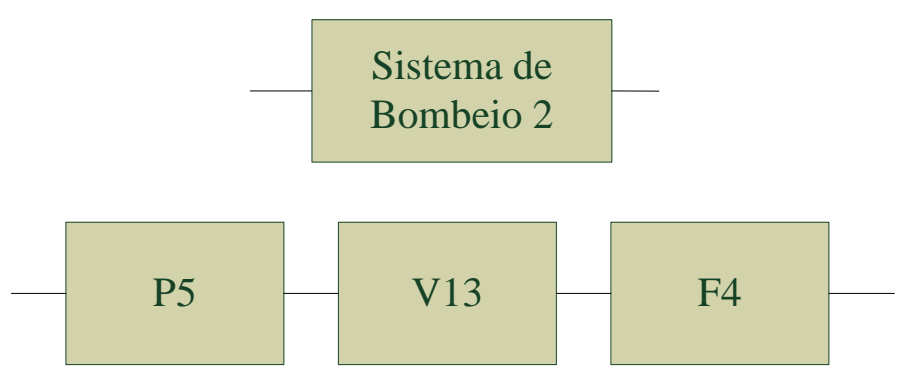

Figura 36 - Sistema de Bombeio 2

Unindo todos os subsistemas é possível obter o diagrama de blocos completo do sistema de Regaseificação, onde cada bloco representa um elemento do sistema (Figura 37). Esse diagrama de blocos será convertido em uma rede bayesiana completando assim o último passo da análise qualitativa. 

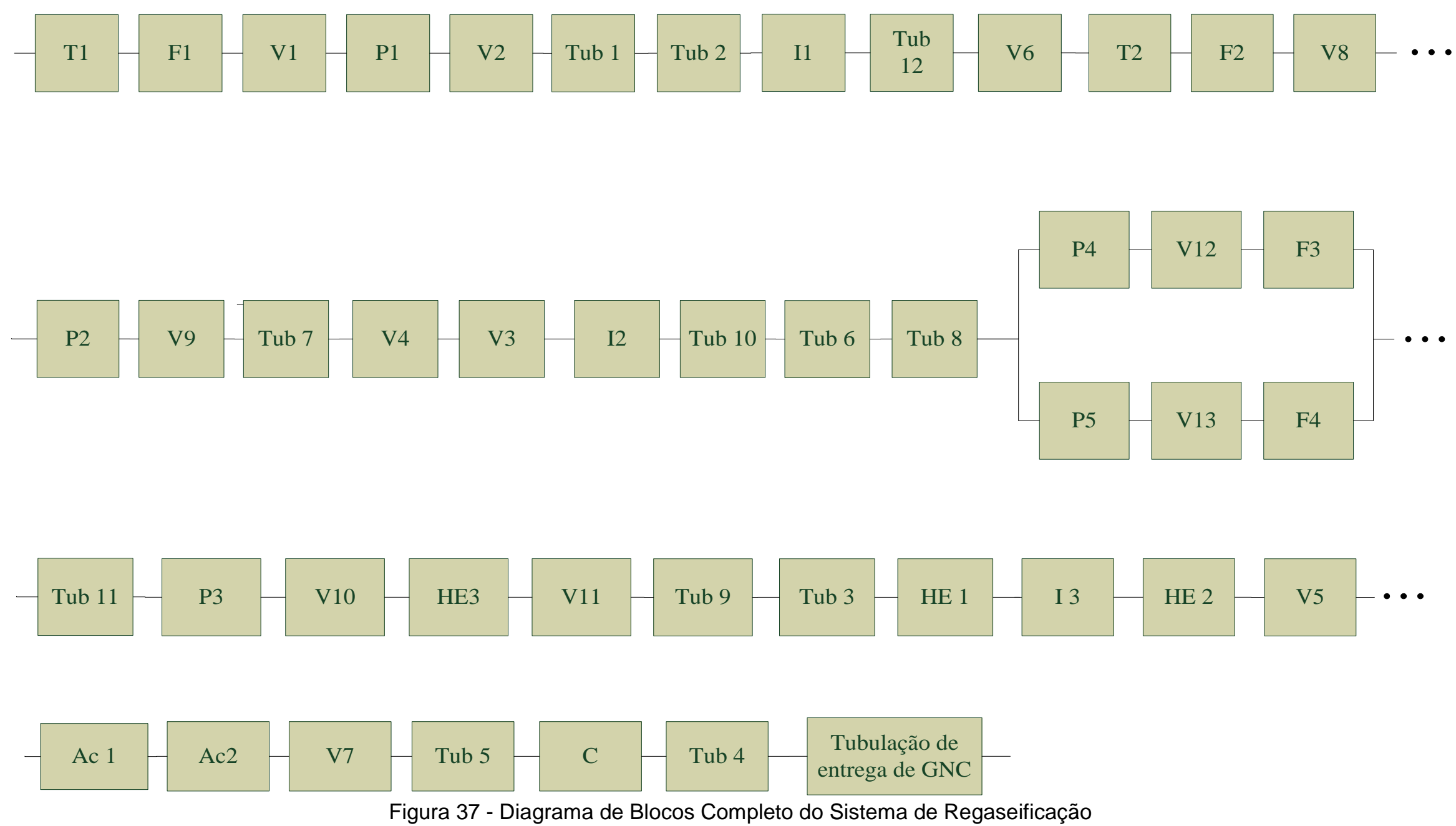

APLICAÇÃO DE REDES BAYESIANAS PARA A ANÁLISE DE CONFIABILIDADE DO SISTEMA DE REGASEIFICAÇÃO DE UMA UNIDADE TIPO FSRU. 


\subsubsection{Conversão do Diagrama de Blocos em Rede Bayesiana}

A conversão do Diagrama de Blocos em Rede Bayesiana é feita de acordo com o apresentado no item 3.2.4.2. São criados nós para representar os elementos e os subsistemas, esses nós são ligados por arcos de acordo com a estrutura apresentada no diagrama de blocos. O que definirá se cada ligação da rede representa uma ligação em paralelo ou em série será a TPC, a qual mostrará as relações presentes no sistema. As TPC e as funções densidade de probabilidade serão apresentadas na próxima etapa, durante a análise quantitativa do sistema.

O nó inicial da Rede Bayesiana é o nó que representa todo o Sistema de Regaseificação, abaixo dele, são construídos os nós do primeiro nível do Diagrama de Blocos: "Sistema de abastecimento" e "Sistema de Conversão e Entrega". Da mesma forma que ocorre no Diagrama de Blocos os subsistemas são detalhados até o nível em que cada nó representa um elemento do sistema. Para facilitar a análise quantitativa, que ocorrerá na próxima etapa, foram criados nós extras de maneira a garantir que cada nó pai tenha no máximo três nós filhos. Essa medida é útil quando se pretende usar nós com variáveis contínuas, pois para cada nó pai é calculada a probabilidade condicional de acordo com os nós filhos; quanto maior a quantidade de nós filhos maior a complexidade no cálculo das probabilidades condicionais e portanto maior o tempo gasto no processamento quando se está usando um programa para desenvolver a rede. Como mencionado anteriormente, neste estudo foi usado o programa AgenaRisk (Agena Risk Desktop, 2011).

Outro ponto importante nesta fase é a inclusão de dependências locais, não é possível a representação destas dependências no diagrama de blocos, porém elas podem ser facilmente inseridas em uma Rede Bayesiana e dessa forma ser explorada uma das vantagens obtidas com o uso de Redes Bayesianas ao invés de técnicas tradicionais.

Os nós "Trocador de calor GNL/Propano" $\mathrm{HE}_{1}$, "Trocador de calor GNL/Água" $\mathrm{HE}_{2}$ e "Trocador de calor Propano/água" $\mathrm{HE}_{3}$, são nós que possuem dependências 
locais associadas, a dependência deve-se ao fato de existir uma relação entre o funcionamento dos trocadores de calor e o funcionamento do isolamento térmico dos locais onde os trocadores de calor estão instalados. Ou seja, no caso do isolamento térmico falhar a probabilidade de falha dos trocadores de calor aumenta. Esta dependência pode ser modelada na Rede Bayesiana pela construção de um arco entre as variáveis em questão e posterior ajuste da tabela de probabilidades condicionais de acordo com as taxas de falhas correspondentes (discutido no item 5.3). Sendo assim são construídos arcos entre os trocadores de calor e os isolamentos térmicos de cada seção, como ilustrado na Figura 38.

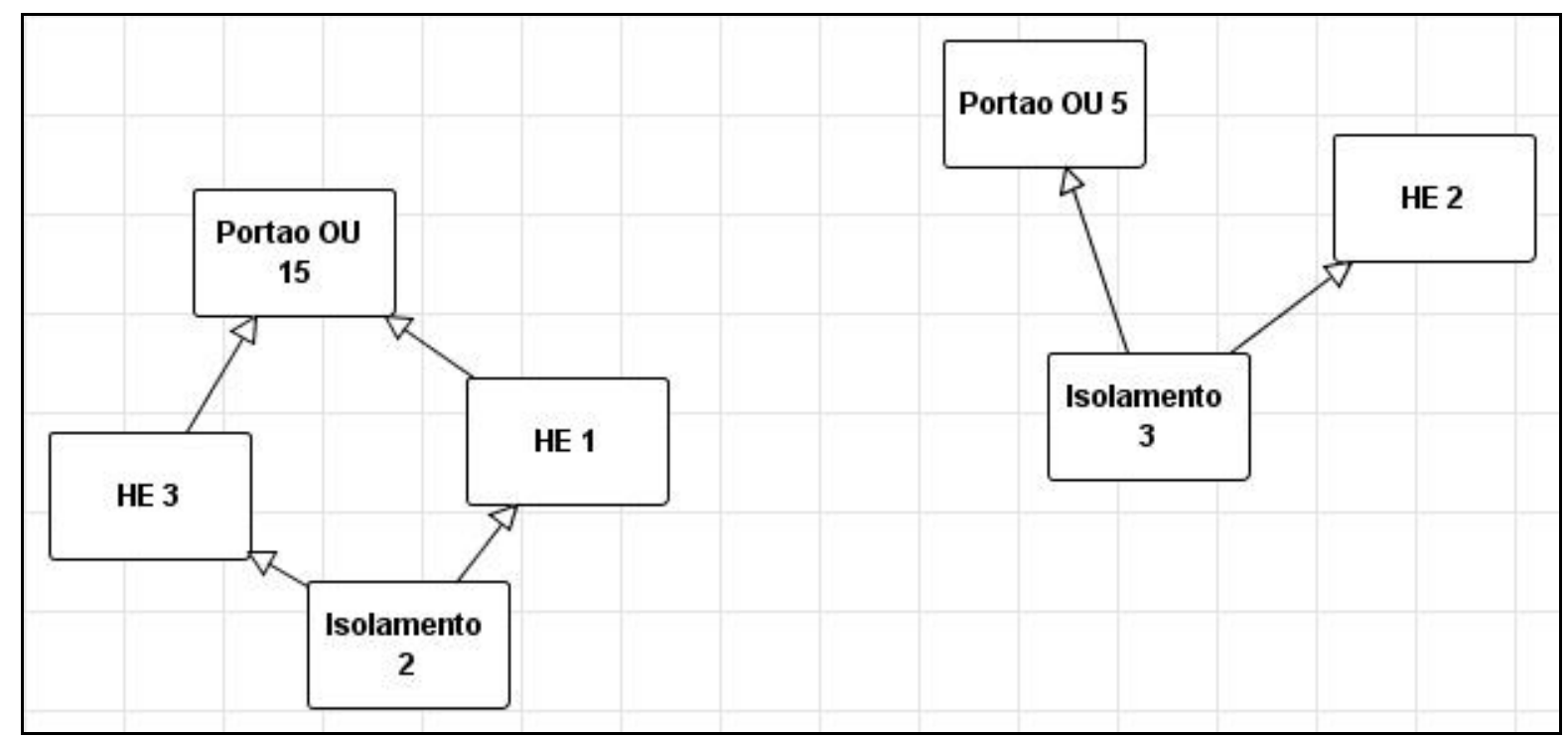

Figura 38 - Nós com dependências locais.

Para melhor compreensão, a Rede Bayesiana criada está ilustrada na Figura 39, onde se pode notar no topo o nó que representa todo o Sistema de Regaseificação e abaixo dele o detalhamento do sistema em subsistemas até o nível em que os nós representam os elementos básicos. Também é possível visualizar os nós extras, criados para facilitar a análise quantitativa, nós chamados de: Portões "OU", Tubulações e Válvulas. Finalmente observa-se um nó "R" conectado ao nó topo "Sistema de Regaseificação", este nó será usado posteriormente para o cálculo da Confiabilidade do sistema para um tempo de missão específico. 


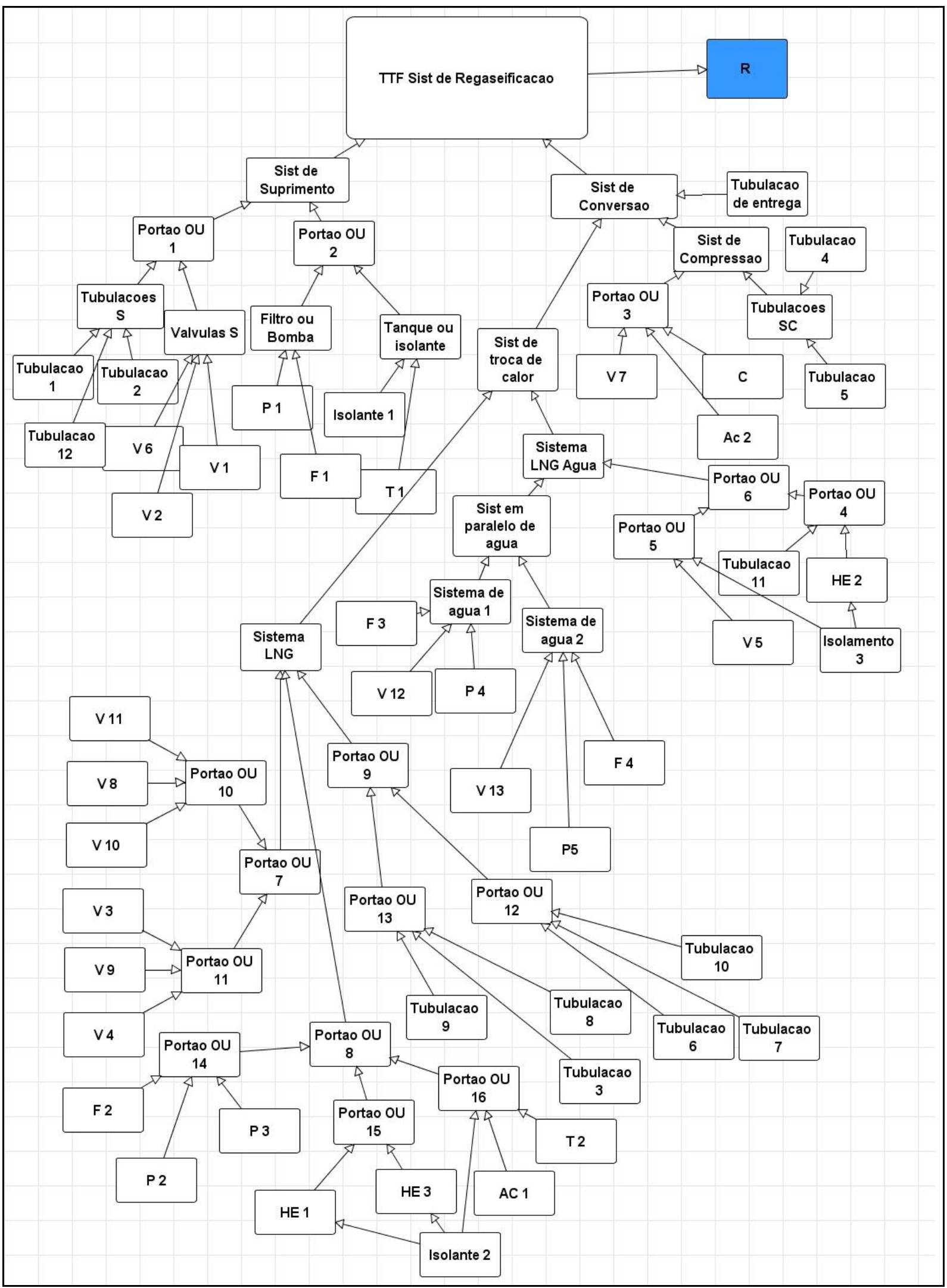

Figura 39 - Rede Bayesiana do Sistema de Regaseificação 


\subsection{ANÁLISE QUANTITATIVA}

Nesta seção serão apresentados os passos executados para 0 desenvolvimento da etapa 3 da metodologia proposta no Capítulo 4. Serão incluídas na Rede Bayesiana todas as probabilidades a priori dos nós raizes. Em seguida serão especificadas as relações entre os nós. E finalmente será obtida a probabilidade conjunta da rede, a qual, no caso estudado, servirá para obtenção da confiabilidade do sistema para um determinado tempo de missão.

Para complementar o estudo será apresentado no primeiro item desta seção (5.3.1) o cálculo de confiabilidade feito através do uso do diagrama de blocos apresentado no item 5.2.2. Salienta-se que tal passo não é necessário para a aplicação da metodologia proposta no Capítulo 4, tendo sido adicionado à esta pesquisa apenas para fornecer ao leitor uma visão mais abrangente, propiciando um exemplo para comparação entre o uso de uma rede bayesiana, conforme proposto no Capítulo 3 e o uso de uma técnica tradicional como o diagrama de blocos.

\subsubsection{Análise quantitativa por diagrama de blocos}

Através do diagrama de blocos ilustrado na Figura 37 é possível calcular a confiabilidade do sistema a partir da confiabilidade dos elementos básicos. Para tanto foi considerada uma taxa de falhas constante, resultando em uma distribuição exponencial para a confiabilidade dos componentes. A Tabela 9 apresenta a taxa de falha considerada para cada componente. As taxas de falhas foram retiradas preferencialmente do banco de dados OREDA (Offshore Reliability Data Handbook) e quando não disponíveis neste banco de dados foram retiradas dos relatórios da HSE (Health \& Safety Executive) e do RAC (Reability Analysis Center). Como tempo de missão considerou-se o tempo necessário para regaseificação do volume correspondente a capacidade máxima de armazenamento do navio Golar Winter, ou seja, quatro dias. Sendo assim a confiabilidade de cada componente é dada por:

APLICAÇÃO DE REDES BAYESIANAS PARA A ANÁLISE DE CONFIABILIDADE DO SISTEMA DE REGASEIFICAÇÃO DE UMA UNIDADE TIPO FSRU. 


$$
R=e^{-\lambda t}
$$

onde $\lambda$ : taxa de falha fornecida pelos bancos de dados;

\section{t: 96 horas}

A lista dos componentes, os valores das taxas de falha, com as respectivas fontes de informação e os valores da confiabilidade de cada equipamento estão apresentados na Tabela 9.

Durante esta pesquisa, não foram encontrados dados estatísticos sobre a probabilidade de falha do sistema de isolamento térmico, que foi estimada como sendo igual a $5,300 \times 10^{-5}$.

Tabela 9 - Componentes

\begin{tabular}{|c|c|c|c|c|}
\hline Componentes & Descrição & Fonte & $\begin{array}{c}\text { Taxa de falha } \\
(\lambda)\end{array}$ & $R=e^{-\lambda t}$ \\
\hline Acumulador GNL & Acumulador com capacidade de $2 \mathrm{~m}^{3}$ & OREDA & $2,883 \times 10^{-5}$ & $9,976 \times 10^{-1}$ \\
\hline Acumulador propano & Acumulador com capacidade de $2 \mathrm{~m}^{3}$ & OREDA & $2,883 \times 10^{-5}$ & $9,976 \times 10^{-1}$ \\
\hline Bomba de propano & Bomba criogênica e centrífuga. & OREDA & $4,801 \times 10^{-5}$ & $9,818 \times 10^{-1}$ \\
\hline Bomba de água & Bomba centrífuga. & OREDA & $5,120 \times 10^{-6}$ & $9,986 \times 10^{-1}$ \\
\hline Bomba de GNL & Bomba criogênica e centrífuga. & OREDA & $4,801 \times 10^{-5}$ & $9,818 \times 10^{-1}$ \\
\hline $\begin{array}{c}\text { Bomba tanque de } \\
\text { propano }\end{array}$ & Bomba criogênica e centrífuga. & OREDA & $4,801 \times 10^{-5}$ & $9,818 \times 10^{-1}$ \\
\hline Compressor GN & $\begin{array}{l}\text { Compressor do tipo "reciprocating" com } \\
\text { capacidade de } 21,75 \text { milhões } \mathrm{m}^{3} / \mathrm{dia}\end{array}$ & OREDA & $1,709 \times 10^{-4}$ & $9,801 \times 10^{-1}$ \\
\hline Filtro de Propano & Filtro para resíduos sólidos. & HSE & $4,155 \times 10^{-7}$ & $9,999 \times 10^{-1}$ \\
\hline Filtros de água & Filtro para resíduos sólidos. & HSE & $4,155 \times 10^{-7}$ & $9,999 \times 10^{-1}$ \\
\hline Filtros GNL & Filtro para resíduos sólidos. & HSE & $4,155 \times 10^{-7}$ & $9,999 \times 10^{-1}$ \\
\hline Tanque de propano & $\begin{array}{c}\text { Tanque de armazenagem com } \\
\text { capacidade de } 3 \mathrm{~m}^{3} \text {. }\end{array}$ & OREDA & $2,883 \times 10^{-5}$ & $9,976 \times 10^{-1}$ \\
\hline
\end{tabular}




\begin{tabular}{|c|c|c|c|c|}
\hline Tanque GNL & $\begin{array}{c}\text { Tanque de armazenagem com } \\
\text { capacidade de } 46000 \mathrm{~m}^{3} \text {. }\end{array}$ & NPRD & $2,760 \times 10^{-8}$ & $9,999 \times 10^{-1}$ \\
\hline $\begin{array}{l}\text { Trocador de calor } \\
\text { GNL/Água }\end{array}$ & $\begin{array}{c}\text { Trocador de calor do tipo "Shell and } \\
\text { Tube". }\end{array}$ & OREDA & $2,739 \times 10^{-5}$ & $9,991 \times 10^{-1}$ \\
\hline $\begin{array}{l}\text { Trocador de calor } \\
\text { Propano/Água }\end{array}$ & $\begin{array}{c}\text { Trocador de calor do tipo "Semi welded } \\
\text { plate". }\end{array}$ & OREDA & $2,175 \times 10^{-5}$ & $9,915 \times 10^{-1}$ \\
\hline $\begin{array}{c}\text { Trocador de calor } \\
\text { Propano/GNL }\end{array}$ & $\begin{array}{l}\text { Trocador de calor do tipo "Printed } \\
\text { circuit - plate compact". }\end{array}$ & OREDA & $3,857 \times 10^{-5}$ & $9,873 \times 10^{-1}$ \\
\hline Tubulação água & Tubulação de aço de 3" & HSE & $6,700 \times 10^{-9}$ & $9,944 \times 10^{-1}$ \\
\hline Tubulação gás & Tubulação de aço de 5" & HSE & $6,700 \times 10^{-9}$ & $9,944 \times 10^{-1}$ \\
\hline $\begin{array}{l}\text { Tubulação gás } \\
\text { comprimido }\end{array}$ & Tubulação de aço de 4" & HSE & $6,700 \times 10^{-9}$ & $9,944 \times 10^{-1}$ \\
\hline $\begin{array}{l}\text { Tubulação gás } \\
\text { comprimido }\end{array}$ & Tubulação de aço de 8" & HSE & $6,700 \times 10^{-9}$ & $9,944 \times 10^{-1}$ \\
\hline Tubulação GNL & Tubulação de aço de 4" & HSE & $6,700 \times 10^{-9}$ & $9,944 \times 10^{-1}$ \\
\hline Tubulação GNL & Tubulação de aço de 12" & HSE & $6,300 \times 10^{-9}$ & $9,947 \times 10^{-1}$ \\
\hline Tubulação propano & Tubulação de aço de 3" & HSE & $6,700 \times 10^{-9}$ & $9,944 \times 10^{-1}$ \\
\hline $\begin{array}{l}\text { Válvula gaveta após } \\
\text { compressor }\end{array}$ & Válvula gaveta para gás. & OREDA & $1,517 \times 10-5$ & $9,960 \times 10-1$ \\
\hline $\begin{array}{l}\text { Válvula gaveta bomba } \\
\text { acumulador }\end{array}$ & Válvula gaveta para líquido. & OREDA & $6,610 \times 10-6$ & $9,988 \times 10-1$ \\
\hline
\end{tabular}

Para calcular a confiabilidade geral do sistema foram consideradas as configurações do diagrama de blocos e as equações 1 e 2 apresentadas no item 3.1.2.3. Sendo assim, a confiabilidade do sistema, calculada com o uso do diagrama de blocos, é de $93,41 \%$. Esse valor nos dá uma estimativa da chance do sistema não falhar dentro do tempo de missão considerado (96 horas). 


\subsubsection{Complementação da Rede Bayesiana: probabilidades a priori e probabilidades condicionais}

A análise quantitativa da Rede Bayesiana se inicia com a inclusão das probabilidades a priori dos nós raiz. Para análise de confiabilidade do Sistema de Regaseificação optou-se pelo uso de uma rede híbrida com variáveis contínuas e discretas. Todos os nós, exceto o nó "R", são variáveis contínuas, as quais representam a distribuição do tempo até a falha (em inglês Time To Failure - TTF) e o nó "R" é uma variável discreta que define o valor da confiabilidade para um determinado tempo de missão.

As probabilidades a priori podem ser fornecidas por dados estatísticos ou por opinião de especialistas. Para uma análise inicial foram consideradas as mesmas taxas de falha usadas na análise por diagrama de blocos (item 5.3.1), ou seja foi assumido que as taxas de falha $(\lambda)$ dos componentes são constantes e que as distribuições de falha são exponenciais. Com esses dados foram completadas as informações de todos os nós raízes.

Como referido anteriormente, durante esta pesquisa, ainda não foram encontrados dados estatísticos sobre a probabilidade de falha do sistema de isolamento térmico, mas esse dado pode ser preenchido pela opinião de especialistas. Os construtores da RB fazem perguntas a um grupo de especialistas e explicam as suposições implícitas nos modelos. Os especialistas fornecem seu conhecimento para os construtores (Langseth e Portinale 2005). Charniak (1992) e Whittaker (1990) demonstram como funciona este processo. Neste estudo foi considerada para o nó "isolamento", uma distribuição Weibull com parâmetro de forma $s=6$ e de escala $\beta=1 / 10000$. Foi escolhida uma distribuição diferente da exponencial para salientar que as tarefas propostas neste estudo podem ser executas para diferentes distribuições e taxas de falhas que não sejam constantes.

Em seguida, foram consideradas as dependências locais. Como mencionado no item anterior, existem dependências locais entre os trocadores de calor e os 
isolamentos térmicos. Para consideração destas dependências foram ajustadas as tabelas de probabilidades dos nós que representam os trocadores de calor incluido duas distribuições: a primeira considera a taxa de falha do trocador no caso do isolamento térmico funcionar e a segunda considera uma taxa de falha maior para o trocador de calor caso o isolamento térmico falhe. Sendo assim, para o trocador de calor $\mathrm{HE}_{1}$ a taxa de falha cresce de $3,857 \times 10^{-5}$ para $4,000 \times 10^{-5}$ caso $\mathrm{o}$ isolamento térmico falhe (Tabela 10); para o trocador de calor $\mathrm{HE}_{2}$ a taxa cresce de $2,739 \times 10^{-5}$ para $3,700 \times 10^{-5}$ (Tabela 11) e finalmente para o trocador de calor $\mathrm{HE}_{3}$ cresce de $2,175 \times 10^{-5}$ para $3,000 \times 10^{-5}$ (Tabela 12).

Tabela 10 - Taxa de falha do trocador de calor GNL/Propano

\begin{tabular}{lc} 
& $\mathbf{H E}_{1}$ \\
\cline { 2 - 2 } Isolamento 1 & $\lambda$ \\
\hline Ok & $3,857 \times 10^{-5}$ \\
Falha & $4,000 \times 10^{-5}$ \\
\hline
\end{tabular}

Tabela 11 - Taxa de falha do trocador de calor GNL/água

\begin{tabular}{lc} 
& $\mathbf{H E}_{2}$ \\
\cline { 2 - 2 } Isolamento 3 & $\lambda$ \\
\hline Ok & $2,739 \times 10^{-5}$ \\
Falha & $3,700 \times 10^{-5}$ \\
\hline
\end{tabular}

Tabela 12 - Taxa de falha do trocador de calor Propano/água

\begin{tabular}{lc} 
& $\mathbf{H E}_{3}$ \\
\cline { 2 - 2 } Isolamento 2 & $\lambda$ \\
\hline Ok & $2,175 \times 10^{-5}$ \\
Falha & $3,000 \times 10^{-5}$ \\
\hline
\end{tabular}


O passo que finaliza a construção da Rede Bayesiana é a determinação das relações entre as variáveis. As relações entre elementos ligados em série, são representadas por portões "OU", os quais definem que para que ocorra uma falha basta ocorrer uma falha em um dos elementos conectados a este portão. A relação nestes portões é representada pela equação (26). As relações entre elementos redundantes são representadas por portões "E", os quais definem que para que ocorra a falha devem falhar todos os elementos conectados a este portão; as relações deste portão são dadas pela equação (25). No caso analisado existe apenas um subsistema redundante, o Sistema de Abastecimento de Água assim esta relação será usada apenas no nó "Sistema em paralelo de água".

A última relação a ser descrita é a relação entre nó discreto " $R$ " e o nó contínuo "Sistema de Regaseificação". O nó "R" é uma representação da confiabilidade do sistema para um dado tempo de missão, ou seja, ele é a probabilidade do sistema não falhar antes de completado o tempo de missão.

Finalmente, com a Rede Bayesiana completa, é possível obter o valor de confiabilidade do sistema para o tempo de missão escolhido.

\subsubsection{Confiabilidade do Sistema de Regaseificação}

A obtenção do valor da confiabilidade do sistema é a última tarefa da etapa 3 da metodologia proposta. Para o caso do Sistema de Regaseificação, a confiabilidade foi analisada considerando um tempo de missão de 96 horas (tempo necessário para regaseificação do volume correspondente a capacidade máxima de armazenamento do navio Golar Winter).

Pela inferência da Rede Bayesiana obteve-se que a confiabilidade do sistema, para um período de missão de 96 horas é de $93,88 \%$. Vale notar que o uso da Rede Bayesiana permitiu a inclusão de dados adicionais, cuja inserção não é possível em técnicas tradicionais como o Diagrama de Blocos; foi possível considerar dependências locais (entre trocadores de calor e isolamento térmico), 
variáveis contínuas (distribuições de falhas) e relações não determinísticas (construção das TPC e funções densidade de probabilidades condicionais).

Com o objetivo de tornar o modelo mais eficaz e realista é possível ainda a inclusão de Falhas de Causa Comum na Rede Bayesiana. Este será o próximo passo da análise.

\subsubsection{Falhas de Causa Comum na Rede Bayesiana}

Para tornar o modelo mais realista foram consideradas falhas de causa comum no sistema de bombeamento de água, que apresenta a única redundância do Sistema de Regaseificação. O bombeamento da água do mar para os trocadores de calor é feito por dois sistemas em paralelo. A metodologia empregada para inclusão desta análise seguiu os seguintes passos: definição dos eventos de causas comuns, seleção do modelo de probabilidade a ser usado, inclusão dos novos eventos à Rede Bayesiana (conforme item 3.2.4.3) e análise dos dados.

O primeiro passo, definição dos eventos de causas comuns, gera uma redefinição da estrutura lógica do modelo, pois nesta fase são agregados novos eventos à estrutura. Os componentes foram agregados em grupos de acordo com sua similaridade, resultando na formação de 3 grupos de eventos de causa comum, conforme mostrado na Tabela 13. O grupo 1 é formado pelas válvulas, o grupo 2 pelas bombas e o grupo 3 pelos filtros usados no Sistema de Abastecimento de Água.

No segundo passo, é necessária a definição da freqüência de ocorrência dos eventos de causa comum de falha, para tanto foi escolhido o uso do modelo simples de probabilidade Beta apresentado no item 3.1.3. Como sugerido por Schüller (2005), foi considerado o fator $\beta=0,1$ para garantir uma avaliação conservativa, obtendo-se assim um valor para cada grupo como apresentados na Tabela 13, onde $\lambda_{g}$ é a taxa de freqüência dos eventos de causa comum de falha do grupo e $\lambda_{c}$ é a 
Escola Politécnica da USP

taxa de falha do componente.

Tabela 13 - Grupos de CCF

\begin{tabular}{|c|c|c|}
\hline & Grupos CCF & $\begin{array}{l}\lambda \text { grupo } \\
\lambda_{g}=\beta \lambda_{c}\end{array}$ \\
\hline 1 & Válvulas para líquido & $6,610 \times 10^{-7}$ \\
\hline 2 & Bombas de água & $5,120 \times 10^{-7}$ \\
\hline 3 & Filtros de água & $0,416 \times 10^{-7}$ \\
\hline
\end{tabular}

Os novos eventos de causas comuns foram adicionados à Rede Bayesiana conforme procedimento apresentado no item 3.2.4.3. Na Figura 40 estão destacados os nós referentes às CCF onde existe um nó para cada um dos grupos da Tabela 13. Após a inclusão desses eventos obteve-se um novo valor para a confiabilidade do sistema dado o mesmo tempo de missão. A Tabela 14 exibe um comparativo entre os valores antes e depois da inclusão das causas comuns ao modelo; é possível notar que as causas comuns contribuem para a redução da confiabilidade do sistema.

Tabela 14 - Probabilidade de falha antes e depois da inclusão de CCF

Probabilidade de falha antes Probabilidade de falha após da inclusão de CCF a inclusão de CCF

\section{Sistema de Água}

(Sistema com redundância)

$$
1,404 \times 10^{-6} \quad 1,174 \times 10^{-4}
$$

\section{Sistema de}
Regaseificação
$6,116 \times 10^{-2}$
$6,127 \times 10^{-2}$

(Probabilidade de falha geral do sistema estudado)

O uso da Rede Bayesiana permitiu a inclusão de CCF ao modelo apesar do uso de variáveis contínuas. A obtenção do valor de confiabilidade para um dado 
tempo de missão encerra a etapa 3 da metodologia proposta e fornece as informações necessárias para o início da etapa 4: análises complementares.

Figura 40 - Rede Bayesiana do Sistema de Regaseificação com CCF

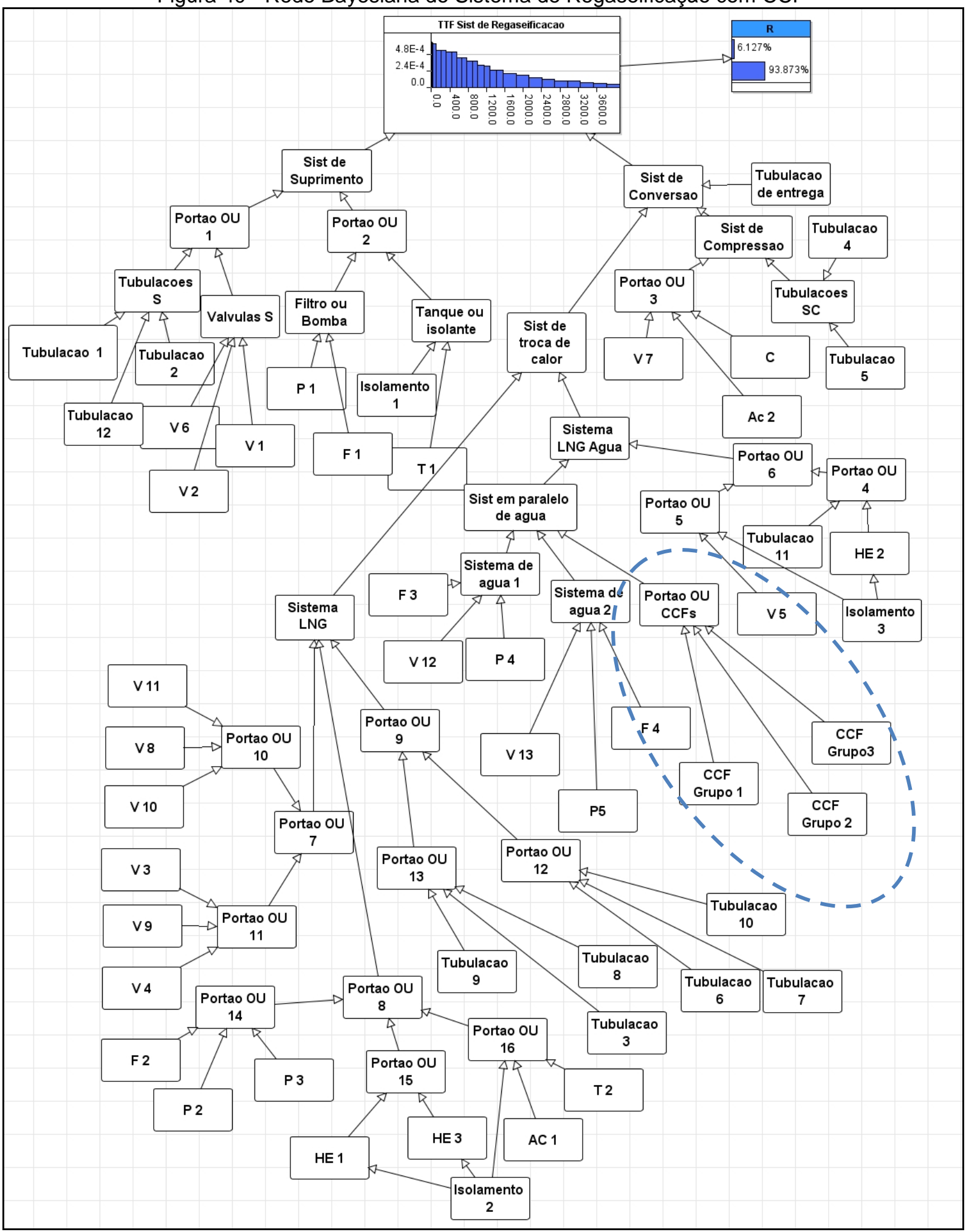




\subsection{ANÁLISES COMPLEMENTARES}

Como previsto na metodologia apresentada no capítulo 3 as análises complementares visam aprimorar a análise de confiabilidade através da exploração dos benefícios que a aplicação de RB oferece. A primeira análise complementar sugerida é a análise de criticidade, seguida da análise de diferentes cenários e finalmente o estudo da confiabilidade condicionada. Nos próximos itens serão apresentadas as análises complementares do sistema de regaseificação do FSRU.

\subsubsection{Análise de criticidade}

A primeira análise complementar sugerida é a Análise de Criticidade: o uso de Redes Bayesianas permite a verificação de quais nós produzem maior impacto no evento principal através da verificação das probabilidades posterioris.

O gráfico da Figura 41 é uma perspectiva visual do impacto que os nós raízes (nós que representam os componentes básicos) têm sobre o nó alvo (TTF do sistema de regaseificação). A primeira barra indica a faixa de valores esperados para o TTF do sistema de regaseificação dado o TTF do compressor $\mathrm{C}$, o ponto inicial da barra (o ponto igual a zero) indica o valor esperado para o TTF do sistema de regaseificação dado o TTF do compressor muito próximo de zero. O ponto final da barra (com o valor de 2208) indica o valor esperado para o TTF do sistema de regaseificação dado o TTF do compressor muito maior que o tempo de missão, até o ponto onde o TTF do compressor influencia o TTF do sistema de regaseificação. Após este ponto, o TTF do sistema dado estabiliza, ou seja, mesmo que exista um acréscimo no TTF do compressor, o valor esperado para o TTF do sistema de regaseificação não sofrerá mais mudanças. A segunda barra do gráfico representa os valores esperados para o TTF do sistema dado o TTF da bomba $\mathrm{P}_{1}$, o TTF da bomba começa a influenciar o TTF do sistema de regaseificação quando o seu valor esperado está em torno de 0,5 e deixa de influenciar quando o valor esperado para 
o TTF do sistema está em torno de 1633. As barras seguintes são plotadas seguindo o mesmo conceito, sendo assim, o gráfico mostra que o componente mais crítico para o sistema de regaseificação é o compressor $\mathrm{C}$, que é o componente com maior influência sobre o TTF do sistema e como esperado, os componentes que causam menor impacto são aqueles que compõem o sistema redundante de bombeio de água: bombas $P_{4}$ e $P_{5}$, válvulas $V_{12}$ e $V_{13}$ e os filtros $F_{3}$ e $F_{4}$.

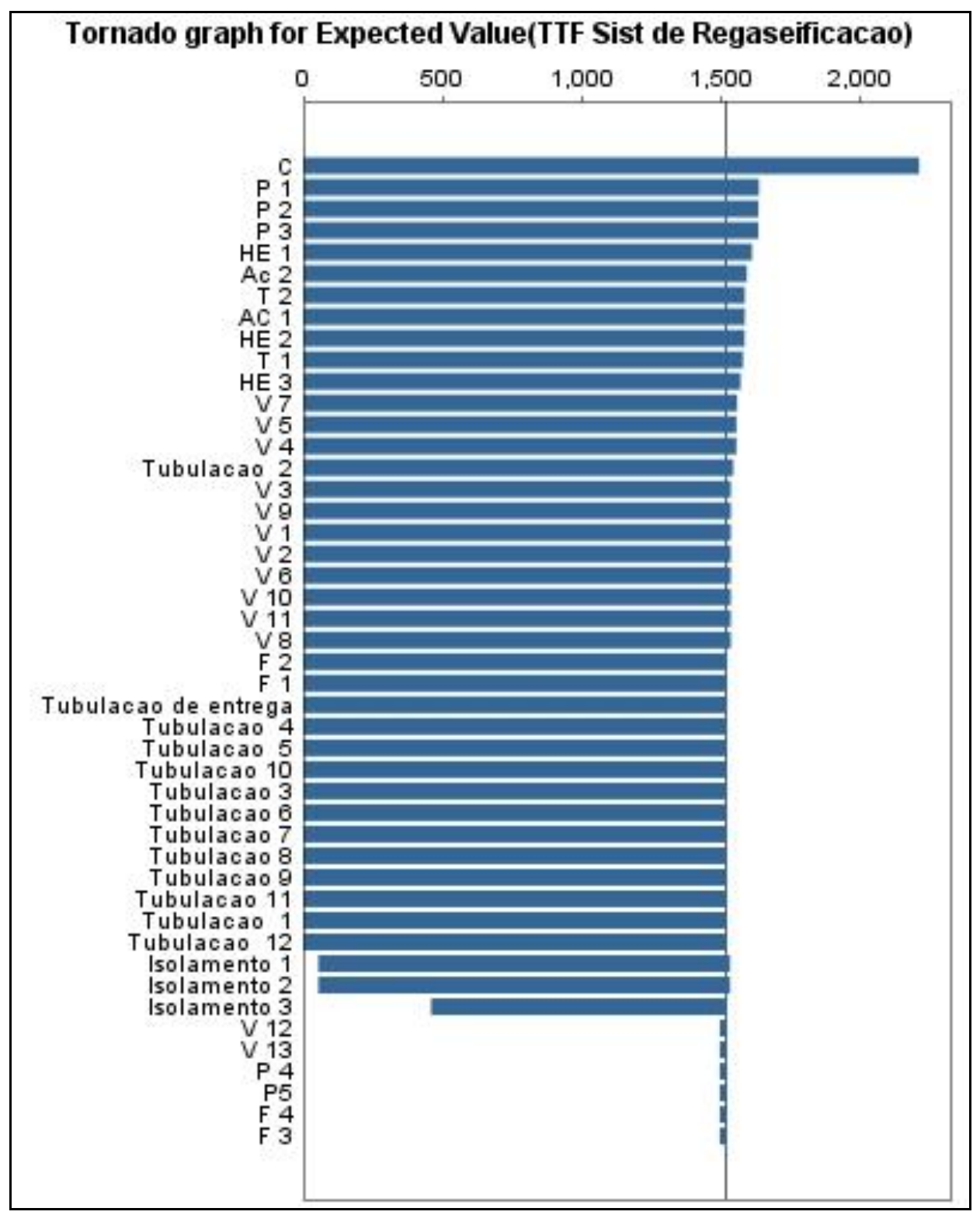

Figura 41 - Gráfico de Criticidade: Componentes X Confiabilidade 
Outro exemplo de Análise de criticidade pode ser visto na Figura 42. Neste caso foi feita uma análise de sensibilidade entre os subsistemas e o sistema de regaseificação. Neste gráfico é possível avaliar o impacto que o TTF de cada subsistema tem sobre o TTF geral do sistema. Verificando-se assim qual é o subsistema que produz maior impacto é possível simular a inserção de um subsistema redundante e posteriormente fazer nova análise e avaliar a melhoria que essa medida causaria na confiabilidade final.

Esta análise é uma ferramenta eficaz na procura de pontos críticos do sistema, contribui para o mapeamento de equipamentos e subsistemas que demandam melhorias ou especial atenção durante a confecção do plano de manutenção.

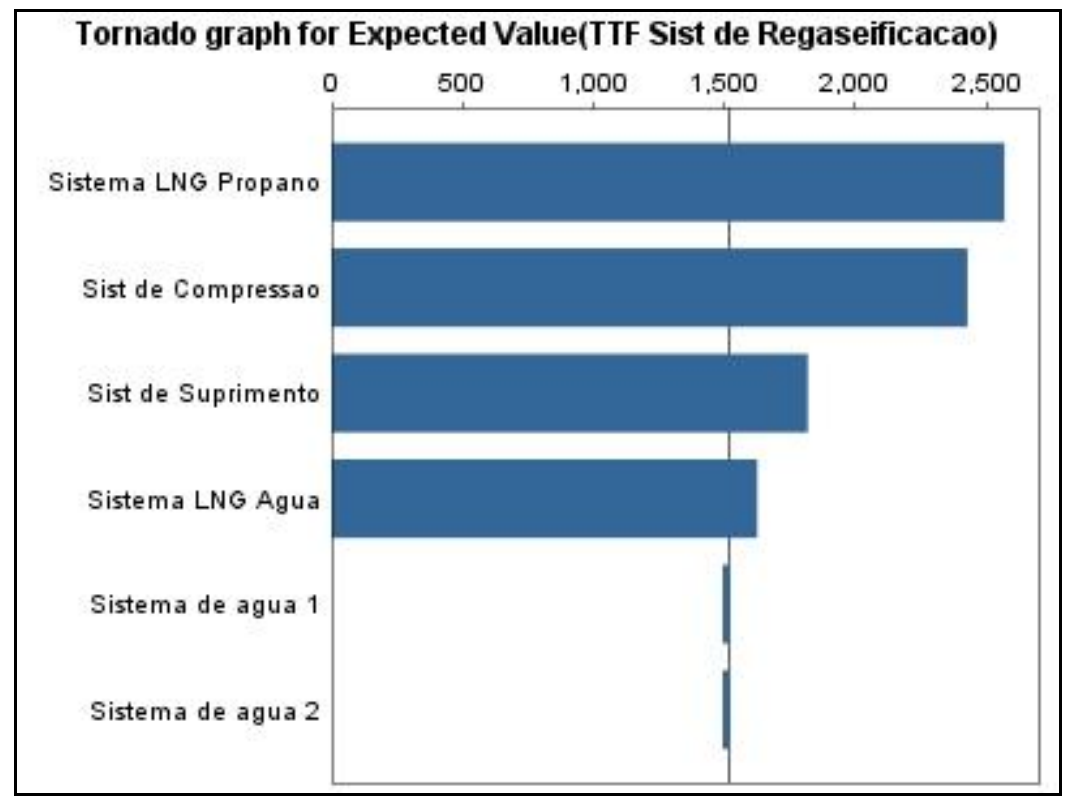

Figura 42 - Gráfico de criticidade Subsistemas X Sistema de regaseificação

\subsubsection{Análise de diferentes cenários}

A segunda análise complementar sugerida na metodologia proposta no capítulo 4 é a análise de diferentes cenários. RB permitem o estudo da propagação 
da evidência e, desta maneira, o estudo de diferentes cenários. Como Jones et al. (2009) apontou, a propagação da evidência permite o aprofundamento do estudo de áreas problemáticas que necessitam de mais atenção. No item 5.4.2.1, é modelada a melhoria da confiabilidade de um componente crítico do sistema.

A observação da propagação da evidência também possibilita analisar os efeitos de determinada falha sobre o sistema, por exemplo, qual seria o efeito de uma falha de um componente redundante na confiabilidade geral do sistema; este cenário é apresentado no item 5.4.2.2. Finalmente, no item 5.4.2.3, é modelada a inclusão de uma redundância no sistema e verificado o impacto que esta alteração causa na confiabilidade total.

\subsubsection{Cenário 1 - Melhoria na confiabilidade de um componente crítico do sistema}

A análise de criticidade apresentada no item 5.4.1 demonstrou que 0 equipamento que tem maior influência na confiabilidade total do sistema é o compressor, sugerindo especial atenção para este componente. Se inserirmos na RB a evidência de que o compressor opera sem falhas, percebemos um acréscimo na confiabilidade total do sistema de regaseificação de 0,93873 para 0,95761 . A Figura 43 mostra em azul os valores da rede bayesiana antes da inclusão da evidência e em laranja os valores obtidos após a inclusão da evidência de que o compressor é ideal, não falha. Este é o maior valor de confiabilidade que o sistema pode apresentar alterando-se apenas as características do compressor. Desta forma pode-se avaliar de maneira direta os efeitos de melhorias em componentes críticos e usar tal informação para auxiliar na tomada de decisões.

O mesmo conceito pode ser usado para avaliar subsistemas, a análise de criticidade do item 5.4.1 identificou o subsistema "Sistema GNL - Propano" como o que causa maior impacto no TTF do sistema de regaseificação, sendo assim pode se tentar melhorar a confiabilidade deste subsistema, simular essa melhoria e 
Escola Politécnica da USP

verificar qual o incremento na confiabilidade geral do sistema.

Simulações de evidências como essas tornam possível verificar a influência de sistemas redundantes; equipamentos críticos ou equipamentos com elevado tempo para reparo. Essa previsão pode contribuir para o desenvolvimento de um plano de manutenção mais eficaz. 
Escola Politécnica da USP

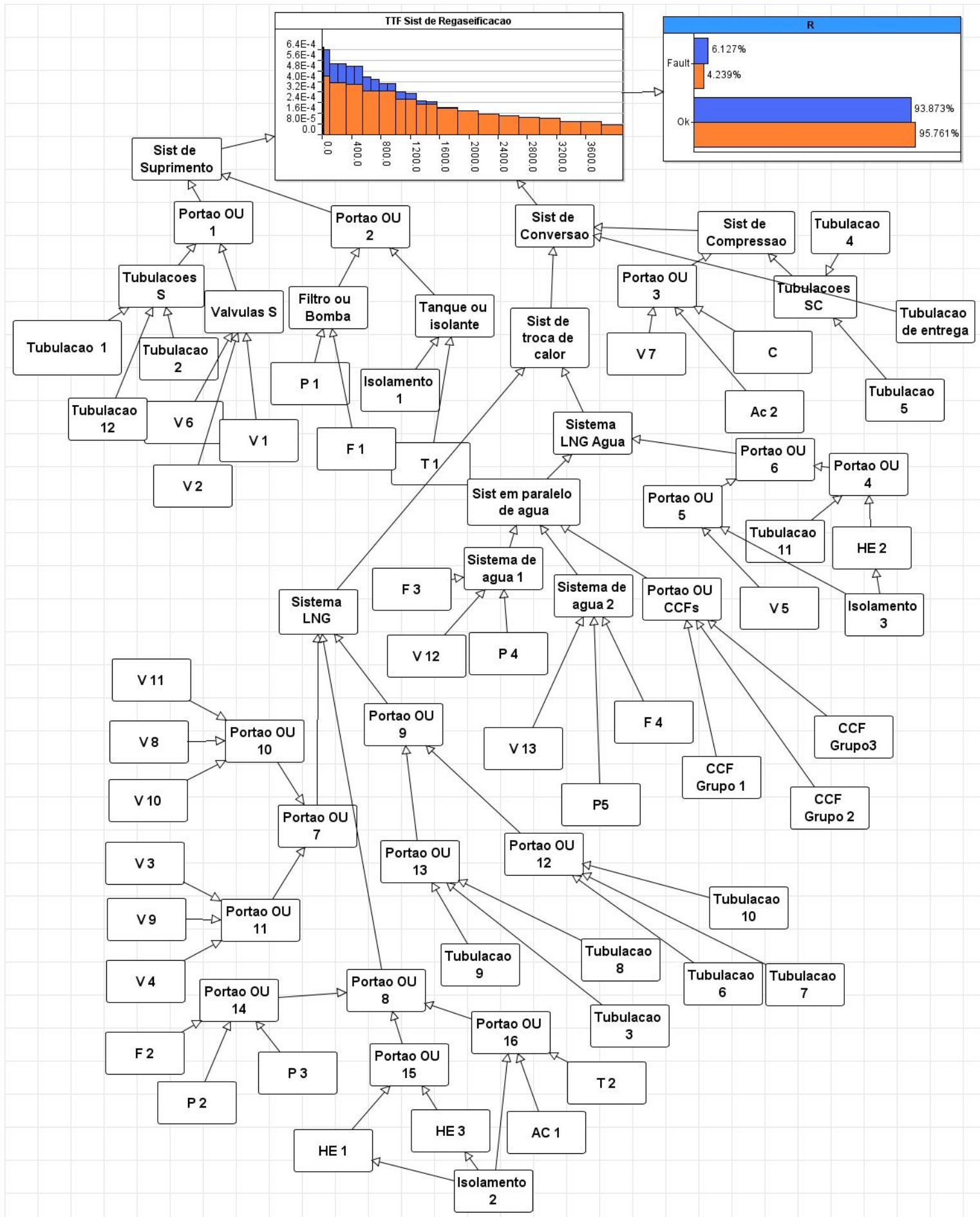

Figura 43 - Rede Bayesiana referente ao cenário 1 


\subsubsection{Cenário 2 - Falha de um componente redundante}

Outra análise que pode ser executada através da propagação de evidências é a verificação dos efeitos que uma falha em sistemas redundantes causa na confiabilidade total ou na confiabilidade de subsistemas. O sistema estudado possui duas bombas que enviam água para os trocadores de calor. É possível analisar o efeito que a falha de uma dessas bombas causaria na confiabilidade do sistema de regaseificação. Para fazer essa análise é preciso apenas compilar a RB colocando a falha da bomba como evidência e então se obtém a confiabilidade do sistema dado que uma bomba de água falhou; como resultado obtém-se que a confiabilidade decresce de 0,93873 para 0,93765. A Figura 44 mostra em azul os valores da rede bayesiana antes da inclusão da evidência e em verde os valores obtidos após a inclusão da evidência que uma bomba de água falhou. A Tabela 15 apresenta os resultados comparativos entre as probabilidades de falha do sistema de regaseificação e do subsistema de água antes de qualquer evidência ser inserida à rede e após a inclusão da evidência "falha da bomba $\mathrm{P}_{4}$ " ser inserida à rede.

Tabela 15 - Probabilidades de falha antes e depois da falha de um equipamento redundante.

\begin{tabular}{ccc}
\hline & $\begin{array}{c}\text { Probabilidade de falha a } \\
\text { priori }\end{array}$ & $\begin{array}{c}\text { Probabilidade de falha após } \\
\text { evidência: falha da bomba } \mathbf{P}_{4}\end{array}$ \\
\hline $\begin{array}{c}\text { Sistema de Água } \\
\text { (Probabilidade de falha do } \\
\text { sistema com redundância) }\end{array}$ & $1,174 \times 10^{-4}$ & $1,269 \times 10^{-3}$ \\
Sistema de & & \\
Regaseificação & $6,127 \times 10^{-2}$ & $6,235 \times 10^{-2}$ \\
(Probabilidade de falha & & \\
geral do sistema estudado) & & \\
\hline
\end{tabular}

Nota-se um aumento significativo da probabilidade de falha do sistema de água, esta informação permite avaliar o comportamento do sistema no caso de uma 
Escola Politécnica da USP

falha e contribui para a elaboração do planejamento da manutenção deste sistema. Esta análise pode ser estendida a qualquer componente de interesse. 
Escola Politécnica da USP

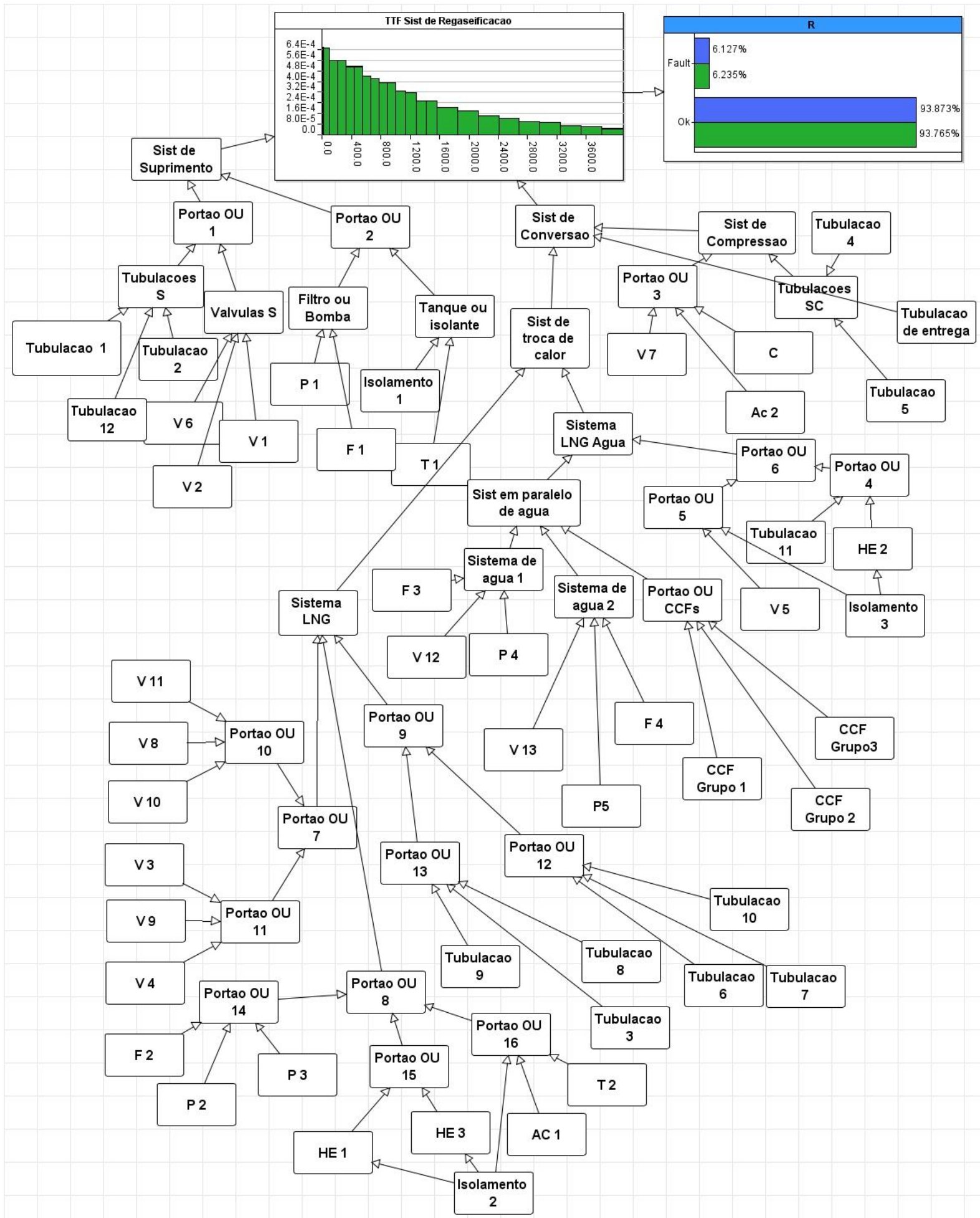

Figura 44 - Rede Bayesiana referente ao cenário 2 


\subsubsection{Cenário 3 - Inclusão de redundância}

Para melhorar a confiabilidade do sistema algumas redundâncias podem ser inclusas, porém existe um custo para esta inclusão e sendo assim deve-se conhecer o real impacto desta inclusão para que seja feita uma análise de custo-benefício. Uma vez que a análise de criticidade apresentada no item 5.4 .1 mostra que o componente que causa maior impacto na confiabilidade total do sistema de regaseificação é o compressor, foi modelada a inclusão de um compressor redundante ativo ao sistema. Um novo nó, que representa o compressor redundante, foi acrescentado à rede e então recalculados os valores da rede e desta maneira a confiabilidade aumentou de 0,93873 para 0,95721. Nota-se que, como esperado, apesar do aumento da confiabilidade este valor ainda é menor do que o encontrado no item 5.4.2.1, onde é simulado um cenário com um compressor ideal.

Uma análise similar pode ser feita para calcular os efeitos da inclusão de um subsistema redundante e não apenas um único componente e assim serem obtidas informações que contribuam para o processo de tomada de decisão sobre alocação de recursos e execução de tarefas que corroborem para melhorar a confiabilidade do sistema.

\subsubsection{Confiabilidade Condicionada}

A taxa de falha para equipamentos com distribuições de probabilidade exponenciais não se alteram ao longo do tempo, porém para equipamentos com distribuições não exponenciais a taxa de falha se modifica ao longo do tempo e consequentemente, a confiabilidade também será diferente para equipamentos com tempo de operação acumulado.

É possível incluir na RB a evidência de que o componente já operou, sem apresentar falhas, durante um determinado tempo de missão. Isto é feito incluindo-

APLICAÇÃO DE REDES BAYESIANAS PARA A ANÁLISE DE CONFIABILIDADE DO SISTEMA DE REGASEIFICAÇÃO DE UMA UNIDADE TIPO FSRU. 
se um nó à $R B$ que representará o estado do componente indicando se o mesmo esteve em operação previamente ou não. Uma vez incluída a evidência, as crenças são recalculadas e se obtêm as probabilidades posterioris do TTF e a confiabilidade condicional dada à existência ou não de tempo de operação prévio.

$\mathrm{Na}$ RB construída para o sistema de regaseificação do FSRU foram consideradas majoritariamente distribuições exponenciais, para as quais as taxas de falha são constantes, porém nos nós que representam os isolamentos térmicos foram usadas distribuições Weibull, o que implica em uma taxa de falha crescente ao longo do tempo e portanto um decréscimo na confiabilidade. A Figura 45 mostra uma vista parcial da RB do sistema de regaseificação onde pode-se visualizar a inclusão de um nó extra no qual é possível indicar se o equipamento já possui tempo de operação. Em azul estão as probabilidades posterioris para o sistema de regaseificação dada a evidência de que os equipamentos não possuem tempo de operação anterior e em verde as probabilidades posterioris dada a evidência de que o equipamento operou previamente e não apresentou falhas. $O$ tempo prévio de operação usado nesta simulação foi de 1000 horas, esse tempo é incluso na RB através do nó que define se o equipamento é novo ou se possui um tempo prévio de operação; Assim como é possível fazer a simulação para qualquer tempo de operação prévio, também é possível incluir diferentes tempos prévios de operação para diferentes equipamentos. Para um tempo de missão de 96 horas verificou-se que a probabilidade de falha do isolamento térmico aumentou de $9,499 \times 10^{-13}$ para $5,094 \times 10^{-5}$ e a confiabilidade geral do sistema de regaseificação diminuiu de 0,93873 para 0,93859 .

Desta maneira pode-se obter a confiabilidade condicional do sistema para qualquer tempo de missão e assim acompanhar o comportamento do sistema e seus equipamentos ao longo do tempo. Estas informações contribuem para a elaboração de um plano de manutenção eficaz e otimizado, uma vez que através da RB pode-se avaliar o estado do sistema após acumulado um determinado tempo de operação para qualquer que seja a distribuição de densidade de probabilidade de falha dos componentes.

APLICAÇÃO DE REDES BAYESIANAS PARA A ANÁLISE DE CONFIABILIDADE DO SISTEMA DE REGASEIFICAÇÃO DE UMA UNIDADE TIPO FSRU. 
Escola Politécnica da USP

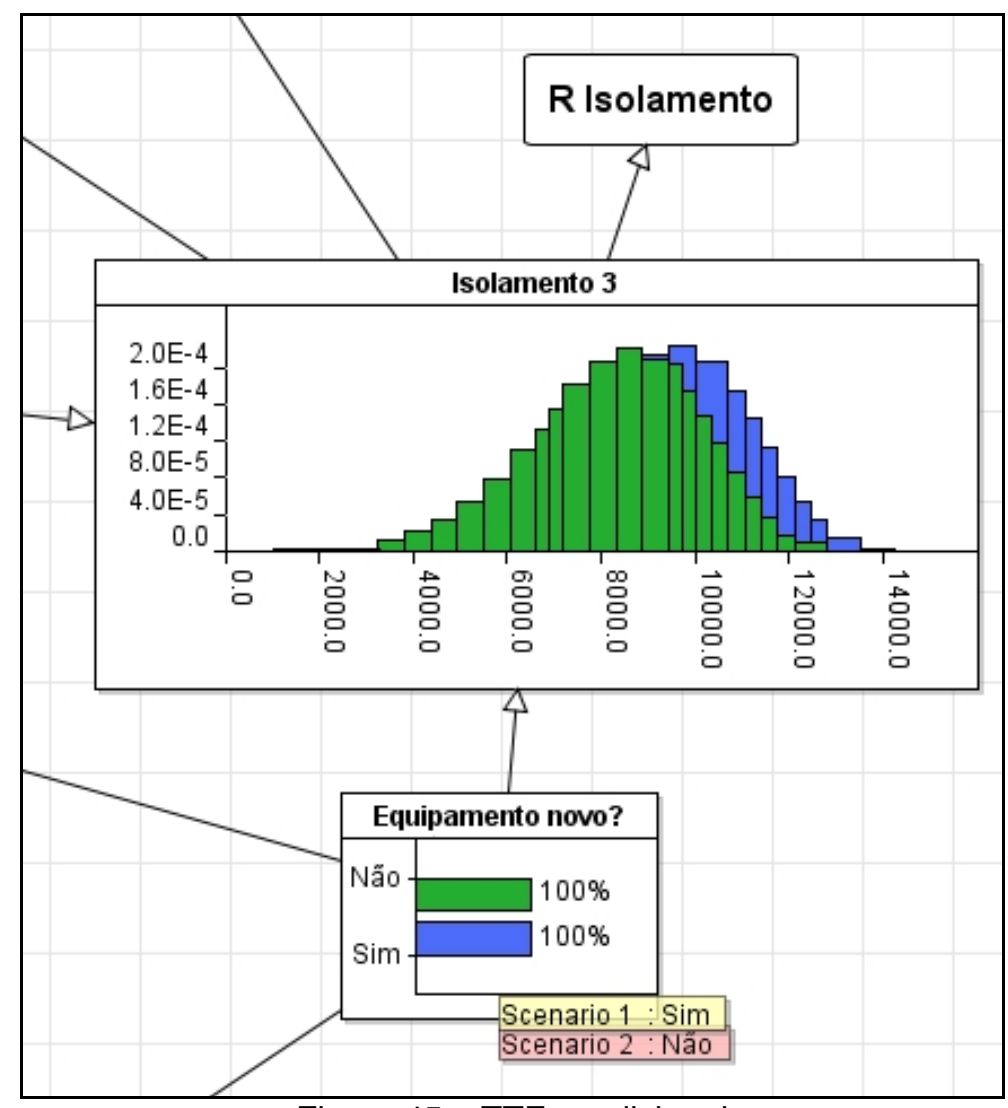

Figura 45 - TTF condicional 


\section{CONCLUSÕES}

O uso de Redes Bayesianas para análise de Confiabilidade tem sido explorado nos últimos anos como uma alternativa para mitigar algumas das limitações apresentadas por técnicas tradicionais. Através do estudo de referências bibliográficas sobre o tema foi possível observar benefícios obtidos com o uso das Redes Bayesianas: desenvolvimento de modelos com variáveis contínuas, uso de eventos não determinísticos, uso de variáveis com múltiplos estados, representação de dependências locais, representação de incertezas e inclusão de evidências.

Durante a aplicação da metodologia para análise do Sistema de Regaseificação foi possível observar a eficácia das Redes Bayesianas na representação de dependências locais (no caso estudado, existentes entre trocadores de calor e isolamento térmicos). Também foi possível explorar o uso de uma rede híbrida, formada por variáveis contínuas e discretas, e relações não determinísticas, o que tornou a análise mais completa comparada com uma análise na qual apenas variáveis discretas fossem usadas. O uso de variáveis contínuas permitiu a inclusão de diferentes distribuições para representar o TTF dos componentes, não limitando o estudo apenas ao uso de distribuições exponenciais; no estudo realizado foram usadas também distribuições Weibull. Já o uso de variáveis discretas permitiu a visualização clara e rápida da confiabilidade do sistema para um dado tempo de missão. Durante a elaboração deste estudo foi encontrado apenas um programa comercial eficaz no tratamento de RB com variáveis contínuas, porém considerando que o uso de variáveis contínuas não só torna o modelo mais realista como elimina a necessidade do preenchimento das TPC, o uso desta ferramenta se justifica; pois a tarefa de preencher adequadamente as TPC é frequentemente apontada como ponto crítico no uso de RB.

Também foi mostrado que para o tratamento de CCF, a Rede Bayesiana dispensa o formalismo de técnicas tradicionais para o caso de variáveis discretas, sendo necessário apenas a inclusão da probabilidade associada à CCF na TPC, e para o caso de variáveis contínuas, aceita uma abordagem muito semelhante à 
usada por FTA, através da inclusão de nós que representem as CCF, porém permitindo o uso de variáveis contínuas e não apenas discretas.

Durante o desenvolvimento das análises complementares, a etapa 4 da metodologia proposta, foi possível notar como as RB são eficazes para modelagem de diferentes cenários. Apenas com a inclusão de evidências ao modelo foi possível avaliar os efeitos na confiabilidade do sistema em função da melhoria em um componente crítico, pela falha de um componente redundante e pela inclusão de uma redundância. Os cenários apresentados neste estudo são apenas alguns exemplos do potencial das RB para análise de diferentes aspectos sobre 0 comportamento de um sistema e análises desta natureza podem contribuir de maneira significativa para a tomada de decisão em processos que visem o aumento da confiabilidade do sistema.

O cálculo da confiabilidade condicionada através da RB mostrou-se uma ferramenta eficaz para avaliação do comportamento do sistema ao longo do tempo; conhecer a confiabilidade do sistema após acumulado determinado tempo de operação colabora para tomadas de decisões sobre tarefas que visem melhorar ou manter a confiabilidade geral do sistema em operação. Esta avaliação pode ser feita de maneira rápida apenas pela inclusão da evidência "tempo de operação" à RB.

Seriam precisos dados mais específicos a respeito do Sistema de Regaseificação do FSRU e seus componentes para se executar uma avaliação mais precisa de sua confiabilidade, porém baseando-se nos dados disponíveis sobre o sistema em questão e em bancos de dados disponíveis, este estudo mostrou que o compressor é o componente crítico deste sistema, uma vez que tem as maiores probabilidades posteriores associadas ao TTF do sistema de regaseificação. Um plano de manutenção deverá tratar este equipamento com atenção especial e considerar a inclusão de um compressor redundante, pois como visto no item 5.4.2.3 a inclusão de um compressor redundante faria com que a confiabilidade geral do sistema sofresse um acréscimo próximo de $2 \%$.

Os resultados da avaliação da confiabilidade condicionada mostraram um aumento significativo na probabilidade de falha do isolamento térmico dado um 
tempo prévio de operação de 1000 horas, o que demonstra que o desempenho dos equipamentos pode variar de forma significativa ao longo do tempo quando suas distribuições de probabilidade de falha não são exponenciais. Sendo assim, recomenda-se que seja feito um levantamento sobre as distribuições de falha dos componentes que compõem o sistema e, caso este levantamento demonstre que existem mais equipamentos com distribuições não exponenciais, que seja calculada a confiabilidade condicionada de acordo com os intervalos previstos para manutenção.

\subsection{SUGESTÕES PARA TRABALHOS FUTUROS}

A metodologia proposta neste estudo pode ser aprimorada para incluir a avaliação da disponibilidade do sistema, porém para avaliar a disponibilidade do sistema será necessária uma avaliação do processo de manutenção.

Outro ponto que pode ser incrementado nesta análise é a simulação da inclusão de redundâncias passivas e não apenas ativas como modelado na análise do cenário 3 .

Nesta pesquisa foi aplicada a Análise de Confiabilidade apenas para o Sistema de Regaseificação do FSRU, sugere-se para trabalhos futuros que esta análise seja expandida para todo o FSRU, na qual sejam inclusas as relações entre os diferentes sistemas presentes nesta unidade.

Outro ponto importante que poderá ser elaborado em estudos futuros é o desenvolvimento de uma metodologia, similar a proposta no capítulo 4, para Análise de Risco. Assim como o desenvolvimento de uma aplicação da mesma, por exemplo, em um FSRU, para que possa existir uma visualização clara sobre a eficácia da metodologia de Análise de Risco e dos riscos envolvidos na operação de um FSRU. 


\section{REFERÊNCIAS BIBLIOGRÁFICAS}

ABS - AMERICAN BUREAU OF SHIPPING (2004) - "Guidance notes on Reliability Centered Maintenance". American Bureau Shipping. Huston - USA

AGENA RISK DESKTOP (2011). Disponível em: http://www.agenarisk.com/ products/desktop.shtml, acessado em 05/04/ 2011.

AYYUB, B.A. (2003) "Risk Analysis for Engineers and Economics", Chapman \& Hall/ CRC, EUA.

BLACKWELL, B. (2009) - "Delivering a new FSRU: presents an insight into delivering the world's first FSRUs based on the conversion of an existing LNG carrier". Golar LNG. Disponível em: www.golarlng.com

BOBBIO, A.; PORTINALE, L.; MINICHINO, M.; CIANCAMERLA, E. (2001) "Improving the analysis of dependable systems by mapping fault trees into Bayesian networks". Reliability Enginnering and System Safety 71, 2001, p.p. 249-260.

BOUDALI, H., DUGAN, J. B. (2006) "A Continuous-Time Bayesian Network Reliability Modeling, and Analysis Framework", IEEE Transactions on Reliability, vol. 55, nำ1.

BUBBICO, R., DI CAVE, S., MAZZAROTTA, B. (2009) - "Preliminary risk analysis for LNG tankers approaching a maritime terminal". Journal of Loss Prevention in the Process Industries pg 1- 5. Disponível em: www.elsevier.com/locate/ilp

CHARNIAK, E. (1992) "Bayesian Networks without tears", Al Magazine, 1991,12-4, p.p. 50-63.

DARKEN, C.; ERDMANN, J. (1999) - "Nuclear Plant Fault Diagnosis using probabilistic reasoning". IEEE pg 714-719.

DESHPANDE, V. S.; MODAK, J. P. (2002) - "Application of RCM to a medium scale industry". Reliability Enginnering and System Safety 77, 2002, p.p. 31-43.

DOGUC, O.; MARQUEZ, J. E. R. (2009) - "A generic method for estimating system reliability using Bayesian networks". Reliability Enginnering ans System Safety 94, 2009, p.p. 542-550.

FIRMINO, P. R. A., (2004) - "Redes Bayesianas para a parametrização da Confiabilidade de Sistemas Complexos". Dissertação submetida à UFPE para obtenção de grau de mestre. Programa de pós-graduação em engenharia de

APLICAÇÃO DE REDES BAYESIANAS PARA A ANÁLISE DE CONFIABILIDADE DO SISTEMA DE REGASEIFICAÇÃO DE UMA UNIDADE TIPO FSRU. 
produção. Recife, novembro de 2004.

FOSS, M. M. (2003) - "LNG Safety and Security". Bureau of Economic Geology. University of Texas - EUA. Disponível em: www.beg.utexas.edu/energyecon/lng

FSA (2007) - "Liquefied Natural Gas (LNG) Carriers Details of the Formal Safety Assessment", Maritimar Safety Committee- 83rd session-Agenda item 21.

HAMADA., M. S.; WILSON, A. G.; REESE, C.S.; MARTZ, H.F. (2008) - "Bayesian Reliability". New York, NY, USA. Springer Science Business Media.

HAMWORTHY (2010) - "LNG System for Marine Application". Disponível em:, acessado em 30/03/2010

HEALTH AND SAFETY EXECUTIVE (2001) - "Offshore Hydrocarbon Releases Statistics, 2001 - Hid Statistics Report HSR 2001 002”. www.hse.gov.uk/hid/osd/hsr2001/contents.htm

HUANG, Y.; HUNG, C.; FANG, C. (2007) - "Bayesian Enhance Decision Making for Deteriorating Repairable System with Preventive Maintenance". Wiley Periodicals. Disponível em: www.interscience.wiley.com

ISO - INTERNATIONAL ORGANIZATION STANDARDIZATION (2004) - "Petroleum and natural gas industries - Collection and exchange of reliability and maintenance data for equipment".

JONES. B.; JENKINSON, I.; YANG, Z.; WANG, J. (2009) - "The use of Bayesian networking for maintenance planning in a manufacturing industry". Reliability Enginnering ans System Safety 95, 2010, p.p. 267-277.

JONHSON, D. W.; CORNWELL, J. B. (2006) - "Modeling the release, spreading, and burning of LNG, LPG, and gasoline on water". ". Journal of Hazardous Materials 140 pg 535- 540. Disponível em: www.sciencedirect.com

KECECIOGLU, D. (1991) - "Reliability engineering handbook". Volume 2. Pennsylvani, USA. Destech Publications, Inc.

KEPPEL,S.; (2009) - "World's second FSRU Delivered". Keppel Group. Disponível em: www.keppelshipyard.com

KIPERSZTOK, O.; DILDY, G. A. (2002) - "Evidence-based Bayesian Networks Approach to airplane Maintenance" IEEE 7 pg 2887-2891.

KOZLOV, A.V.; KOLLER, D. (1997) - "Nonuniform dynamic discretization in hybrid networks". Geiger, D., Shenoy, P.P. eds.13, 314-325.

LANGSETH, H., PORTINALI, L. (2005) - "Bayesian networks in reliability", Reliability Enginnering and System Safety 92, 2007, p.p. 92-108. 
LANGSETH, H.; NIELSEN, T. D.; RUMI, R.; SALMERON, A. (2009) - "Inference in hybrid Bayesian networks ", Reliability Enginnering and System Safety 94, 2009, p.p. 1499-1509.

LEE ET AL., W. S.; GROSH, D. L.; TILLMAN, F. A.; LIE, C. H. (1985) - "Fault tree analysis, Methods, and Aplications". Transactions on Reliability, IEEE Press Vol R-34 ํo 3 .

LEITCH, R. D., (1995) - "Reliability Analysis for Enginners - A introduction". Oxford Universty Press Inc., New Yotk, UK, 1995.

LEVESON, N., (1995) - "SafeWare: system safety and computers". Michigan, USA. Addison-Wesley Inc.

LEWIS, E. E. (1994) - "Introduction to Reliability engineering". Illinois, USA. 2" edição. John Wiley \& Sons, Inc.

MARQUEZ, D., NEIL, M., FENTON, N. (2010) "Improved reliability modeling using Bayesian Networks and dynamic discretization". Reliability Enginnering and System Safety 95, 2010, p.p. 412-425.

MARQUEZ, D., NEIL, M., FENTON, N. (2011) "A new Bayesian Networks approach to Reliability modeling". Disponível em: http://www.agenarisk.com/studies.shtml, acessado em 05/04/ 2011.

MATURANA, M. C. (2010) - "Aplicação de Redes Bayesianas na análise de contribuição do erro humano em acidentes de colisão". Dissertação para obtenção do título de mestre. Departamento de Engenharia Naval e Oceânica da Escola Politécnica da Universidade de São Paulo.

MIL-STD-1629A - MILITARY STANDARD (1980) - "Procedures for performing a failure mode, effects and criticality analysis". Waschington, DC, USA.

MODARRES, M. (1993) - "What Every Engineer Should Know apout Reliability and Risk Analysis", Marcel Dekker, EUA.

MOUBRAY, J. (1997) - "Reliability Centered Maintenance". 2ª Edição. New York, NY, USA. Industrial Press Inc.

NATACCI, F. B., MARTINS, M. R., E SOUZA, G. F. M. (2009) - "Proposta de método de análise de confiabilidade de navios". Disponível em http://www.fontem.com/archivos/194.pdf.

NATACCI, F. B.; IKEDA, N. H.; MARTINS, M. R. (2010) - "Consequence analysis of a liquefied gas leakage". Proceedings of the ASME, $29^{\text {th }}$ International Conference on Ocean, Offshore and Artic Enginnering, OMAE 2010.Shanghai, China.

NEAPOLITAN, R. E. (2004) - "Learning Bayesian Networks". New Jersey, Pearson 
Prentice Hall, 2004.

NEIL, M.; TAILOR, M.; MARQUEZ, D. (2007) - "Inference in Bayesian Networks using dynamic discretization". Journal of Statistics and Computing, 17-3.

NEIL, M.; TAILOR, M.; MARQUEZ, D.; FENTON, N.; HEARTY, P. (2008) "Modeling dependable systems using Bayesian Networks". Reliability Enginnering and System Safety 93, 2008, p.p. 933-939.

OREDA (2002) - "Offshore Reliability Data Handbook", DET NORSKE VERITAS DNV, 2002, 4th Edition.

RAC - RELIABILITY ANALYSIS CENTER (1995) - "Noneletronic Parts Reliability Data". Griffiss AFB, NY, USA.

RAJ, P. K. (2005) - "Large Hydrocarbon fuel pool fires: Physical characteristics and thermal emission variations with height". Journal of Hazardous Materials 140 pg 280- 292. Disponível em: www.sciencedirect.com

RUSSEL, S.; NORVIG, P. (2004) - "Inteligência Artificial". $2^{\mathrm{a}}$ edição. Rio de Janeiro - BR. Editora Elsevier Ltda.

SCHLEDER, A. M., SILVA, D. W. R. (2010) - "Confiabilidade de um sistema de regaseificação de gás natural liquefeito". Seminário final da disciplina PMR5201 da Escola Politécnica da Universidade de São Paulo.

SCHLEDER, A. M. ; MARTINS, M. R. ; SOUZA, G. F. M. (2011) - "Bayesian networks on risk analysis of a regasification system on an offshore unit." In: International Conference on Ocean, Offshore and Arctic Engineering, 2011, Rotterdam, Netherlands. Proceedings of the ASME 2011 30th International Conference on Ocean, Offshore and Arctic Engineering, 2011. p. 1-8.

SCHLEDER, A. M. ; MARTINS, M. R. ; Souza, G. F. M. (2011) - "Preliminary risk analysis of a liquefied natural gas regasification system in an offshore unit." In: Inrternational Conference on Vulnerability and Risk Analysis and Management, , College Park, Maryland, US. Proceedings of the Inrternational Conference on Vulnerability and Risk Analysis and Management, 2011. p. 1-8.

SCHULLER, J. C. H (2005) - "Methods for determining and processing probabilities - CPR 12E". The Hague, Netherlands. $2^{\mathrm{a}}$ edition. Gervarlijke Stoffen Publicattiereeks.

SIGURDSSON, J. H.; WALLS, L. A.; QUIGLEY, J. L. (2001) - "Bayesian Belief Nets for managing expert judgment and modeling reliability". Quality and Reliability Enginnering International.

SMITH, D. J. (2001) - "Reliability, Maintainability and Risk". Woburn,UKA. 6” edição. Butterworth Heinemann. 
VANEM, E.; ANTÃO, P.; OTVIKC, I.; COMAS, F. Del C. (2007) - "Analysing the risk of LNG carrier operations". Disponível em: www_sciencedirect_com

WATSON, H. A. (1961) - "Launch Control Safety Study". Section VII, Vol 1. Bell Labs, Murray Hill, NJ.

WHIIAKER, J. (1990) "Graphical Models en apllied multivariate statistics", Chichester, UK, Wiley.

WHITE MARTINS (2004) - "Ficha de Informações de Segurança de Produtos Químicos". P-4880-A, Pb-0027, P-4646-D. Disponível em: www_whitemartins_com_br

WIGNUS, R. (1994) - "Fires on Offshore process installations", J. Loss Prev. Process Ind., Vol 7, número 4. Butterworth Heinemann LTD. Pg 305 -309 


\section{APÊNDICE A: DISCRETIZAÇÃO DINÂMICA}

Este item foi criado para apresentar de maneira mais detalhada o processo de discretização dinâmica executado pelo software comercial AgenaRisk, que foi usado na elaboração deste estudo. O detalhamento do processo de inferência e os exemplos apresentados neste item foram reportados por Marquez, Neil e Fenton (2010), Neil e Marquez (2007) e Neil et al. (2008).

No processo de discretização dinâmica, sendo X um nó contínuo dinâmico, o domínio de $X$ é dado por $\Omega_{x}$, e a função densidade de probabilidade de $x$ por $f_{x}$. A idéia da discretização é aproximar $f_{x}$ primeiramente particionando $\Omega_{x}$ em um conjunto do intervalo $\Psi_{x}=\left\{w_{j}\right\}$, depois, definindo uma função constante local nos intervalos particionados. A tarefa consiste em achar um conjunto ótimo de discretização $\Psi_{x}=\left\{w_{i}\right\}$ e valores ótimos para a função densidade de probabilidade $\widetilde{f_{x}}$

Essa abordagem de discretização dinâmica procura a especificação mais acurada para as regiões de alta densidade (RAD), dado o modelo e a evidência, avaliando uma seqüência de intervalos em $\Omega_{\mathrm{x}}$ iterativamente. A cada iteração a discretização de $\Psi_{X}$ é testada para verificar se a $\widetilde{f}_{x}$ resultante converge para a real $f_{x}$ dentro de um grau aceitável de precisão. Na convergência $f_{x}$ é aproximada para $\widetilde{f_{x}}$

Em complementação ao processo de discretização, para executar a inferência da RB, são usadas estruturas usualmente usadas em árvores de junção (do inglês Junction Trees - JT), sendo a única mudança nos algoritmos a execução da propagação iterativa e não única, conforme descrito no parágrafo anterior.

De maneira sintetizada, a discretização segue os seguintes passos:

- Escolhe-se uma discretização inicial para todas as variáveis contínuas;

- Calcula-se a densidade de probabilidade condicional discretizada para cada 
nó contínuo dada a discretização corrente e a evidência através da RB;

- Executa-se a inferência da RB para obter as densidades de probabilidades de cada nó e divide-se os intervalos de cada nó com maior erro entrópico;

- Continua-se iterativamente o processo, pelo recálculo das densidades de probabilidades condicionais e propagação da RB, e então obtendo-se as probabilidades marginais e dividindo-se os intervalos com altos erros entrópicos, até que o modelo convirja para um nível aceitável de acuracidade.

O método para avaliação do erro entrópico é o proposto por Koslov e Koller (1997), o Kullback-Leiber (KL) que usa a distância entre duas funções densidades $f$ e $g$ como métrica do erro entrópico:

$$
D(f \| \mid g)=\int_{S} f(x) \log \frac{f(x)}{g(x)} d x
$$

Koslov e Koller (1997) também recomendam o uso de um limite $\left(E_{j}\right)$ para a distância entre a função $f$ e sua discretização a partir da função média $\bar{f}$, da função máxima $f_{\max }$ e da função mínima $f_{\min }$, dado um intervalo de discretização $w_{j}$. As funções $f_{\max }, f_{\min }$, e $\bar{f}$ são estimadas através de amostragem aleatória de $f$ em diversos pontos.

$$
E_{j}=\left[\frac{f_{\max }-\bar{f}}{f_{\max }-f_{\min }} f_{\min } \log \frac{f_{\min }}{\bar{f}}+\frac{\bar{f}-f_{\min }}{f_{\max }-f_{\min }} f_{\max } \log \frac{f_{\max }}{\bar{f}}\right]\left|w_{j}\right|
$$

Para controlar o crescimento dos conjuntos de discretização do domínio, $\Psi x$, depois de cada iteração, são fundidos aqueles intervalos consecutivos em $\Psi x$ com o mais baixo erro entrópico ou que tenham massa zero e erro zero. Fundir esses intervalos é difícil na prática por muitos fatores: primeiramente não é desejável necessariamente fundir intervalos porque tenham erro zero, como nos casos de distribuições uniformes, pois estes intervalos são necessários para atingir uma fina discretização em alguns dos nós filhos; também espera-se garantir que os nós com intervalos de massa zero e erro zero serão fundidos apenas se eles pertencerem à sequências de massa zero, pois alguns intervalos de massa zero podem ser 
separados por máximos locais.

Um desafio chave desta abordagem ocorre quando alguma evidência, $X=x$, reside na região do $\Omega x$ onde temporariamente não há massa de probabilidade. Isso pode ocorrer simplesmente, porque o modelo como um todo está longe de convergir para uma solução aceitável e ocorre quando a amostra não gerou massa de probabilidade no intervalo de interesse. Esse problema foi resolvido postergando a informação da evidência e durante esse intervalo de tempo assumindo o intervalo mais próximo; esse procedimento objetiva maximizar a massa de probabilidade na região mais próxima da atual região de alta densidade.

Similarmente, para entrar com valores de evidências em um nó contínuo $X$, é assumida uma fronteira de tolerância ao redor da evidência, chamada de $\delta(x)$, e assumido $x$ no intervalo $(x-\delta(x), x+\delta(x))$.

Considerando uma RB para um conjunto de variáveis, $X$, e dividindo $X$ nos conjuntos $X q$ e $X e$, representando as variáveis de interesse $\mathrm{e}$ as variáveis observadas, o algoritmo para a discretização dinâmica seria:

1. Iniciar a discretização, $\Psi_{X}^{0}$, para cada variável contínua $X \in X$;

2. Construir uma estrutura de Junction Tree (JT) para determinar os cliques, F, e os sepsets (subconjuntos da JT);

3. Para (For) $I=1$ to Max_num_ite

4. Computar as Tabelas de densidades de probabilidades dos nós (NPT), $p^{l}(X \mid p a\{X\})$, on $\Psi_{X}^{(l-1)}$ para todos os nós pertencentes a $X q$ que tenham nova discretização ou que sejam filhos de nós pais que tenham nova discretização;

5. Iniciar a JT multiplicando as NPT por todos os nós relevantes dentro de F;

6. Entrar a evidencia, $X e=e$, na JT;

7. Fazer a propagação global na JT; 
8. Para (For) todos os nós $X \in X_{q}$

a. Marginalizar/normalizar para obter as posterioris marginais discretizadas $P^{l}\left(X \mid X_{E}=e\right)$

b. Computar o erro entrópico relativo aproximado $s_{X}^{(l)}=\Sigma_{w_{j}} E_{j}$, para $P^{l}\left(X \mid X_{E}=e\right)$ sobre todos os intervalos wj em $\Psi_{X}^{(l-1)}$

9. Se (If)

$\left\{1-\alpha \leq \frac{S_{X}^{(l-k)}}{S_{X}^{(l-k+1)}} \leq 1+\alpha\right.$ para $\left.k=1,2,3\right\}$ erro entrópico estável, parar regra Ou (Or)

$\left\{S_{i}^{X}<\beta\right\}$ baixo erro entrópico, parar regra

Sendo $\alpha$ e $\beta$ constantes definidas de acordo com a acuracidade e precisão desejada para a convergência.

10. Então parar discretização para nó $X$;

11. Se não (Else) criar uma nova discretização $\Psi_{X}^{(l)}$ para o nó $X$;

12. Dividir em duas metades os intervalos $w_{j}$ em $\Psi_{x}^{(l-1)}$ com o maiores erros entrópicos $E_{j}$;

13. Fundir os intervalos consecutivos em $\Psi_{X}^{(l-1)}$ com os menores erros ou que tenham massa zero e erro zero;

14. End If 


\section{End for}

\section{End for}

Para resolver todas as funções determinísticas elas são modeladas como uma mistura aproximada de distribuições uniformes. Isso envolve considerar os limites máximos e mínimos de cada intervalo em $\Psi_{p a(X)}^{(l)}$, multiplicar todos os valores usando a função determinística e então calcular os valores mínimo e máximo e incluir esses valores como parâmetros em uma distribuição uniforme. Na discretização dinâmica um número crescente de intervalos é produzido, resultando em muito mais combinações de intervalos, os quais tem como efeito produzir um histograma composto de uma distribuição uniforme da função contínua e resultando em um pedaço de função contínua sem vazios.

Para que o processo de discretização seja mais bem compreendido são apresentas as figuras 46, 47, 48, 49 e 50; nelas é possível visualizar como a discretização dinâmica detalha as regiões de maior densidade. Estas figuras representam a distribuição do nó nas primeiras 4 iterações respectivamente. $O$ nó usado para este exemplo tem uma distribuição normal, com média 100, variância 500. A cada iteração é estimado o limite da distância entre a função e sua discretização $\left(E_{j}\right)$, conforme visto no início deste apêndice; os valores estimados das funções $f_{\min }, f_{\max }$, e $\bar{f}$, o valor de $E_{j}$ para cada intervalo e os intervalos usados são apresentados na Tabela 16. Nota-se nesta tabela que os intervalos que possuem a maior distância entre a função e sua discretização são divididos na iteração seguinte, estes intervalos estão destacados em negrito.

A Figura 46 representa a distribuição do nó após a primeira iteração, a maior distância encontrada entre a função e sua discretização é a do intervalo entre $100 \mathrm{e}$ 200, sendo assim esse intervalo será dividido em 2 na próxima iteração (Figura 47): de 100 a 150 e de 150 a 200. Esse processo é repetido até que a discretização atinja o grau de precisão desejado para a convergência, ou seja, até que $E_{j}$ esteja abaixo do valor considerado aceitável. A Figura 51 mostra a distribuição do nó após 
45 iterações já com uma boa representação da distribuição.

Tabela 16 - Iterações de uma distribuição normal.

\begin{tabular}{|c|c|c|c|c|c|c|}
\hline $\begin{array}{c}\text { no de } \\
\text { iterações }\end{array}$ & \multicolumn{2}{|c|}{ Intervalo $\left(w_{j}\right)$} & $f_{\min }$ & $f$ & $f_{\max }$ & $E_{j}$ \\
\hline \multirow{8}{*}{1} & -100 & -10 & $1,000 \times 10^{-21}$ & $4,500 \times 10^{-21}$ & $1,000 \times 10^{-20}$ & $8,545 \times 10^{-20}$ \\
\hline & -10 & -1 & $1,000 \times 10^{-21}$ & $4,500 \times 10^{-21}$ & $1,000 \times 10^{-20}$ & $4,013 \times 10^{-21}$ \\
\hline & -1 & 0 & $1,000 \times 10^{-21}$ & $4,500 \times 10^{-21}$ & $1,000 \times 10^{-20}$ & $9,494 \times 10^{-22}$ \\
\hline & 0 & 1 & $1,000 \times 10^{-21}$ & $4,500 \times 10^{-21}$ & $1,000 \times 10^{-20}$ & $4,013 \times 10^{-21}$ \\
\hline & 1 & 10 & $1,000 \times 10^{-21}$ & $2,000 \times 10^{-04}$ & $4,000 \times 10^{-04}$ & $5,419 \times 10^{-04}$ \\
\hline & 10 & 100 & $4,000 \times 10^{-04}$ & $2,500 \times 10^{-03}$ & $5,400 \times 10^{-03}$ & $1,991 \times 10^{-03}$ \\
\hline & 100 & 200 & $3,400 \times 10^{-03}$ & $1,000 \times 10^{-03}$ & $5,400 \times 10^{-03}$ & $7,704 \times 10^{-02}$ \\
\hline & 200 & 300 & $1,000 \times 10^{-21}$ & $1,700 \times 10^{-03}$ & $3,400 \times 10^{-03}$ & $1,024 \times 10^{-03}$ \\
\hline \multirow{9}{*}{2} & -100 & -10 & $1,000 \times 10^{-21}$ & $4,500 \times 10^{-21}$ & $1,000 \times 10^{-20}$ & $8,545 \times 10^{-20}$ \\
\hline & -10 & -1 & $1,000 \times 10^{-21}$ & $4,500 \times 10^{-21}$ & $1,000 \times 10^{-20}$ & $4,013 \times 10^{-21}$ \\
\hline & -1 & 0 & $1,000 \times 10^{-21}$ & $4,500 \times 10^{-21}$ & $1,000 \times 10^{-20}$ & $9,494 \times 10^{-22}$ \\
\hline & 0 & 1 & $1,000 \times 10^{-21}$ & $4,500 \times 10^{-21}$ & $1,000 \times 10^{-20}$ & $4,013 \times 10^{-21}$ \\
\hline & 1 & 10 & $1,000 \times 10^{-21}$ & $2,000 \times 10^{-04}$ & $4,000 \times 10^{-04}$ & $8,127 \times 10^{-04}$ \\
\hline & 10 & 100 & $4,000 \times 10^{-04}$ & $4,050 \times 10^{-03}$ & $8,500 \times 10^{-03}$ & $2,982 \times 10^{-03}$ \\
\hline & 100 & 150 & $5,000 \times 10^{-03}$ & $1,750 \times 10^{-03}$ & $8,500 \times 10^{-03}$ & $1,410 \times 10^{-03}$ \\
\hline & 150 & 200 & $3,000 \times 10^{-04}$ & $2,350 \times 10^{-03}$ & $5,000 \times 10^{-03}$ & $2,087 \times 10^{-03}$ \\
\hline & 200 & 300 & $1,000 \times 10^{-15}$ & $1,500 \times 10^{-04}$ & $3,000 \times 10^{-04}$ & $1,505 \times 10^{-03}$ \\
\hline \multirow{10}{*}{3} & -100 & -10 & $1,000 \times 10^{-21}$ & $4,500 \times 10^{-21}$ & $1,000 \times 10^{-20}$ & $8,545 \times 10^{-20}$ \\
\hline & -10 & -1 & $1,000 \times 10^{-21}$ & $4,500 \times 10^{-21}$ & $1,000 \times 10^{-20}$ & $8,545 \times 10^{-21}$ \\
\hline & -1 & 0 & $1,000 \times 10^{-21}$ & $4,500 \times 10^{-21}$ & $1,000 \times 10^{-20}$ & $9,494 \times 10^{-22}$ \\
\hline & 0 & 1 & $1,000 \times 10^{-21}$ & $4,500 \times 10^{-21}$ & $1,000 \times 10^{-20}$ & $9,494 \times 10^{-22}$ \\
\hline & 1 & 10 & $1,000 \times 10^{-21}$ & $2,000 \times 10^{-04}$ & $4,000 \times 10^{-04}$ & $5,419 \times 10^{-04}$ \\
\hline & 10 & 55 & $4,000 \times 10^{-04}$ & $2,350 \times 10^{-03}$ & $5,100 \times 10^{-03}$ & $2,394 \times 10^{-02}$ \\
\hline & 55 & 100 & $5,100 \times 10^{-03}$ & $2,700 \times 10^{-03}$ & $1,050 \times 10^{-02}$ & $3,230 \times 10^{-02}$ \\
\hline & 100 & 150 & $5,000 \times 10^{-03}$ & $2,750 \times 10^{-03}$ & $1,050 \times 10^{-02}$ & $3,350 \times 1^{0-02}$ \\
\hline & 150 & 200 & $2,000 \times 10^{-04}$ & $2,400 \times 10^{-03}$ & $5,000 \times 10^{-03}$ & $3,068 \times 10^{-02}$ \\
\hline & 200 & 300 & $1,000 \times 10^{-21}$ & $1,000 \times 10^{-04}$ & $2,000 \times 10^{-04}$ & $3,010 \times 10^{-03}$ \\
\hline \multirow{11}{*}{4} & -100 & -10 & $1,000 \times 10^{-21}$ & $4,500 \times 10^{-21}$ & $1,000 \times 10^{-20}$ & $8,545 \times 10^{-20}$ \\
\hline & -10 & -1 & $1,000 \times 10^{-21}$ & $4,500 \times 10^{-21}$ & $1,000 \times 10^{-20}$ & $8,545 \times 10^{-21}$ \\
\hline & -1 & 0 & $1,000 \times 10^{-21}$ & $4,500 \times 10^{-21}$ & $1,000 \times 10^{-20}$ & $9,494 \times 10^{-22}$ \\
\hline & 0 & 1 & $1,000 \times 10^{-21}$ & $4,500 \times 10^{-21}$ & $1,000 \times 10^{-20}$ & $9,494 \times 10^{-22}$ \\
\hline & 1 & 10 & $1,000 \times 10^{-21}$ & $3,000 \times 10^{-04}$ & $6,000 \times 10^{-04}$ & $8,128 \times 10^{-04}$ \\
\hline & 10 & 55 & $6,000 \times 10^{-04}$ & $2,200 \times 10^{-03}$ & $5,000 \times 10^{-03}$ & $1,948 \times 10^{-02}$ \\
\hline & 55 & 100 & $5,000 \times 10^{-03}$ & $3,500 \times 10^{-03}$ & $1,200 \times 10^{-02}$ & $1,960 \times 10^{-02}$ \\
\hline & 100 & 125 & $1,300 \times 10^{-03}$ & $2,850 \times 10^{-03}$ & $7,000 \times 10^{-03}$ & $1,050 \times 10^{-02}$ \\
\hline & 125 & 150 & $3,100 \times 10^{-03}$ & $1,950 \times 10^{-03}$ & $7,000 \times 10^{-03}$ & $8,439 \times 10^{-03}$ \\
\hline & 150 & 200 & $2,000 \times 10^{-04}$ & $1,450 \times 10^{-03}$ & $3,100 \times 10^{-03}$ & $1,715 \times 10^{-02}$ \\
\hline & 200 & 300 & $1,000 \times 10^{-21}$ & $1,000 \times 10^{-04}$ & $2,000 \times 10^{-04}$ & $3,010 \times 10^{-03}$ \\
\hline
\end{tabular}

APLICAÇÃO DE REDES BAYESIANAS PARA A ANÁLISE DE CONFIABILIDADE DO SISTEMA DE REGASEIFICAÇÃO DE UMA UNIDADE TIPO FSRU. 
Escola Politécnica da USP

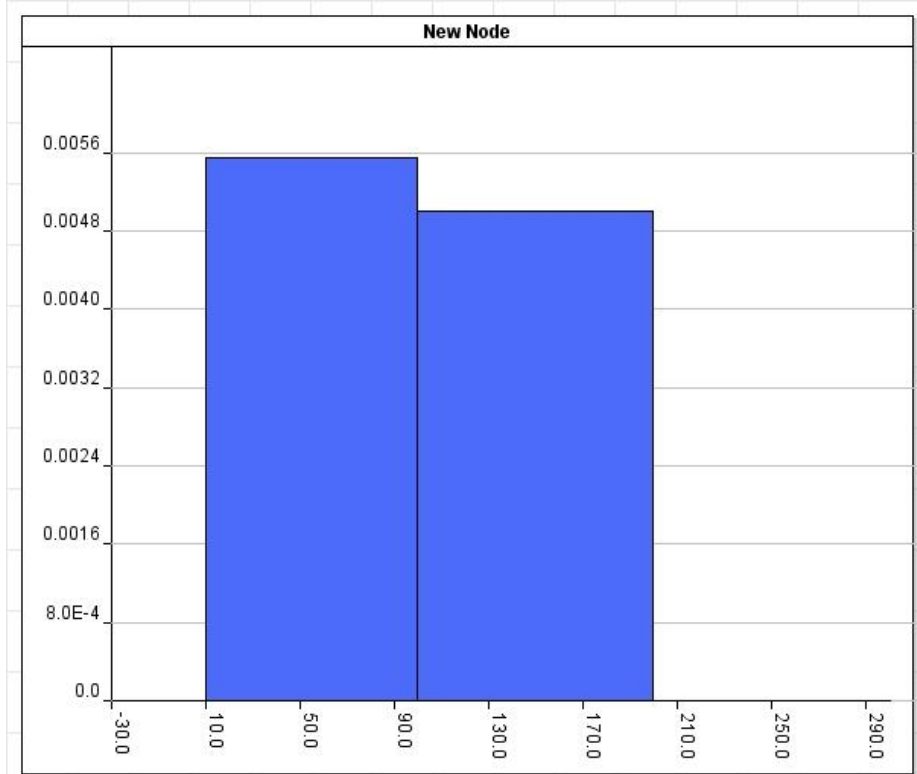

Figura 46 - Distribuição após 1 iteração

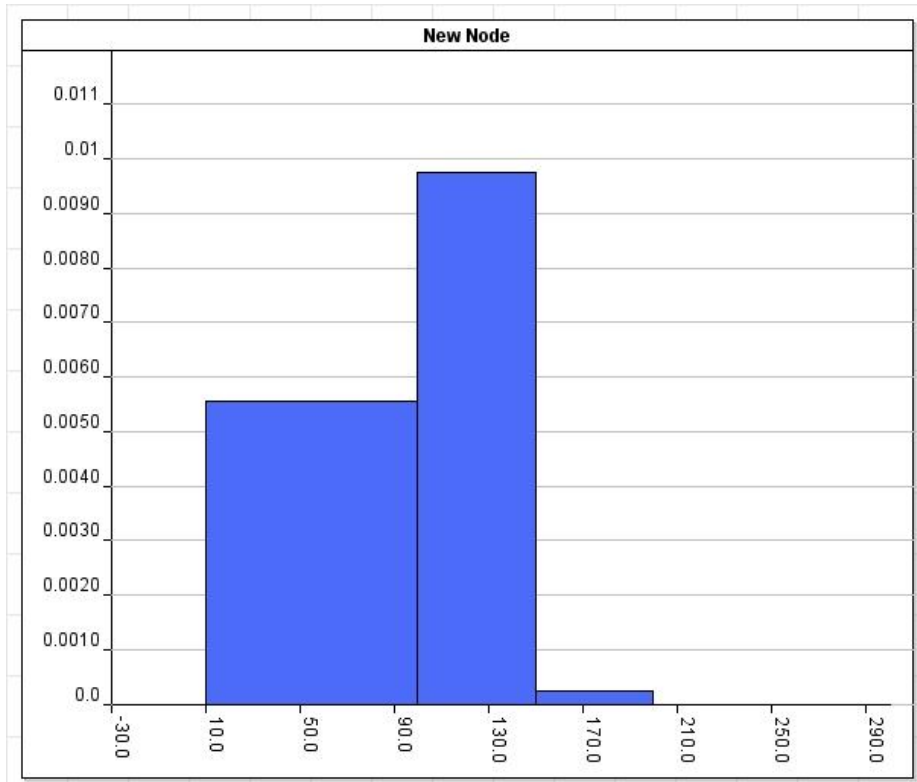

Figura 47 - Distribuição após 2 iterações 
Escola Politécnica da USP

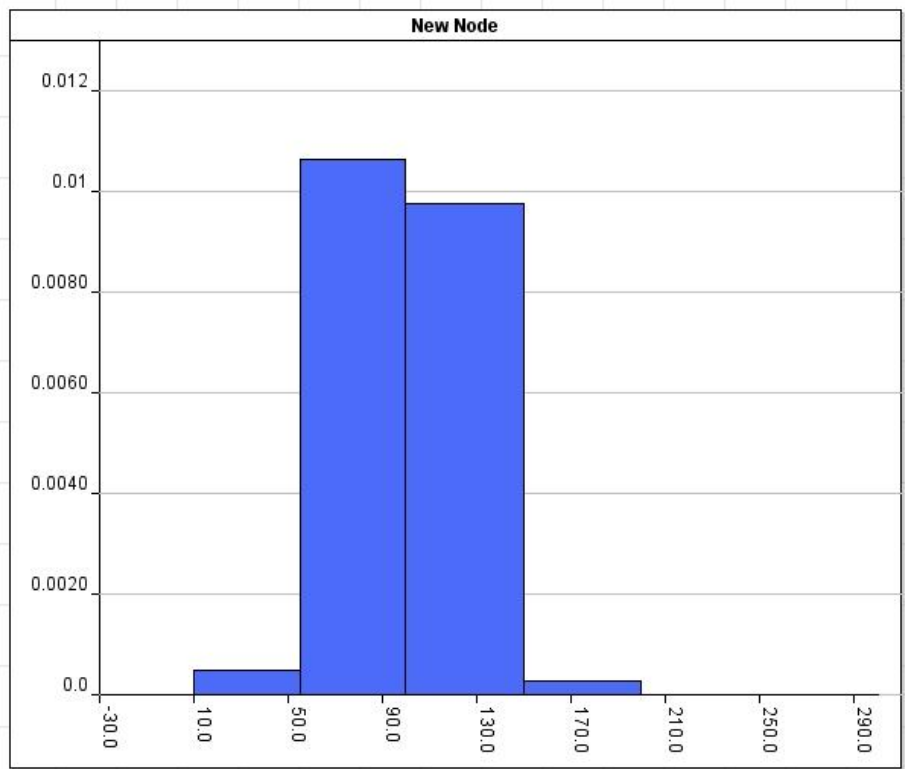

Figura 48 - Distribuição após 3 iterações

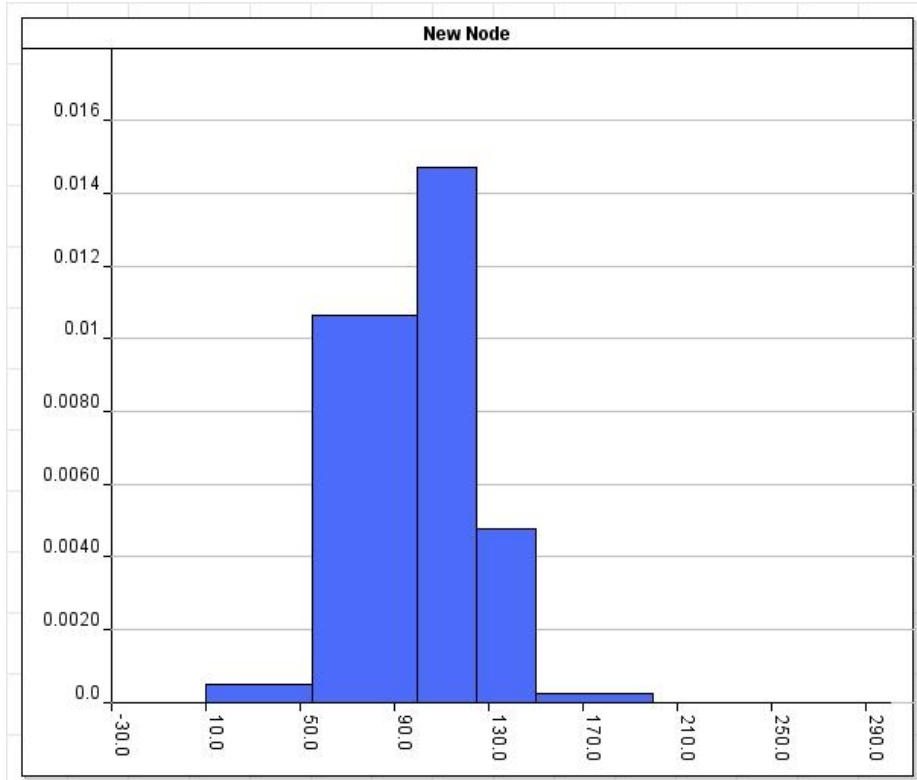

Figura 49 - Distribuição após 4 iterações 
Escola Politécnica da USP

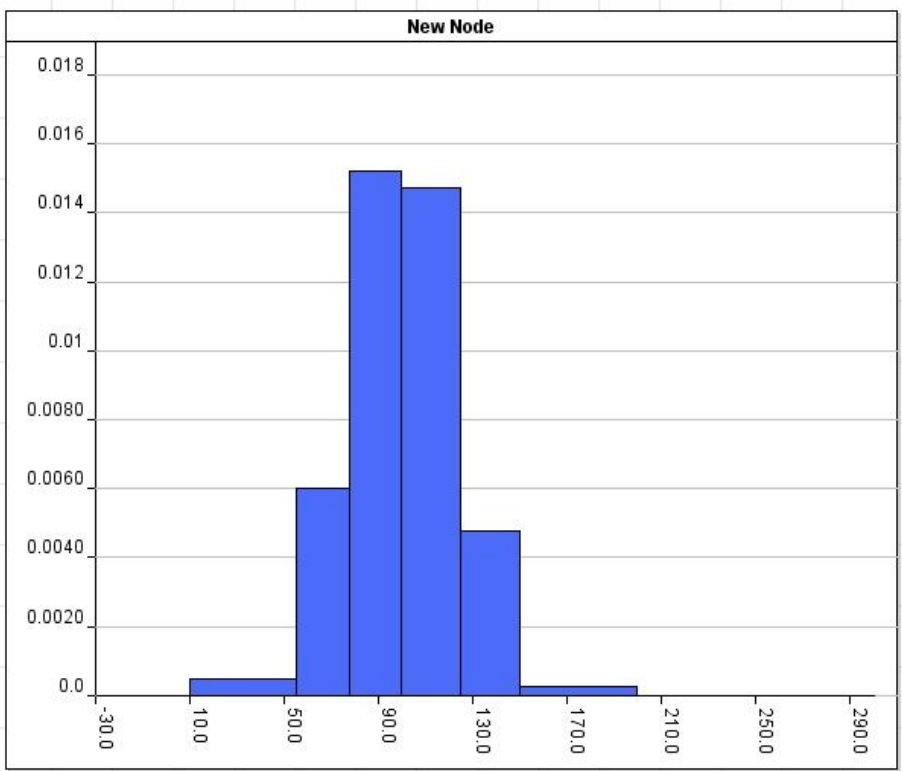

Figura 50 - Distribuição após 5 iterações

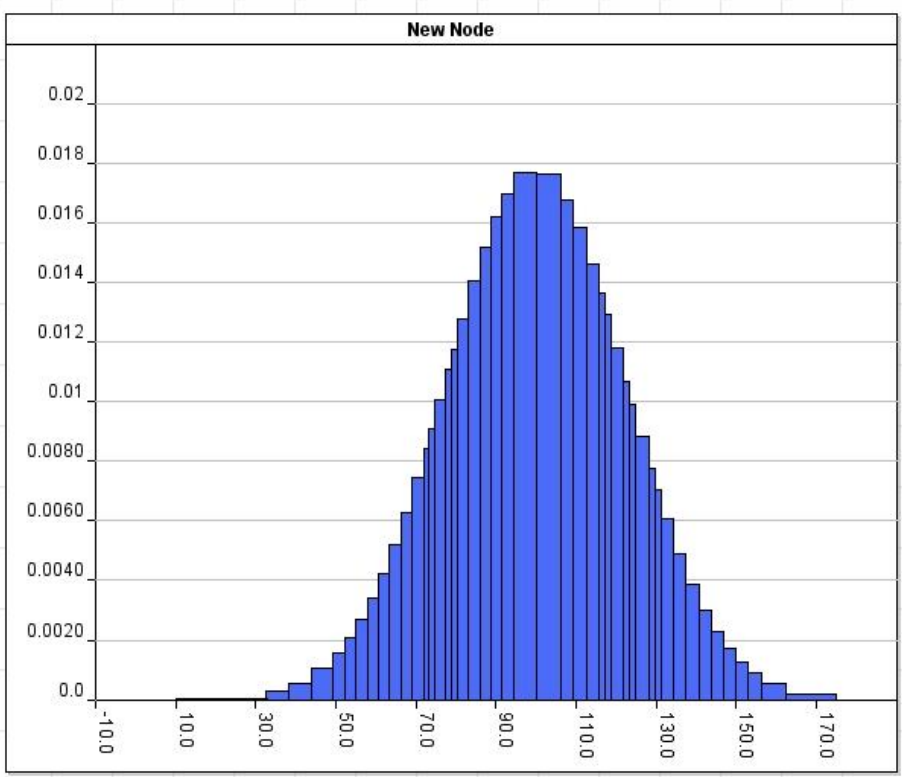

Figura 51 - Distribuição após 45 iterações 